\title{
SIMULATION AND ECONOMIC SCREENING OF IMPROVED OIL RECOVERY METHODS WITH EMPHASIS ON INJECTION PROFILE CONTROL INCLUDING WATERFLOODING, POLYMER FLOODING AND A THERMALLY ACTIVATED DEEP DIVERTING GEL
}

\author{
A Thesis \\ by \\ TOBENNA DANIEL OKEKE
}

\author{
Submitted to the Office of Graduate Studies of \\ Texas A\&M University \\ in partial fulfillment of the requirements for the degree of \\ MASTER OF SCIENCE
}

May 2012

Major Subject: Petroleum Engineering 
Simulation and Economic Screening of Improved Oil Recovery Methods with Emphasis on Injection Profile Control Including Waterflooding, Polymer Flooding and a

Thermally Activated Deep Diverting Gel

Copyright 2012 Tobenna Daniel Okeke 


\title{
SIMULATION AND ECONOMIC SCREENING OF IMPROVED OIL RECOVERY METHODS WITH EMPHASIS ON INJECTION PROFILE CONTROL INCLUDING WATERFLOODING, POLYMER FLOODING AND A THERMALLY ACTIVATED DEEP DIVERTING GEL
}

\author{
A Thesis \\ by \\ TOBENNA DANIEL OKEKE
}

\author{
Submitted to the Office of Graduate Studies of \\ Texas A\&M University \\ in partial fulfillment of the requirements for the degree of \\ MASTER OF SCIENCE
}

\begin{abstract}
Approved by:
Chair of Committee, Robert H. Lane

Committee Members, Hisham A. Nasr-El-Din Yuefeng Sun

Head of Department, Stephen A. Holditch
\end{abstract}

May 2012

Major Subject: Petroleum Engineering 


\begin{abstract}
Simulation and Economic Screening of Improved Oil Recovery Methods with Emphasis on Injection Profile Control Including Waterflooding, Polymer Flooding and a Thermally Activated Deep Diverting Gel.
\end{abstract}

(May 2012)

Tobenna Daniel Okeke, B.S., Drexel University

Chair of Advisory Committee: Dr. Robert H. Lane

The large volume of water produced during the extraction of oil presents a significant problem due to the high cost of disposal in an environmentally friendly manner. On average, an estimated seven barrels of water is produced per barrel of oil in the US alone and the associated treatment and disposal cost is an estimated \$5-10 billion. Besides making oil-water separation more complex, produced water also causes problems such as corrosion in the wellbore, decline in production rate and ultimate recovery of hydrocarbons and premature well or field abandonment.

Water production can be more problematic during waterflooding in a highly heterogeneous reservoir with vertical communication between layers leading to unevenness in the flood front, cross-flow between high and low permeability layers and early water breakthrough from high permeability layers. Some of the different technologies that can be used to counteract this involve reducing the mobility of water or using a permeability block in the higher permeability, swept zones. 
This research was initiated to evaluate the potential effectiveness of the latter method, known as deep diverting gels (DDG) to plug thief zones deep within the reservoir and far from the injection well. To evaluate the performance of DDG, its injection was modeled, sensitivities run for a range of reservoir characteristics and conditions and an economic analysis was also performed. The performance of the DDG was then compared to other recovery methods, specifically waterflooding and polymer flooding from a technical and economic perspective.

A literature review was performed on the background of injection profile control methods, their respective designs and technical capabilities. For the methods selected, Schlumberger's Eclipse software was used to simulate their behavior in a reservoir using realistic and simplified assumptions of reservoir characteristics and fluid properties. The simulation results obtained were then used to carry out economic analyses upon which conclusions and recommendations are based. These results show that the factor with the largest impact on the economic success of this method versus a polymer flood was the amount of incremental oil produced. By comparing net present values of the different methods, it was found that the polymer flood was the most successful with the highest NPV for each configuration followed by DDG. 


\section{DEDICATION}

I would like to take the opportunity to express my heartfelt gratitude to my research advisor, Dr. Robert Lane, for giving me the opportunity to work on this project with him and without whose constant encouragement and motivation this research would not have been completed.

I would also like to thank the members of my committee, Dr. Hisham Nasr-ElDin and Dr. Yuefeng Sun for their contribution of time and knowledge.

Special appreciation also to the faculty and staff of the Harold Vance Department

of Petroleum Engineering at Texas A\&M University for providing the necessary facilities to complete this work as well as making my stay in Aggieland a very pleasurable one.

This work is dedicated to Ubanagu, Emeka, Ossie, Laura and Paul; my family here in the United States and back home in Nigeria for their continued love and support.

Gig 'em! 


\section{NOMENCLATURE}

$d M$, mass per unit surface density accumulated during the current time step, $d t$;

$\mathrm{F}$, net flow rate into neighboring grid blocks;

Q, net flow rate into wells during the current time step;

$R_{f l}$, non-linear residual error for each fluid component

$q_{p, j}$, volumetric flow rate of phase $\mathrm{p}$ in grid block, $\mathrm{j}$,

$T_{w, j}$, transmissibility factor of the grid block which is a function of the wellbore radius,

skin, and the $\mathrm{x}$ - and $\mathrm{y}$ - dimensions and directional permeabilities of the grid block,

$M_{p, j}$, the mobility of the phase and is a function of its relative permeability, viscosity

and formation volume factor in the grid block,

$P_{j}$, nodal pressure in the grid block,

$P_{w}$, bottom hole pressure of the well, and

$H_{w j}$, wellbore pressure head between the grid block and the bottomhole datum depth

$V$ is the block pore volume

$S_{w}$, water saturation

$S_{o}$, water saturation

$B_{r}, B_{w}$, are the rock and water formation volumes

$\rho_{r}, \rho_{w}$, rock formation and water densities

$k_{r w}$, water relative permeability

$k_{\text {ro, }}$ oil relative permeability 
$\mu_{a, e f f}$ is the effective viscosity of the water or polymer when $\mathrm{a}=\mathrm{w}$ or $\mathrm{a}=\mathrm{p}$

$R_{k}$, relative permeability reduction factor for the aqueous phase due to polymer retention

$P_{w}$, water pressure

$\mathrm{g}$, acceleration due to gravity

$D_{z}$, the cell center depth

$Q_{w}$, water production rate

$Q_{l}$, liquid production rate

$C_{p}$, polymer concentration in the aqueous phase and,

$C_{p}^{a}$, polymer adsorption concentration

$\varphi$, porosity

$S_{d p v}$, dead pore space within each grid cell

$\mu_{m}\left(C_{p}\right)$, mixture polymer concentration in solution

$\mu_{p}$, polymer concentration in solution

$\omega$, Todd-Longstaff mixing parameter

HL, High Perm Layer on top of Low Perm Layer

LH, Low Perm Layer on top of High Perm Layer 


\section{TABLE OF CONTENTS}

Page

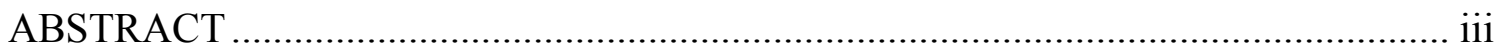

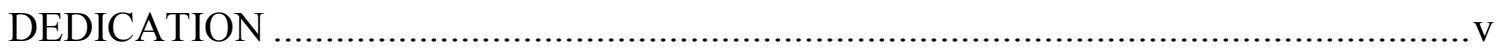

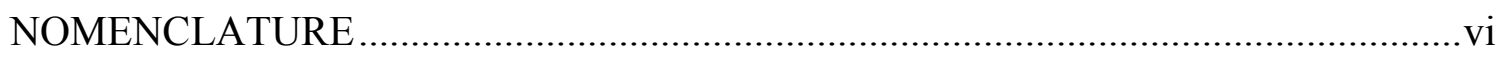

TABLE OF CONTENTS .............................................................................. viii

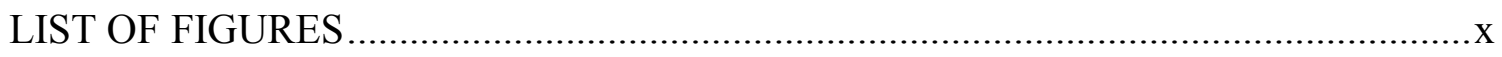

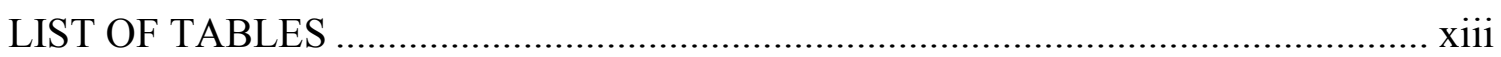

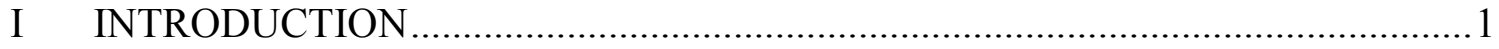

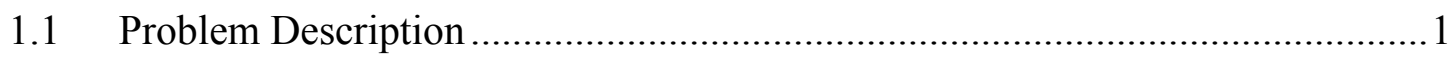

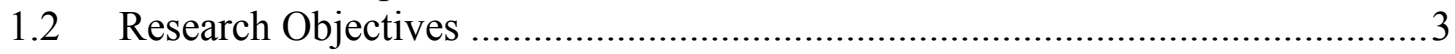

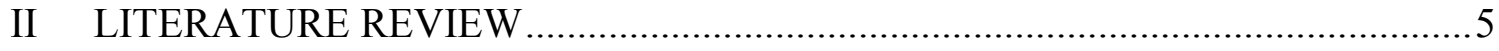

$2.1 \quad$ Water Production ......................................................................................

2.2 Injection Profile Modification Methods ........................................................ 6

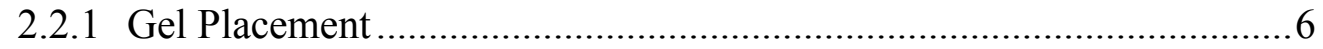

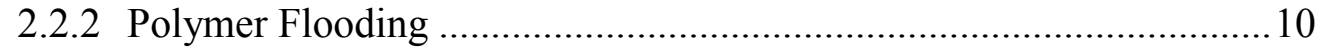

2.2.3 Deep Diverting Gels ......................................................... 11

III RESERVOIR MODELING ......................................................................... 16

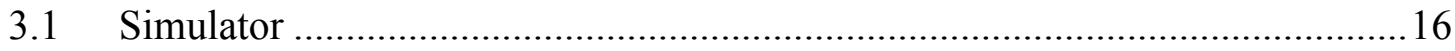

3.1.1 Black Oil Fully Implicit Solutions .............................................. 16

3.1.2 Well Inflow Performance................................................................ 17

3.1.3 Polymer Flood Model .......................................................... 18

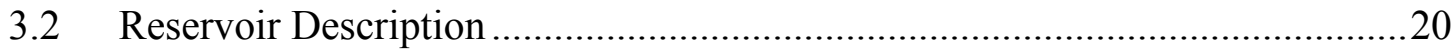

3.2.1 Base Reservoir Model...................................................................21

3.2.2 Polymer Flood Model .................................................................24

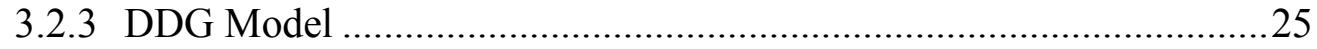




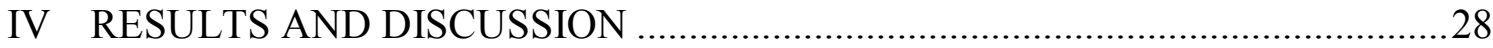

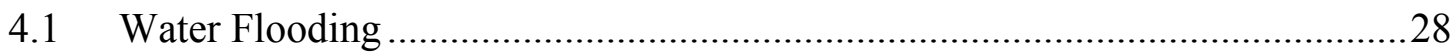

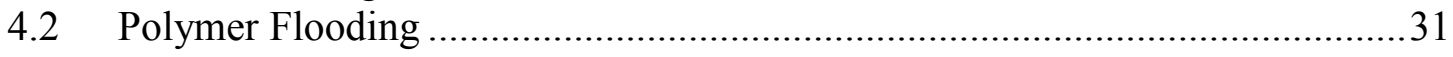

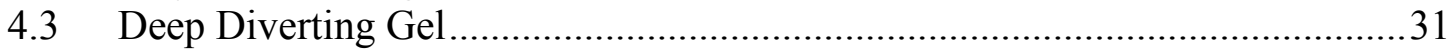

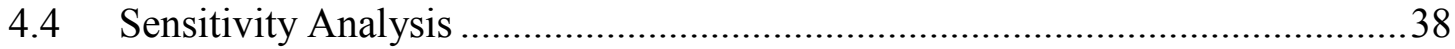

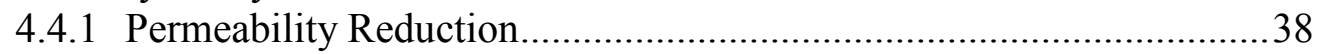

4.4.2 Polymer Concentration ..................................................................40

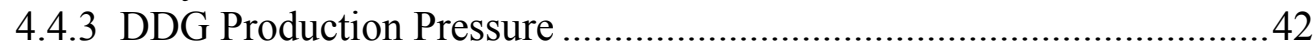

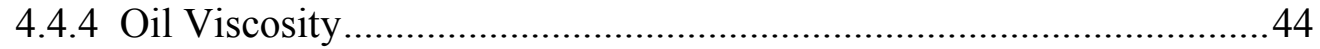

4.4.5 Polymer Flood Pressure Control ........................................................46

4.4.6 Calculation of Polymer Viscosity ...................................................49

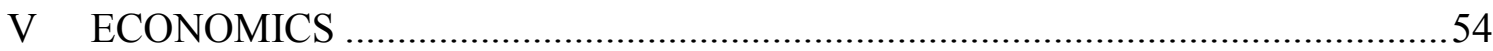

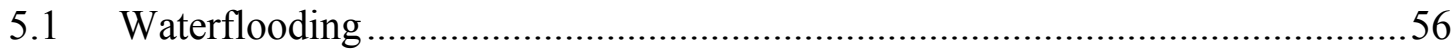

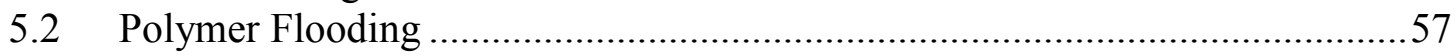

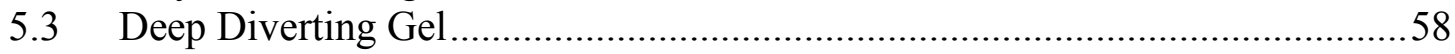

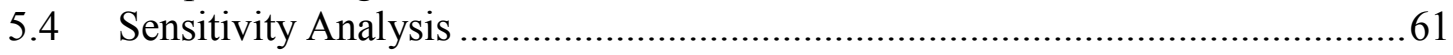

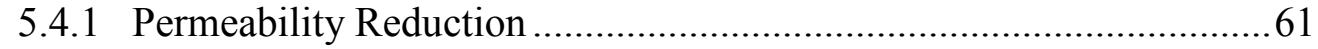

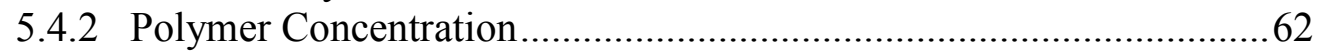

5.4.3 DDG Production Pressure .............................................................65

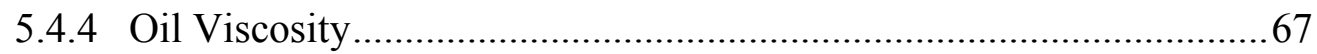

5.4.5 Polymer Flood Pressure Control ..................................................... 70

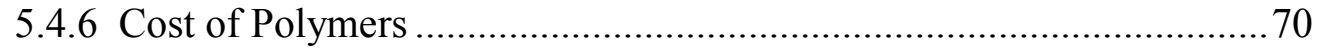

VI CONCLUSIONS AND RECOMMENDATIONS.............................................. 73

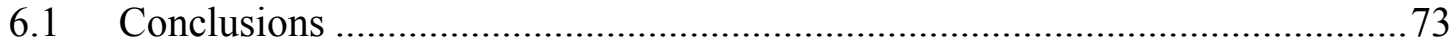

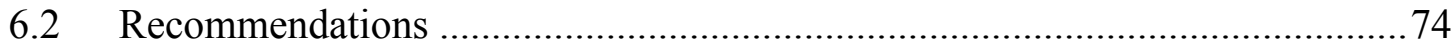

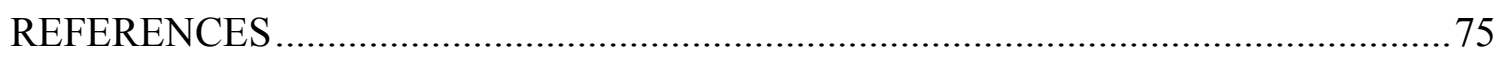

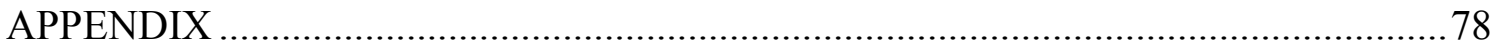

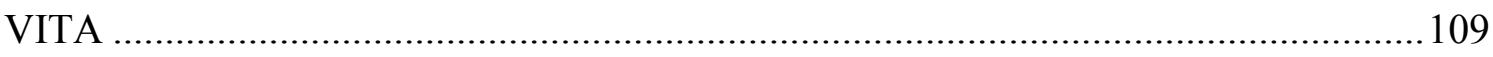




\section{LIST OF FIGURES}

Page

Figure 1: Injection of a low viscosity gel ...........................................................

Figure 2: Injection of water post-flush to create pathways .......................................

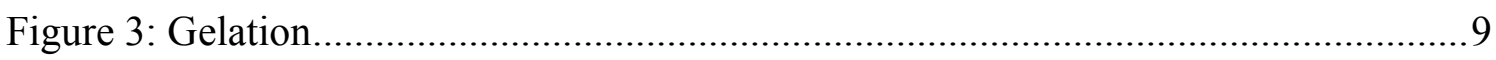

Figure 4: Water Injection after gelation ......................................................... 10

Figure 5: Reservoir before DDG Treatment ...................................................... 13

Figure 6: DDG Activation showing diversion of water ....................................... 14

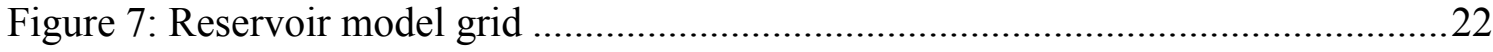

Figure 8: HL Reservoir Oil Saturation at breakthrough...........................................29

Figure 9: LH Reservoir Oil Saturation at breakthrough.........................................29

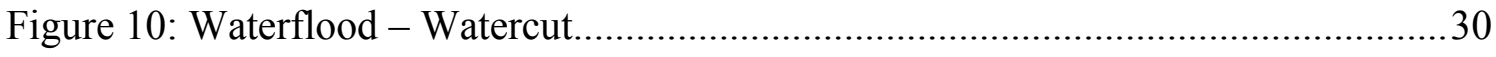

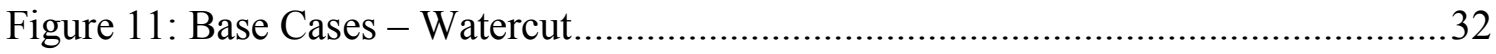

Figure 12: Waterflood [LH] - Oil Saturation at 85\% Watercut...................................33

Figure 13: Waterflood [LH] - Oil Saturation at 90\% Watercut...................................33

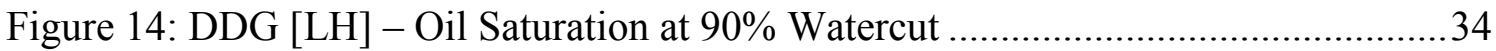

Figure 15: Polymer flood [LH] - Oil Saturation at 90\% Watercut ................................34

Figure 16: Waterflood [LH] - Oil Saturation at 95\% Watercut.................................. 35

Figure 17: DDG [LH] - Oil Saturation at 95\% Watercut ..................................... 35

Figure 18: Polymer flood [LH] - Oil Saturation at 95\% Watercut ............................... 36

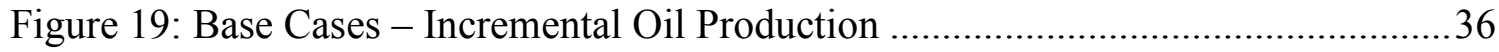

Figure 20: Base Cases - Incremental Water Production ........................................... 37 
Figure 21: Base Cases - Project Life ….................................................................. 37

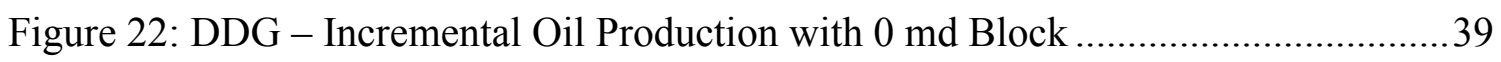

Figure 23: DDG - Incremental Water Production with 0 md Block.............................39

Figure 24: Polymer Flood - Oil Production at Different Concentrations ....................... 40

Figure 25: Polymer Flood - Water Production at Different Concentrations ..................4 41

Figure 26: Polymer Flood - Project Life at Different Concentrations ...........................41

Figure 27: DDG - Oil Production with lowered Production Pressure ...........................43

Figure 28: DDG - Water Production with lowered Production Pressure .......................43

Figure 29: DDG - Project Life with lowered Production Pressure...............................44

Figure 30: Incremental Oil Production for 10 and $100 \mathrm{cp}$ Oil ...................................45

Figure 31: Incremental Water Production for 10 and $100 \mathrm{cp}$ Oil.................................45

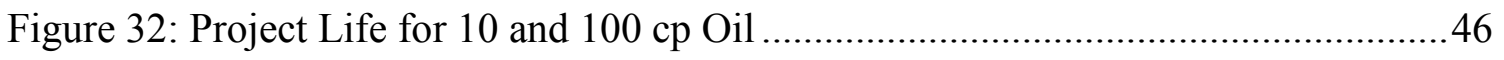

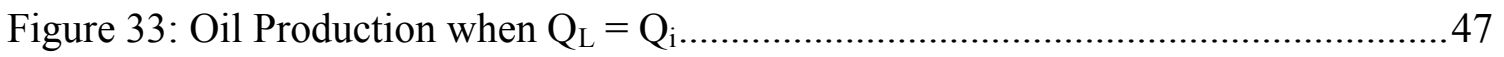

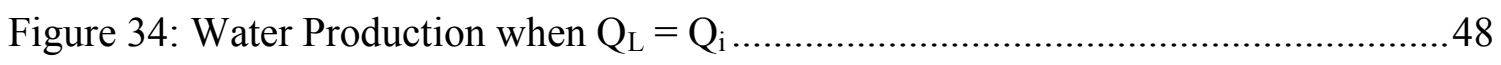

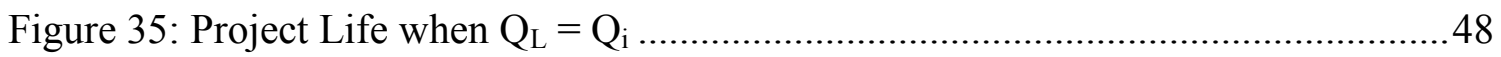

Figure 36: 1000 ppm PF Viscosity using Default \& Herschel-Bulkley Models.............50

Figure 37: PF [LH] Oil Production using Default \& Herschel-Bulkley Models .............50

Figure 38: PF [LH] Water Production using Default \& Herschel-Bulkley Models.........51

Figure 39: PF [LH] Field Life using Default \& Herschel-Bulkley Models ....................51

Figure 40: Waterflooding - Monthly Income ....................................................56

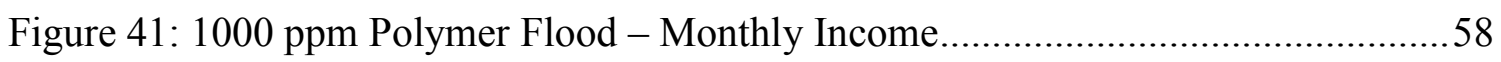


Figure 42: Deep Diverting Gel - Monthly Income ................................................59

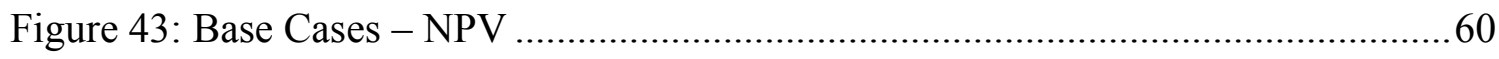

Figure 44: Deep Diverting Gel - Monthly Income ................................................61

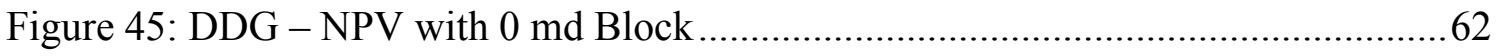

Figure 46: Polymer Flood (HL) - Monthly Income ..............................................6 63

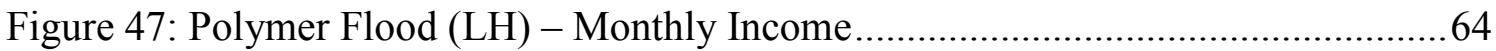

Figure 48: Polymer Flood - NPV at Different Concentrations ...................................64

Figure 49: DDG (HL) - Monthly Income with lowered Production Pressure .................66

Figure 50: DDG (LH) - Monthly Income with lowered Production Pressure.................66

Figure 51: DDG - NPV with lowered Production Pressure......................................67

Figure 52: Monthly Income from simulations using $10 \mathrm{cp}$ Oil .................................68

Figure 53: Monthly Income from simulations using $100 \mathrm{cp}$ Oil ...............................68

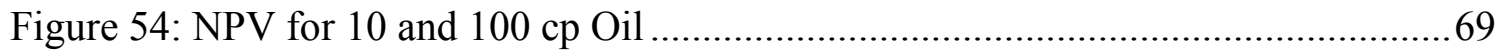

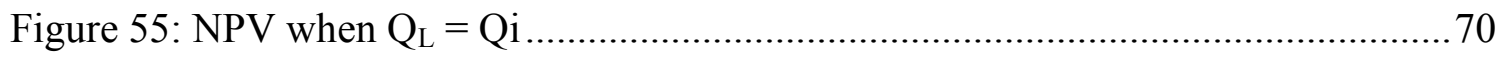

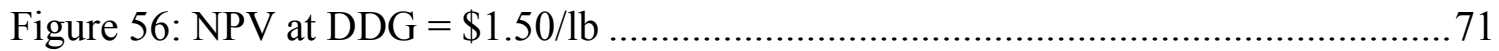

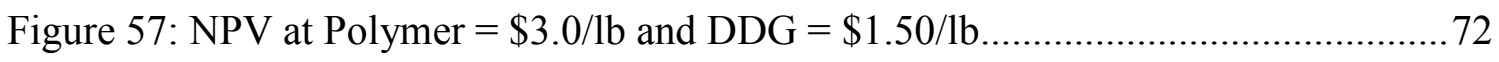




\section{LIST OF TABLES}

Page

Table 1: Reservoir Model Input Data......................................................................22

Table 2: Results from Waterflood Simulation at $85 \%$ Watercut ..................................28

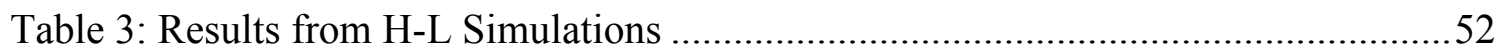

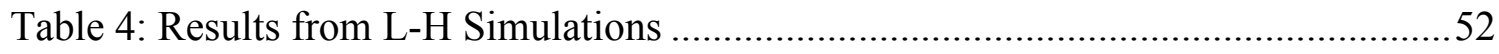

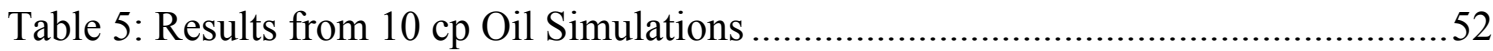

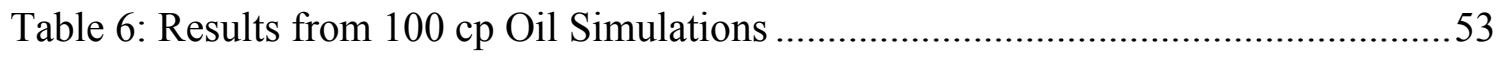

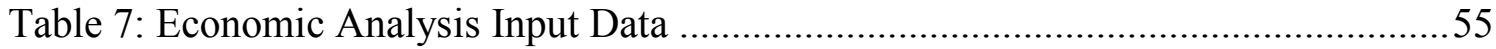

Table 8: Base Case (HL) - Economic Results Summary...........................................60

Table 9: Base Case (LH) - Economic Results Summary ........................................60

Table 10: DDG (0 \& 40 md) - Economic Results Summary ....................................62

Table 11: Polymer Flood (HL) - Economic Results Summary ....................................65

Table 12: Polymer Flood (LH) - Economic Results Summary ..................................65

Table 13: 10 cp Oil - Economic Results Summary for All Methods............................69

Table 14: 100 cp Oil - Economic Results Summary for All Methods ...........................69 


\section{INTRODUCTION}

\subsection{Problem Description}

Highly permeable layers within a heterogeneous reservoir can distort the flood front of a waterflood. These layers, often referred to as thief zones, essentially divert injection water causing early breakthrough at the production well and reducing the effectiveness of the waterflood project with regards to oil recovery. The high volumes of water produced present an expensive challenge in light of the need for environmentally friendly methods of disposal, cost of equipment needed for separation and treatment and reduction in oil production, ultimate recovery and field life. On average, an estimated seven barrels of water is produced per barrel of oil in the US (three barrels of water per barrel of oil worldwide) with the annual cost of its treatment and disposal estimated at between $\$ 5-10$ billion (Seright et al. 2003).

Currently, waterflooding is responsible for over $50 \%$ of all oil recoveries in the world oil fields, for instance $60 \%$ of BP's oil production in 2007 came from water floods and this was set to increase to $80 \%$ by 2010 . (Morgan 2007) Typically by the time this method reaches its economic limit, which usually occurs at some predetermined watercut, roughly half to two-third of the original oil in place is still left in the ground (Brown et al. 2003).

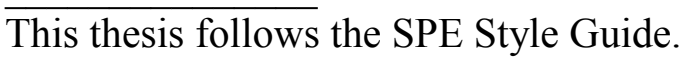


Some of the methods used to address this problem have included the use of mechanical plugs, cement squeezes and polymer gels at the injection and production wells to shut off the thief zones. These methods are limited though because their effectiveness is restricted to the near-wellbore region with little or no effect on the injection profile deep within the reservoir in those reservoirs where cross-flow is possible. One promising method that has yielded consistent sound results has been the use of polymer floods.

Polymer floods work by increasing the viscosity of the injected water and reducing its mobility with respect to the oil it is displacing. This in turn reduces the effect of highly permeable zones on the flood front and allows for a more efficient sweep. While this method is technically sound, its cost-effectiveness is often an issue due to the quantities of polymer needed, capital costs of polymer blending equipment and decreased injectivity (thereby decreasing drive fluid throughput and reservoir pressure support).

An alternative approach that requires much less chemical and equipment investment was developed based on the concept of forming a permeability block in the thief zones at some distance from the injection wellbore. The block would then divert flow into lower permeability unswept areas to mobilize previously bypassed oil. The early technology to form the block was through the use of a low viscosity polymer solution containing aluminum citrate as cross-linker which was designed to set and form a diverting gel far from the injection well.

This class of gel was called a Deep Diverting Gel (DDG), and the specific system just described was called the Colloidal Dispersion Gel. (Mack et al. 1994) More 
recently, a different approach to applying DDG has been developed as evidenced by patents and work done by the referenced authors. (Chang 2006, 2007; Frampton et al. 2004; Pritchett et al. 2003) This system is an internally cross-linked polymer consisting of sub-micron sized particles. Some of the internal cross-links are relatively permanent, while others contain ester groups that can hydrolyze. This arrangement allows the particles to swell to many times their initial size when the ester cross-linking groups hydrolyze. The expansion is triggered over time and accelerated by increased temperature.

A number of articles have been published on the successful application of this type of DDG (Fethi et al. 2010; Husband et al. 2010; Mustoni et al. 2010; Ohms et al. 2009; Yanez et al. 2007) but to our knowledge, it has as yet not been comprehensively compared with polymer flooding and waterflooding in terms of recovery and economics in any open literature.

\subsection{Research Objectives}

The primary question being addressed by this research is to determine whether in-depth profile modification using a thermally activated deep diverting gel is a better alternative to polymer flooding both technically and economically when faced with excess water production. This was done by modeling the DDG injection process as well as a polymer flood using a reservoir simulator, Schlumberger's Eclipse (Schlumberger 2010).

An outline of the objectives of this research is listed below: 
- Model the injection and application of thermally activated Deep Diverting Gels (DDG) in a heterogeneous reservoir to predict performance using Schlumberger's Eclipse simulation software.

- Build simulation models of water and polymer flooding methods using the same base conditions as in the DDG model to compare performance.

- Run sensitivities for a range of conditions such as permeability contrast between layers, varying fluid viscosities and permeability drop at DDG activation site.

- Perform an analysis comparing economics and recoveries due to the use of DDG versus continued water flood and polymer flood. 


\section{LITERATURE REVIEW}

This chapter examines the existing methods of reservoir sweep improvement during waterflooding and reduced water production through the use of polymer floods and gel placement with a view of giving the reader a better understanding of the processes.

\subsection{Water Production}

The reasons for reduced sweep efficiency and increased water production will be presented and typically include mechanical problems usually as a result of casing integrity issues, completion problems - most commonly channels behind the casing, coning and poor frac jobs - and finally reservoir heterogeneity-related problems. This last includes dual porosity problems such as naturally fractured and karstified reservoirs, and heterogeneous matrix problems (the subject of this study).

In reservoirs with permeability variations between contacting layers, channeling can occur between an injector and a producer when hydrocarbons are swept faster from the high permeability layer and subsequently, injected water gets preferentially transported through it without sweeping the layers with lower permeability.

Other factors such as depleted hydrocarbon reserves and coning due to vertical pressure gradients near the wellbore drawing water from lower zones toward the well can contribute to excessive water production (Seright et al. 2003). 


\subsection{Injection Profile Modification Methods}

As mentioned in the introduction, various methods have been employed to address the thief zone problem in waterfloods, with the focus here being on the use of polymers to modify flow profiles.

Attempts have been made to control the injection profile in the near wellbore region with mechanical plugs, cement squeezes and injecting polymer gels but because their area of influence is fairly limited, typically no more than 15 feet ( 5 meters), these methods are unable to exert much control over reservoir flow.

\subsubsection{Gel Placement}

Research has also been done on the use of polymer gels to reduce flow through high permeability zones while diverting injected fluids into the lower permeability hydrocarbon-bearing layer(s). The low-viscosity gels are added to the injected water at some point after early breakthrough and designed such that gelation occurs farther in the layer with higher permeability than in the lower permeability zone thereby improving areal and vertical sweep efficiencies. This way the injected water gets diverted to the lower permeability layer. This of course depends on the presence of vertical communication, that is, cross-flow between the layers. (Sorbie et al. 1992) Where such communication does not exist, the gels may be successfully placed closer to the injection well and in only the high permeability layer (Bai et al. 2004).

These gels are often referred to as deep diverting gels due to their ability to go deep into the reservoirs in highly permeable zones and only a shallow distance into the 
lower permeability zones before gelling and creating resistance to flow. In the past, they have generally consisted of a polymer solution cross-linked with chromium acetate or aluminum citrate. In one of the early forms of this gel, the Colloidal Dispersion Gels (CDG), the concentrations of both components are kept low by design to retard their reaction kinetics enough that they gel in-situ at some distance from the point of injection.

However, this process has been controversial with the accuracy of presented lab and field results called into question. Claims of successful application of CDG by Tiorco in the Daqing Field in China (Chang et al. 2006) and Argentina's Loma Alto Sur Field (Muruaga et al. 2008) among others, have been refuted and found inconclusive. In his work, Seright concluded that the benefits attributed to CDG could be explained by other more plausible concepts and that the claims by Tiorco and other supporters of this process are untenable. (Sorbie et al. 1992) Further lab studies on the propagation and gelation of CDG were also ambiguous with findings suggesting results similar to those obtained by polymer floods. (Ranganathan et al. 1998) Variables like gelling time, gel strength and depth of penetration are too easily influenced by factors such as shear stresses, the geochemical characteristics of the reservoir as well as adsorption and the subsequent dilution of the gel during placement. Some other limitations are the limited range of effectiveness whereby sweep efficiency is restricted to the region penetrated by the gel and no further. The applicable viscosity and resistance factors must also be small enough for the gelant to stay within the highly permeable zones without penetrating the lower permeability layers.

One misconception about these gels and blocking agent was that they exclusively targeted and penetrated highly permeable zones in a reservoir. More research has 
however shown that penetration does occur in the lower permeability layers with an accompanying permeability reduction that may sometimes be even greater than in the highly permeable layers. (Seright et al. 2011) Viscous fingering in the high perm zone has also been shown to occur when water is injected after the gel has formed. This is because as the gel penetrates the less permeable layers, it hardens and creates a barrier to flow thus forcing injected water to create pathways through the gelant bank in the highly permeable layer.

A proposed correction involves reducing the viscosity and resistance factor of the gelant being used and adding a water injection step between its injection and when gelation occurs. This intermediate step is to ensure that there is room between the rear of the gelant bank being formed in the high permeability layer and the front of the bank formed in the adjacent lower permeability zones. The lowered viscosity and resistance factors minimizes gel penetration from the high permeability zone into the adjacent layers while the spacing created by the water post-flush creates a pathway for water to flow into the less permeable zones. This process is shown below in Figures $1-4$ in which the higher permeability layer is above the low permeability layer. 


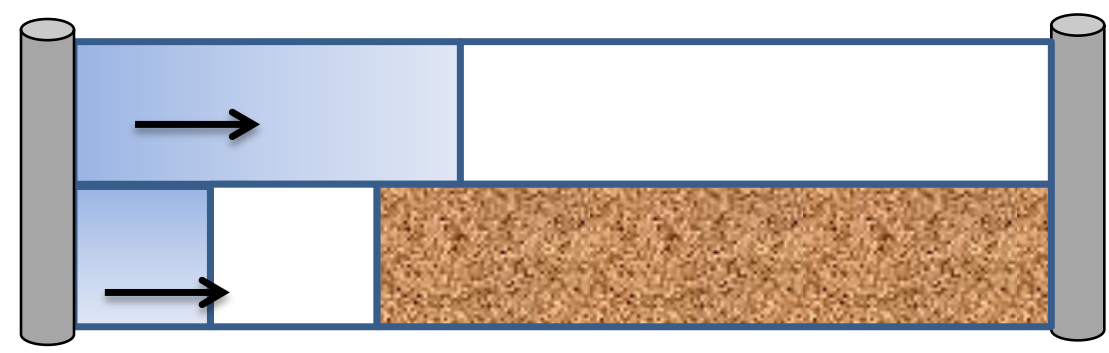

Figure 1: Injection of a low viscosity gel

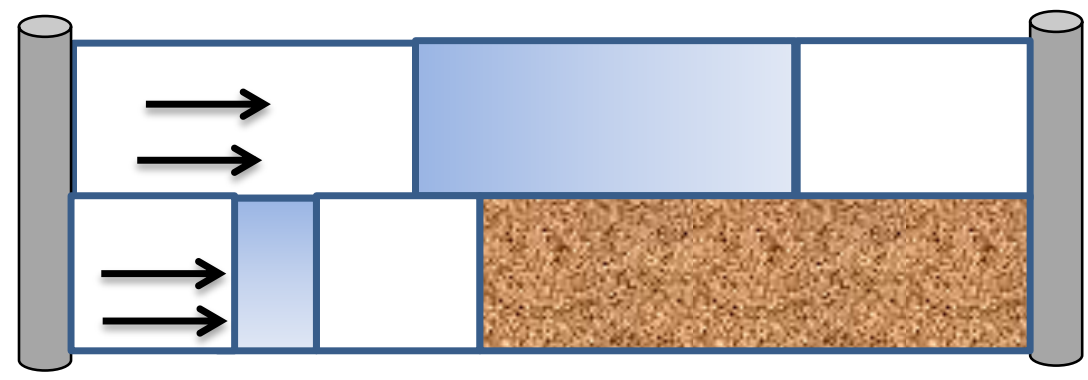

Figure 2: Injection of water post-flush to create pathways

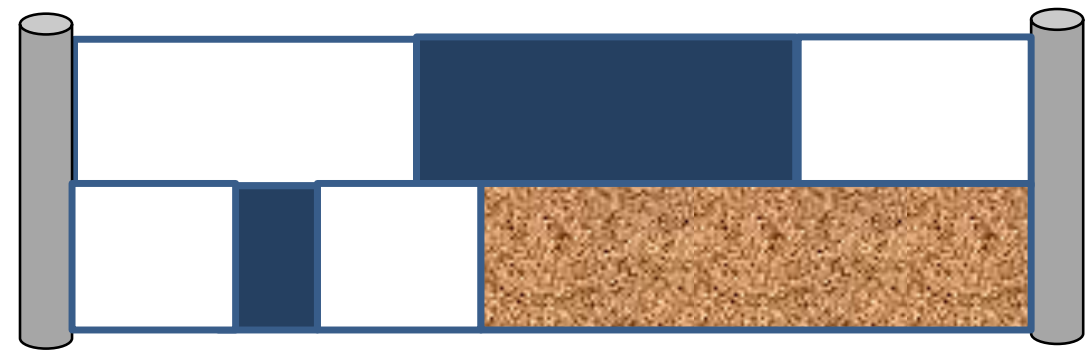

Figure 3: Gelation 


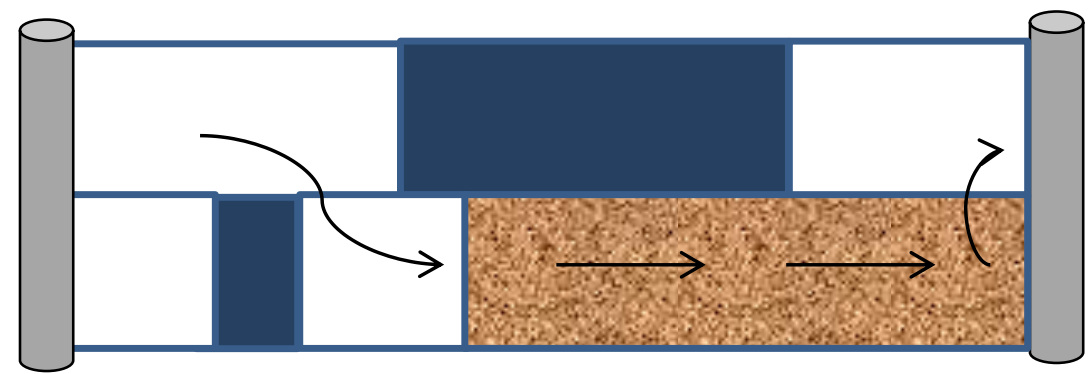

Figure 4: Water Injection after gelation

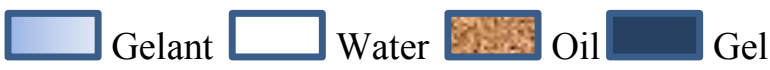

\subsubsection{Polymer Flooding}

Polymer flooding is another process designed to provide technical advantages over waterflooding. The advantage which is of particular relevance to this study is its improvement in areal and vertical sweep efficiency and more efficient oil displacement. (Mungan 1970) These can be attributed to two fundamental concepts of polymer flooding which control the effect it has on the mobility ratio of the injected water and recoverable oil and the penetrated depth.

The first effect is that the efficiency of oil displacement increases as the viscosity of the displacing agent (here polymer-treated water) increases leading to the lowering of its mobility ratio. This lowering can be particularly beneficial when the reservoir is highly heterogeneous in the vertical direction with cross-flow between layers (Akanni 2010).

The second is that for a given distance of viscous fluid penetration into a high permeability zone, the distance of penetration into less permeable zones becomes greater 
with increased viscosity of the injected fluid. With this then, vertical sweep efficiency becomes more uniform across layers with different permeabilities. (Seright 2010) While in-depth permeability reduction is not achieved with polymer flooding, the method does result in greater volumetric sweep efficiency and oil recovery.

Among the limitations of the polymer flooding process are the sensitivity of polymer to salinity, temperature, shear and biological degradations and the high production costs associated with attempts to circumvent these shortcomings. Injectivity issues are also a major concern at high viscosities and it is typical for the maximum usable viscosity to be limited to between three and ten times that of the injected water, with a maximum resistance factor of about 10 (Frampton et al. 2004).

In 1996, the cost of the incremental oil was estimated at between $\$ 8$ to 10 per barrel with more recent estimates from the Daqing Field in 2002 putting this cost at $\$ 9.34$ per barrel for polymer flooding versus $\$ 9.42$ for continued waterflooding. This lower cost was due to the high incremental recovery of $12 \%$ OOIP, a production rate that was four times higher than with the waterflood and a five-fold reduction in the water oil ratio (Demin et al. 2003).

\subsubsection{Deep Diverting Gels}

The deep diverting gel that will be studied and compared to waterflooding and polymer flooding was the result of a research project undertaken in 1997. This was a joint venture between Mobil, BP and ChevronTexaco, also known as MoBPTeCh who agreed to share the costs of the research and development of an effective DDG. Their primary objective was to develop a time-delayed, highly expandable polymer-based gel 
to improve reservoir sweep efficiency of waterflooding. (Pritchett et al. 2003) Nalco Exxon (later Ondeo Nalco) Energy Services was brought on at some point during the development phase as their associate manufacturing company.

The gel is characterized as a specially designed, long-chain, temperaturesensitive polymer that is formulated by its manufacturers to produce sub-micron size particles made up of tightly-bound tangles of polymer. Its behavior has been likened to that of popcorn in that it would move freely through the rock matrix along with the injection water until a reservoir trigger causes some of the particles' internal crosslink bonds to break, thus allowing the particles to absorb water and swell in size to block the thief zone pore throats.

This material, with the commercial product name Bright Water ${ }^{\mathrm{TM}}$, is a highly cross-linked, sulfonate-containing poly-acrylamide micro-particle whose conformation is constrained by labile and stable internal cross-links. The particles, called kernels, are applied in the constrained state but at a designed temperature, de-crosslinking occurs and they expand. These kernels are prepared using an inverse emulsion polymerization process and have diameters ranging from about 0.1 to 3 microns. The temperature required for activation depends on the chemical structure of the cross-linker, and its stability gives the particles conformational integrity even after expansion. These polymer particles can also be prepared by the cross-linking achieved during the ester formation between the polymer's pendant carboxylic acid and hydroxyl groups. The esterification process could be through azeotropic distillation or thin film evaporation. After preparation, these particles can then be individually dispersed into the injection water in a high shear environment and using surfactants (Frampton et al. 2004). 
The thermal front caused by the temperature differences between injected water and the reservoir is the basis of this DDG's activation. The thermal front generally lags behind the waterflood injection front; the characteristics and location of this front can be computed from heat transfer equations or modeled with a computer simulator that contains a thermal function. In addition to the thermally-triggered particles, systems that rely primarily on time without major temperature changes were also developed although these are not the focus of this research. Figures 5 and 6 below illustrate the DDG treatment process.

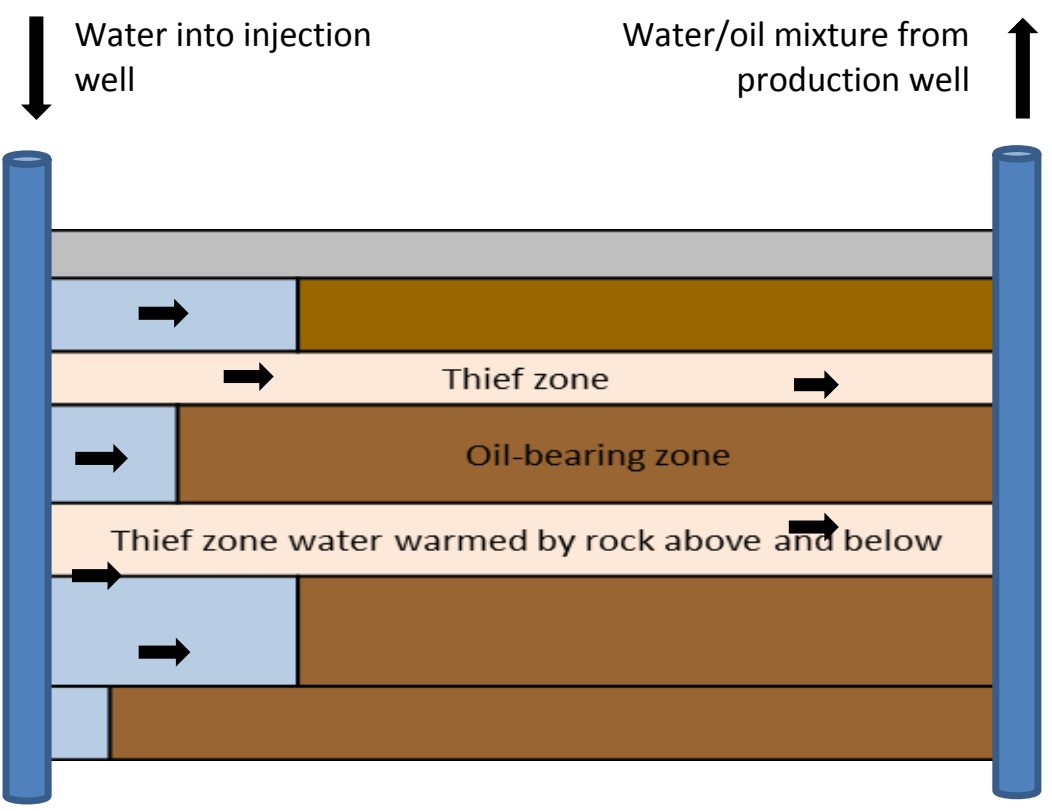

Figure 5: Reservoir before DDG Treatment 


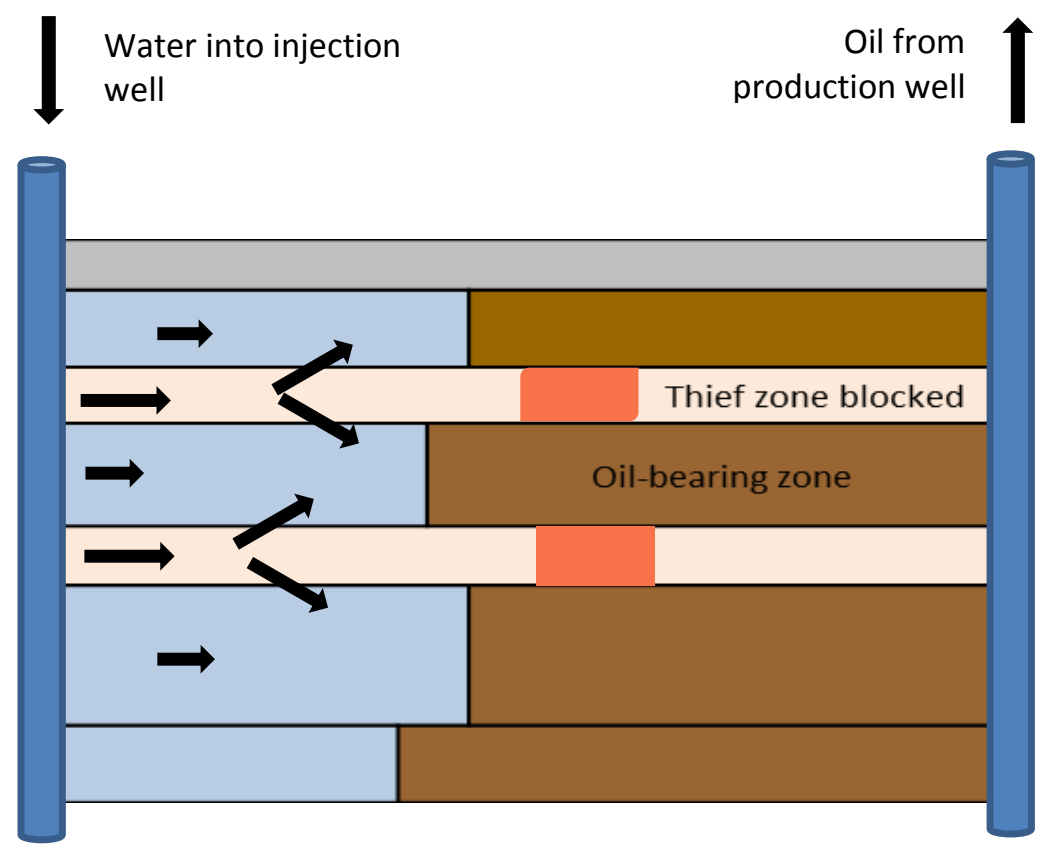

Figure 6: DDG Activation showing diversion of water

After the laboratory stage of preparation was completed, a series of field trials were carried out with the first being in Chevron's Minas Field in Indonesia. This field trial was run with the objectives being to assess the application of the DDG and verify that significant volumes could be injected at a viscosity close to that of water and penetrate deep within the reservoir before expanding at a pre-designed interval. (Pritchett et al. 2003) This was done by conducting injection tracer studies before and after treatment as well as bottom hole pressure fall off tests. These objectives were satisfied without raising the injection pressure or blocking the injection well bore.

Other trials have been completed both offshore and onshore, and in reservoirs with different permeabilities, porosities and temperatures, proving the versatility of this 
material. The trials have yielded varying levels of technical and economic success (Husband et al. 2010; Ohms et al. 2009).

While it can be concluded that this DDG can be successful in some cases, it has not been conclusively compared to polymer flooding. This research will try to find out which of the methods is the better alternative, either in terms of recovery or economics and how reservoir characteristics such as permeability contrast between layers, viscosity of fluids or cost of materials used affects the outcome. 


\section{RESERVOIR MODELING}

\subsection{Simulator}

Schlumberger's Eclipse 100 was used for all simulations in this research. This choice was in part due to its use in previous attempts to address this topic (Akanni 2010; Seright et al. 2011) and the desire to ensure that a similar approach with regards to software used was taken. In this way, any differences in results would be due to the assumptions made by the user and not the underlying algorithms and calculations employed by the software. Eclipse 100 is described as "a fully-implicit, three phase,

three dimensional, general purpose black oil simulator" which uses non-linear equations in material balance equations during simulation runs. The underlying equations used in the software are presented in the relevant sections below with the purpose being to aid in understanding how the results were derived.

\subsubsection{Black Oil Fully Implicit Solutions}

In this method, the non-linear residual error for each fluid component, $R_{f l}$ in the mass balance equations is computed in each grid block as a function of pressure and saturations at each time step and is given as;

$$
R_{f l}=\frac{d M}{d t}+F+Q
$$

where,

$\mathrm{dM}$ is the mass per unit surface density accumulated during the current time step, $\mathrm{dt}$; $\mathrm{F}$ is the net flow rate into neighboring grid blocks; 
Q is the net flow rate into wells during the current time step; and $R_{f l} \rightarrow 0$

\subsubsection{Well Inflow Performance}

The inflow performance relationship used by Eclipse is given in terms of volumetric flow rate of each phase in the production fluid, i.e. oil, water, polymer etc. at stock tank conditions. It is written as:

$$
q_{p, j}=T_{w, j} * M_{p, j} *\left(P_{j}-P_{w}-H_{w j}\right)
$$

where

$q_{p, j}$ is volumetric flow rate of phase $\mathrm{p}$ in grid block, $\mathrm{j}$,

$T_{w, j}$ is the transmissibility factor of the grid block which is a function of the wellbore radius, skin, and the $\mathrm{x}$ - and $\mathrm{y}$ - dimensions and directional permeabilities of the grid block,

$M_{p, j}$ is the mobility of the phase and is a function of its relative permeability, viscosity and formation volume factor in the grid block, $P_{j}$ is the nodal pressure in the grid block, $P_{w}$ is the bottom hole pressure of the well, and $H_{w j}$ is the well bore pressure head between the grid block and the bottom hole datum depth 


\subsubsection{Polymer Flood Model}

The polymer option was enabled in Eclipse for polymer flood simulations and implements a fully implicit, five component model that includes, oil, water, gas, polymer and brine. In this model, there is no gas as mentioned above and brine was assumed to be absent as well. The equations for the flow of a standard waterflood with polymer added are given below as:

$$
\begin{gathered}
\text { Water } \rightarrow \frac{d}{d t}\left(\frac{V S_{w}}{B_{r} B_{w}}\right)=\sum\left[\frac{T k_{r w}}{B_{w} \mu_{w, e f f} R_{k}}\left(\delta P_{w}-\rho_{w} g D_{z}\right)\right]+Q_{w} \\
\text { Polymer } \rightarrow \frac{d}{d t}\left(\frac{V^{*} S_{w} C_{p}}{B_{r} B_{w}}\right)+\frac{d}{d t}\left(V \rho_{r} C_{p}^{a} \frac{1-\varphi}{\varphi}\right) \\
=\sum\left[\frac{T k_{r w}}{B_{w} \mu_{p, \text { eff }} R_{k}}\left(\delta P_{w}-\rho_{w} g D_{z}\right)\right] C_{p}+Q_{w} C_{p}
\end{gathered}
$$

where

$V$ is the block pore volume

$S_{w}$ is the water saturation

$B_{r}, B_{w}$ are the rock and water formation volumes

$\rho_{r}, \rho_{w}$ are the rock formation and water densities

$T$ is the transmissibility

$k_{r w}$ is the water relative permeability

$\mu_{a, e f f}$ is the effective viscosity of the water or polymer when $\mathrm{a}=\mathrm{w}$ or $\mathrm{a}=\mathrm{p}$

$R_{k}$ is the relative permeability reduction factor for the aqueous phase due to polymer retention 
$P_{w}$ is the water pressure

$\mathrm{g}$ is the acceleration due to gravity

$D_{z}$ is the cell center depth

$Q_{w}$ is the water production rate

$C_{p}$ is the polymer concentration in the aqueous phase and,

$C_{p}^{a}$ is the polymer adsorption concentration

$\varphi$ is the porosity and

$S_{d p v}$ denotes the dead pore space within each grid cell

This model includes representations of increases in the viscosity of the injectant upon addition of polymer as well as the losses in polymer solution viscosity that occurs as a result of non-Newtonian shear at high flood velocities. The effective viscosity of a fully mixed polymer solution is given as a function of mixture polymer concentration in solution, $\mu_{m}\left(C_{p}\right)$, the Todd-Longstaff mixing parameter, $\omega$ and the polymer concentration in solution, $\mu_{p}$ and is written as:

$$
\mu_{p, e f f}=\mu_{m}\left(C_{p}\right)^{\omega} * \mu_{p}^{1-\omega}
$$

The effective water viscosity is also calculated in an analogous manner. 


\subsection{Reservoir Description}

The reservoir conditions used in generating the base case model are listed below. Some of these assumptions such as well spacing are based on commonly observed practice while others are to reduce complexity such as the use of two layers instead of three or more.

- The field under study is fictitious. A base case model was developed first and used in the waterflooding component of this research. Changes were then made to this model and used in modeling the DDG and the polymer flood.

- A quarter of a 5-spot well spacing, as is commonly used with waterflooding, was used with one producer and one injector placed diagonally on opposite corners of the square.

- The reservoir has two layers of equal thickness and porosity penetrated completely by both wells and with vertical communication between layers. The layers have different permeabilities.

- The only fluids present are oil and water with no aquifer support.

- The effects of capillary pressure are negligible.

- Each layer as modeled is homogeneous. 


\subsubsection{Base Reservoir Model}

The Black-Oil, fully implicit solution method was used in Eclipse 100 to model the performance predictions and solve the governing equations for the simulation's results of the three recovery methods. The grid blocks describing the XYZ-directions were 44 x 44 x 16 and described a 10-acre area of dimensions $660 \mathrm{ft}$ x $660 \mathrm{ft}$ by $60 \mathrm{ft}$. This grid configuration was chosen to accurately represent the regions under consideration while keeping resource allocation of time and processor requirement manageable.

The injection well was placed in the cell $(1,44,1)$ and the producer in cell $(44,1$, 1) with both perforated in all grid blocks in the vertical (Z) direction to ensure direct contact with the entire thickness of the reservoir as shown in the figure below. Both wells are controlled by assigned liquid rate and bottomhole pressure limits. 


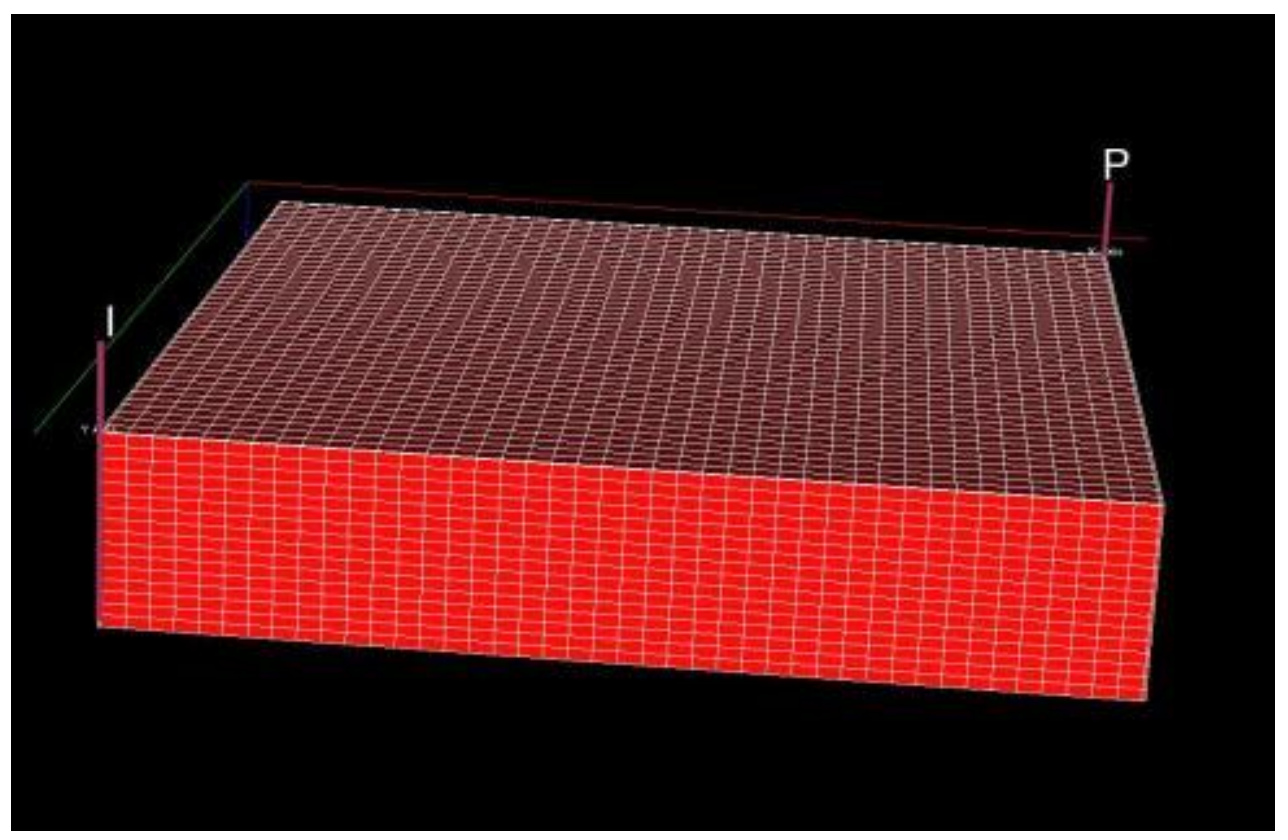

Figure 7: Reservoir model grid

Table 1 below shows the input data used to describe the base case reservoir model's initial conditions and PVT properties. This base model will be modified for both the polymer flood and the DDG cases with any changes stated when made.

Table 1: Reservoir Model Input Data

\begin{tabular}{|c|c|}
\hline Start Date & $1 / 1 / 2000$ \\
\hline Reservoir thickness, $\mathrm{ft}$ & 60 \\
\hline Reservoir length, $\mathrm{ft}$ & 660 \\
\hline Depth, $\mathrm{ft}$ & 8000 \\
\hline Areal extent, acres & 10 \\
\hline XY High Permeability, md & 1200 \\
\hline XY Low Permeability, md & 100 \\
\hline
\end{tabular}


Table 1 Continued

\begin{tabular}{|c|c|}
\hline Z High Permeability, md & 100 \\
\hline Z Low Permeability, md & 10 \\
\hline XYZ Porosity, fraction & 0.25 \\
\hline Oil API & 34.2 \\
\hline Oil viscosity, cp & 2.0 \\
\hline Oil formation volume factor, rb/stb & 1.01 \\
\hline Oil saturation, fraction & 0.8 \\
\hline Water viscosity, cp & 0.7 \\
\hline Water formation volume factor, rb/stb & 1.0 \\
\hline Connate water saturation, fraction & 0.2 \\
\hline 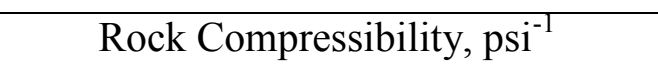 & $5.00 \mathrm{E}-06$ \\
\hline Water Compressibility, $\mathrm{psi}^{-1}$ & $3.03 \mathrm{E}-06$ \\
\hline Water injection rate, bbl/day & 500 \\
\hline Liquid production rate, bbl/day & 500 \\
\hline Number of grid blocks & $44 \times 44 \times 16$ \\
\hline Production well location & $44,1,1-16$ \\
\hline Injection well location & $1,44,1-16$ \\
\hline Economic limit & $0.95 \mathrm{WCT}$ \\
\hline Reservoir Temperature, $\mathrm{F}$ & 210 \\
\hline Injected water temperature, F & 70 \\
\hline Rock specific heat, btu/ $\mathrm{ft}^{3} . \mathrm{F}$ & 25 \\
\hline
\end{tabular}


Table 1 Continued

\begin{tabular}{|c|c|}
\hline Oil specific heat, btu/lbm.F & 0.5 \\
\hline Water specific heat, btu/lbm.F & 0.95 \\
\hline
\end{tabular}

\subsubsection{Polymer Flood Model}

The polymer viscosity was specified as a function of polymer concentrations in the injected water by applying a multiplier to the water viscosity that ranged from 1 to 100 for concentrations from 0 to 0.70 pounds per barrel. Polymer adsorption was kept low to maximize effectiveness of the flood. A Todd-Longstaff mixing parameter was used to model the degree of segregation of the polymer solution and the injection water at the trailing edges of the slug with 1.0 being used to indicate that the polymer and water in the relevant grid cells are fully mixed. This also helps minimize polymer loss which typically occurs at the leading edges of the polymer slug where stripped water banks are created when there is poor mixing.

The polymer flood was timed to commence when the base case water flood reached a water-cut of $85 \%$. Polymer injection was performed for a period of time that closely approximated breakthrough time and its injection rates were calculated by applying an upper limit on the allowable bottom-hole pressure at the injection well. This was done to accommodate the drop in injectivity during the period the polymer is being injected due to the increased viscosity of the drive fluid (Seright 2010).

At low flow rates, polymer floods typically exhibit Newtonian or nearNewtonian characteristics and viscosity remains relatively constant and depends only on 
polymer concentration. This behavior has been supported by Seright's findings in the paper above. As flow rates increase however, polymer molecules begin to break up and viscosity reduces, first reversibly and then irreversibly as rates further increase. The default model Eclipse uses focuses on the shear thinning of polymer and calculates polymer viscosity based on shear rates which it assumes is proportional to flow viscosity.

\subsubsection{DDG Model}

The development of the model used to simulate the performance of the DDG was based on the mechanism of its treatment which can be separated into three different steps:

1. The particles are injected into the formation with the injection water. As with the polymer flood, this was set to commence when a watercut of $85 \%$ was reached in the base case waterflood. In this step, the particles are inert and still sub-micron sized. This was the basis for assigning the same viscosity and injectivity as water.

2. The sub-micron sized particles are transported through the reservoir in the waterflood. Since the particle slurry has the same viscosity as the water, most of it is also diverted to the thief zones. To avoid loss of particles during this propagation and maximize efficiency, the adsorption and retention of the particles onto the rock pore walls was designed to be negligible.

3. The particles reach the design temperature and 'pop', i.e. the internal crosslinks break and the particles expand and absorb water, effectively blocking the throats of the pores they are travelling through. At this point, the permeability of the 
cells predetermined to be occupied by the DDG slug are reduced from 1200 to 40md in the $\mathrm{X}$ and $\mathrm{Y}$ direction and from 100 to $10 \mathrm{md}$ in the Z-direction. The slug was set to form only in the watered out high permeability zone again assuming ideal behavior and maximum utility.

Eclipse does not currently have the functionality to model the application of the DDG in one simulation, i.e. by coupling running the base case simulation to a designated water-cut or time-step and seamlessly reducing the permeabilities of specified grid blocks then continuing to the project's economic limit. It does however allow the above described scenario to be broken into two steps whereby the DDG simulation can import the reservoir conditions such as saturations and pressure as well as the results of the previously run base case waterflood from time zero up to a predetermined time-step using Eclipse's RESTART function. In the second step, the modified properties (permeability) replace the original values and the run continues to the economic limit.

The time-step at which this occurs is determined by first modeling the thermal front in the base case waterflood using the simulator's TEMP keyword. The temperatures of the cells are then calculated and outputted as a function of time. Energy balance equations are solved after the flow equations at each time-step to calculate the temperature in each grid block. The results of these are then used to modify fluid viscosities as functions of temperature for subsequent time steps.

In practice, the transit time and temperature profile between the wells would be determined to identify the location the bulk of the DDG would go then it would be designed to activate at that temperature. This transit time is then added to the time-step at 
which $85 \%$ water-cut occurs to get the actual time-step at which reservoir parameters from the base case are to be imported. For instance, if a water-cut of $85 \%$ occurs after 1000 days of production and it takes 400 days for the waterflood to travel from the injection well to the zone of interest, the time step at which the DDG simulation begins would be after 1400 days. This approach is of importance in accurately comparing the technical performance and economic value of DDG to those of waterflood and polymer flood. 


\section{RESULTS AND DISCUSSION}

The simulation results for the three different methods will be presented and discussed below from the time the water-flood reaches $85 \%$ water-cut. This is of particular importance in evaluating the performance of each method from the same starting point. The base case will be described and modifications made to its configuration and relevant properties within each method as well as the effects these changes had on results.

\subsection{Water Flooding}

This method served as the base case and will be simulated using two configurations; one with the high permeability layer on top (H-L) and the second with it on the bottom (L-H). As expected, the high permeability layer watered out quickly causing injected water to preferentially flow through it and leading to high water production. Figures 8 and 9 below use oil saturation in the reservoir at breakthrough to illustrate this. In both cases, the high permeability layer has very little oil left while the lower permeability layer still contains a considerable amount yet to be recovered.

Table 2: Results from Waterflood Simulation at $85 \%$ Watercut

\begin{tabular}{|c|c|c|c|c|}
\hline & Oil (MSTB) & Water (MSTB) & Life (Years) & RF \\
\hline HL & 424 & 398 & 4.50 & $43.13 \%$ \\
\hline LH & 393 & 398 & 4.33 & $40.06 \%$ \\
\hline
\end{tabular}




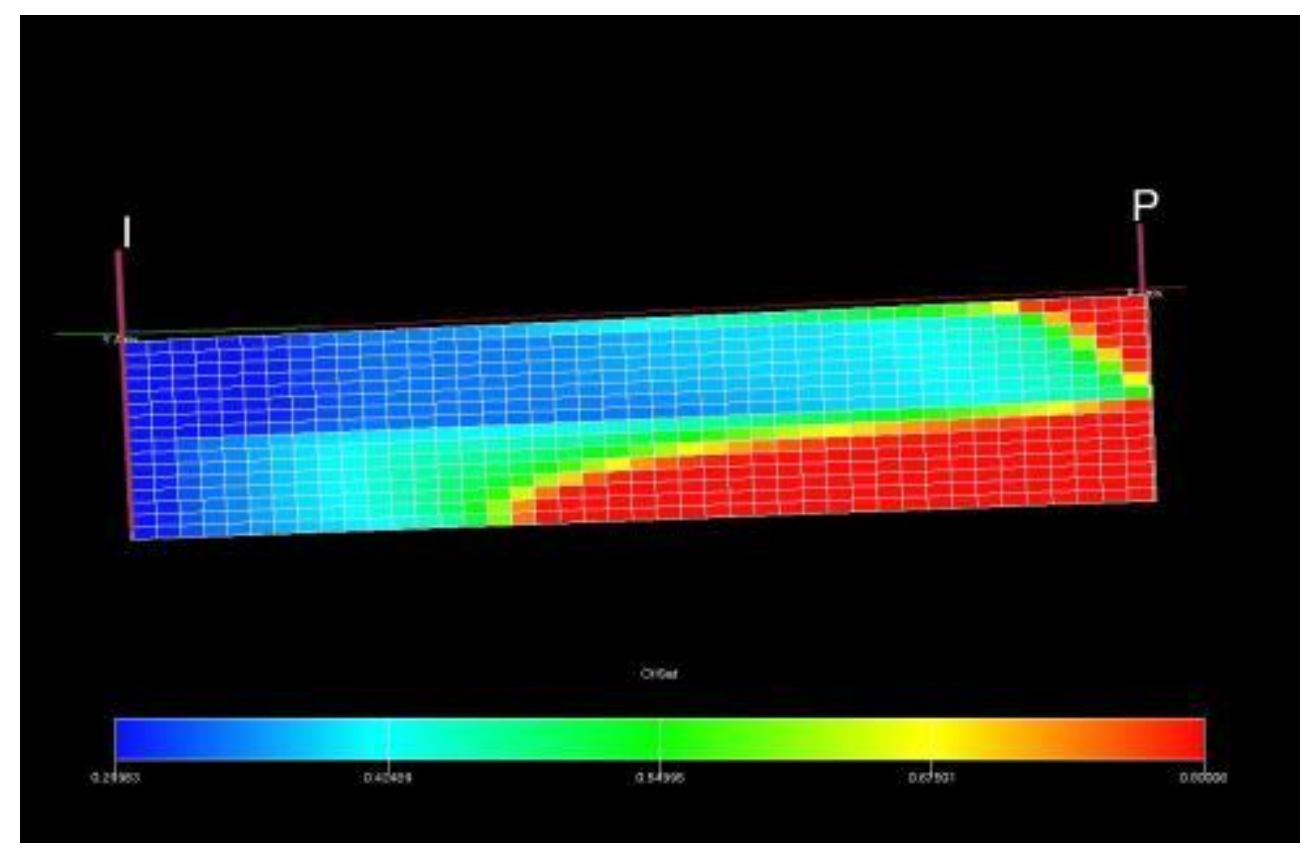

Figure 8: HL Reservoir Oil Saturation at breakthrough

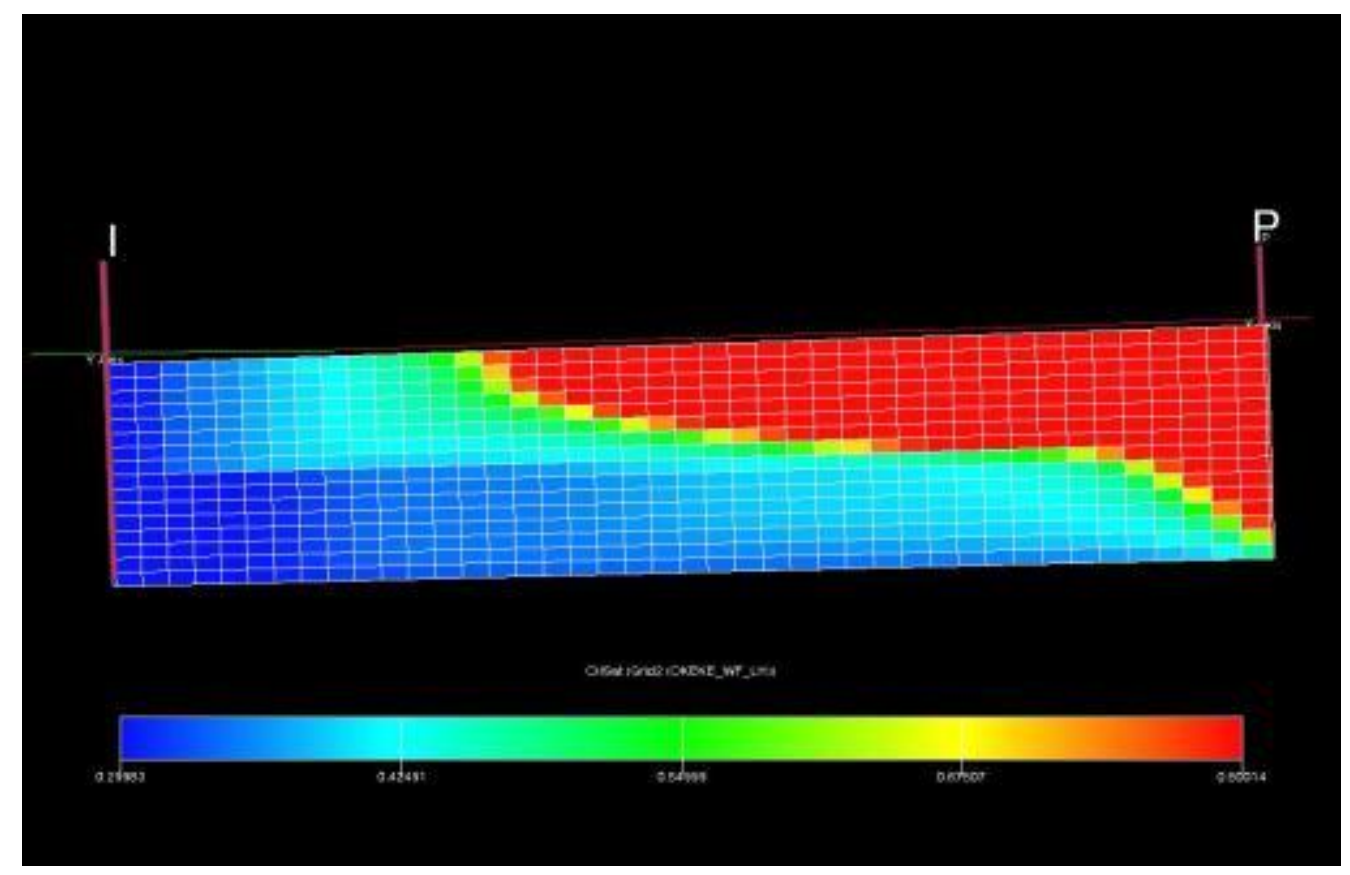

Figure 9: LH Reservoir Oil Saturation at breakthrough 
Breakthrough occurs at about the same time in both configurations but as can be seen in Figure 10, the project reaches the economic limit of $95 \%$ water-cut about 500 days sooner when the high permeability layer is on top. Table 2 above shows that from the start of the waterflood to $85 \%$ watercut, oil recovery is higher in the H-L case due to gravity causing the denser water to slump into the low permeability layer thereby enhancing sweep efficiency. This is also the reason why the watercut in the L-H configuration is steeper than in the H-L.

Incremental oil production is however about 11,000 barrels lower in the H-L run from $85-95 \%$ watercut due to the fact that there is less oil to recover in its high permeability layer so recovery efficiency drops. On the other hand, about 250,000 barrels more water is produced in the L-H case.

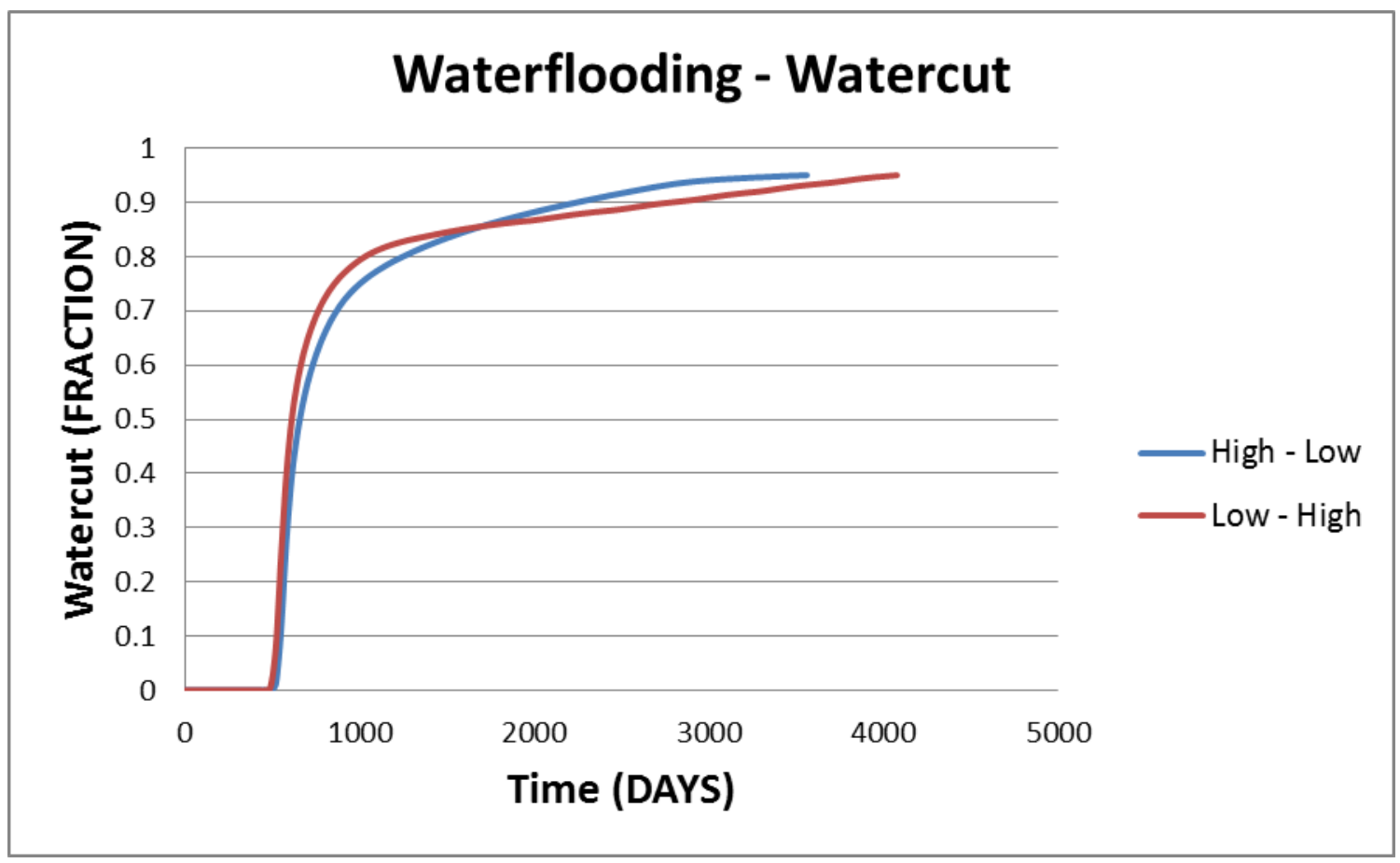

Figure 10: Waterflood - Watercut 


\subsection{Polymer Flooding}

Polymer was injected into the reservoir starting when the corresponding waterflood base cases, i.e. for the H-L and L-H configurations reached $85 \%$ water-cut. The polymer concentration used in the base case was $1000 \mathrm{ppm}(0.35 \mathrm{lb} / \mathrm{stb})$. Injection went on until breakthrough of polymer was observed at the production well at which point a waterflood post-flush was restarted.

As expected, improving the mobility ratio caused better sweep efficiency which in turn led to increased oil recovery and a reduction in water production. Due to its impact on mobility ratio, an increase in recovery over waterflooding of 121,000 and 112,000 barrels in the H-L and L-H configurations respectively was observed with corresponding reductions in water production of 62,000 and 345,000 .

\subsection{Deep Diverting Gel}

The figures below show the incremental oil and water production rates when the DDG is used as well as the effect this method has on water-cut. These results are compared to those from the other two methods. As can be seen in Figure 11 below, when the DDG 'pops', there is a sharp decline in water-cut resulting in a decrease in water production and an increase in oil recovery. The effect of cross-flow is particularly highlighted by the difference in results for the H-L configuration versus the L-H. Oil recovery is higher than in the waterflood case with the figures below highlighting the increases in recovery of $2.30 \%$ for the HL and $1.80 \%$ for the $\mathrm{LH}$ arrangement. Water production is also better controlled as can be seen in Figure 20 where the total water 
produced with this method is lower than in the other two methods for the HL and LH configurations respectively.

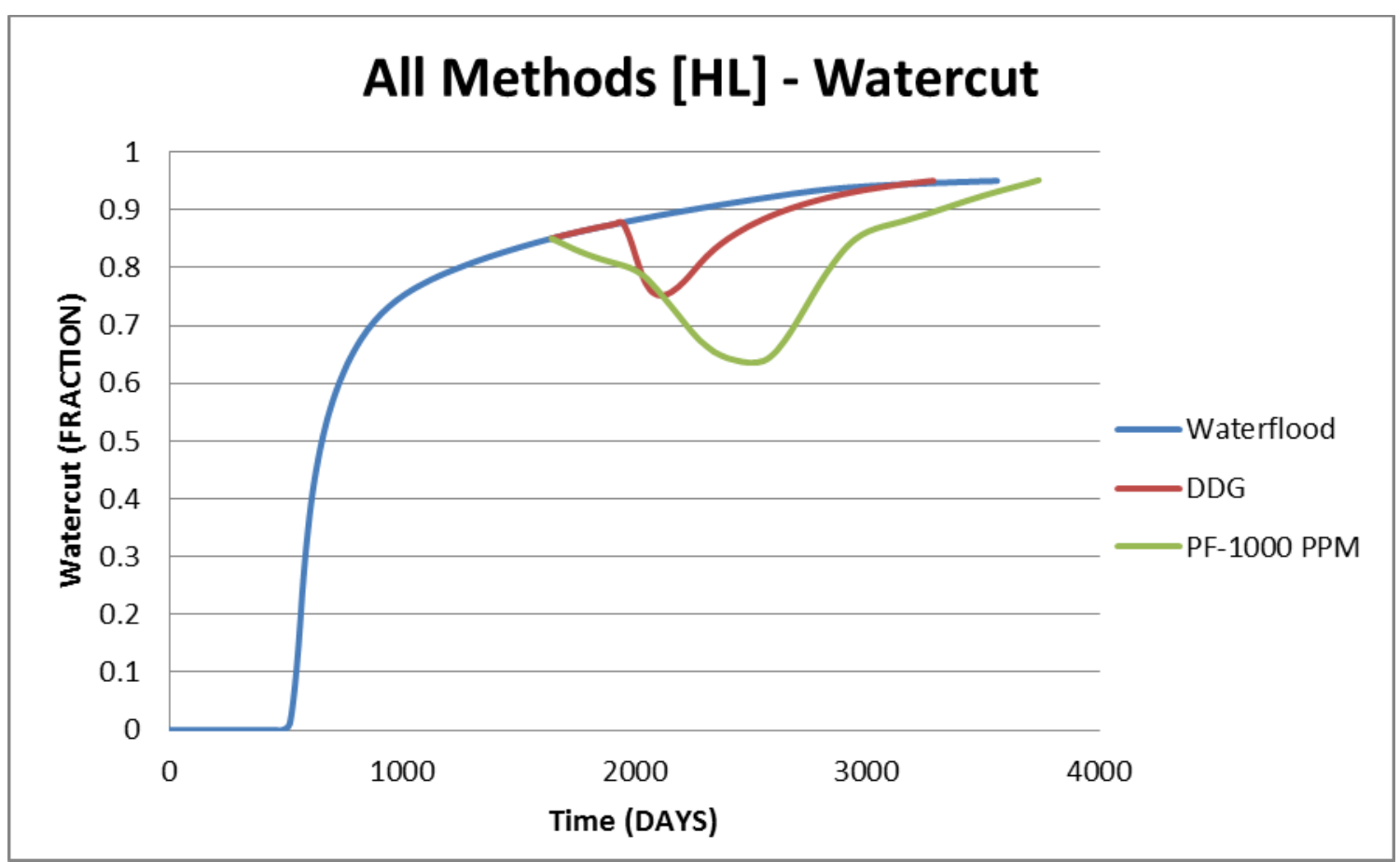

Figure 11: Base Cases - Watercut

The figures below show the oil saturations of the three methods at different watercuts. Figures 13 - 15 show each method at 90\% watercut while Figures $16-18$ shows the oil saturations at $95 \%$ water-cut. As we can see, the DDG treatment and polymer flood improve sweep efficiency through the life of the project. Figure 14 shows the water being diverted into the low permeability layer over the plug formed close to the production well. From Figure 18, due to its more effective piston-like displacement of oil, we can conclude that the polymer flood leaves less oil in the less permeable layer than the DDG treatment at the end of the project at $95 \%$. 


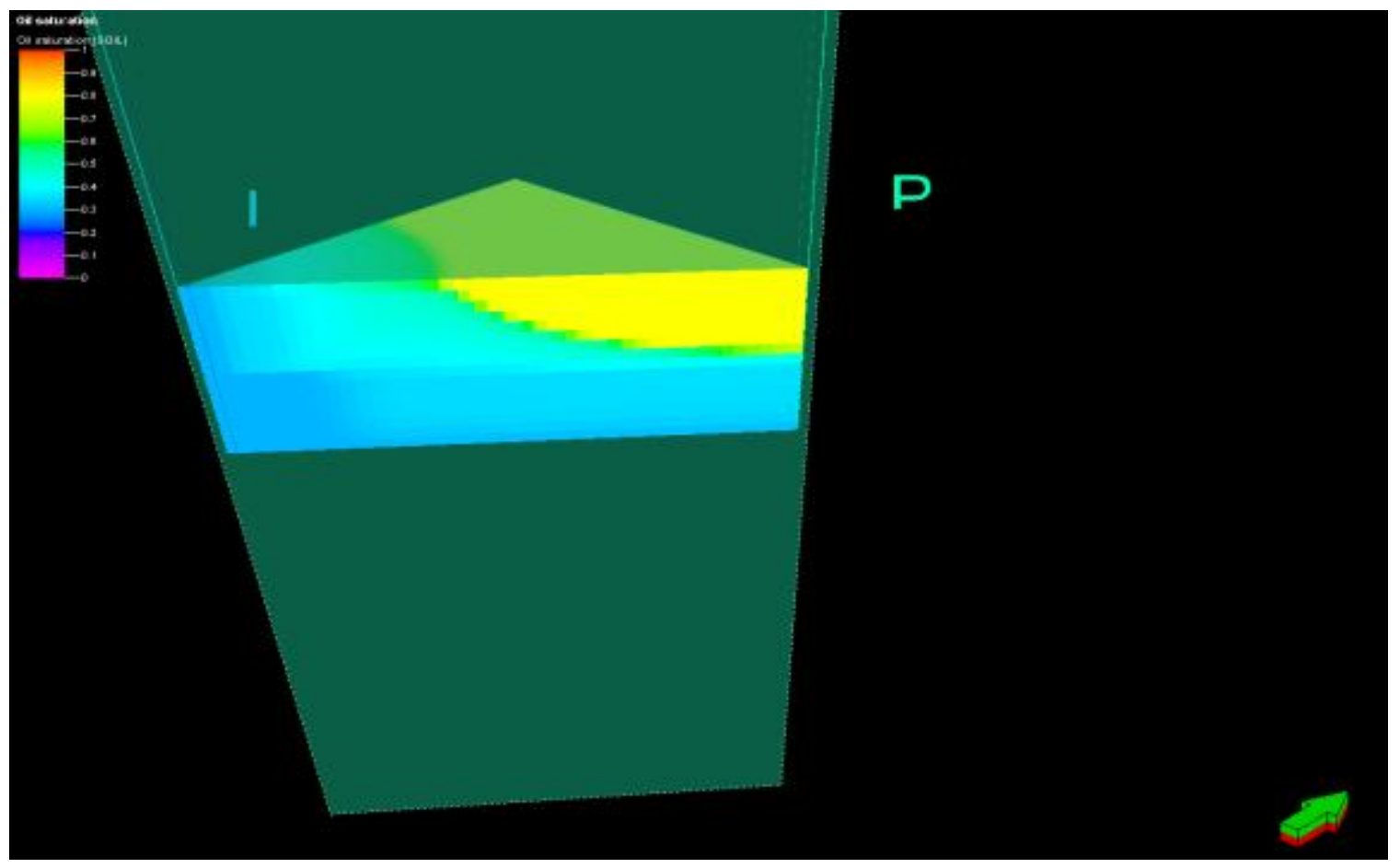

Figure 12: Waterflood [LH] - Oil Saturation at $85 \%$ Watercut

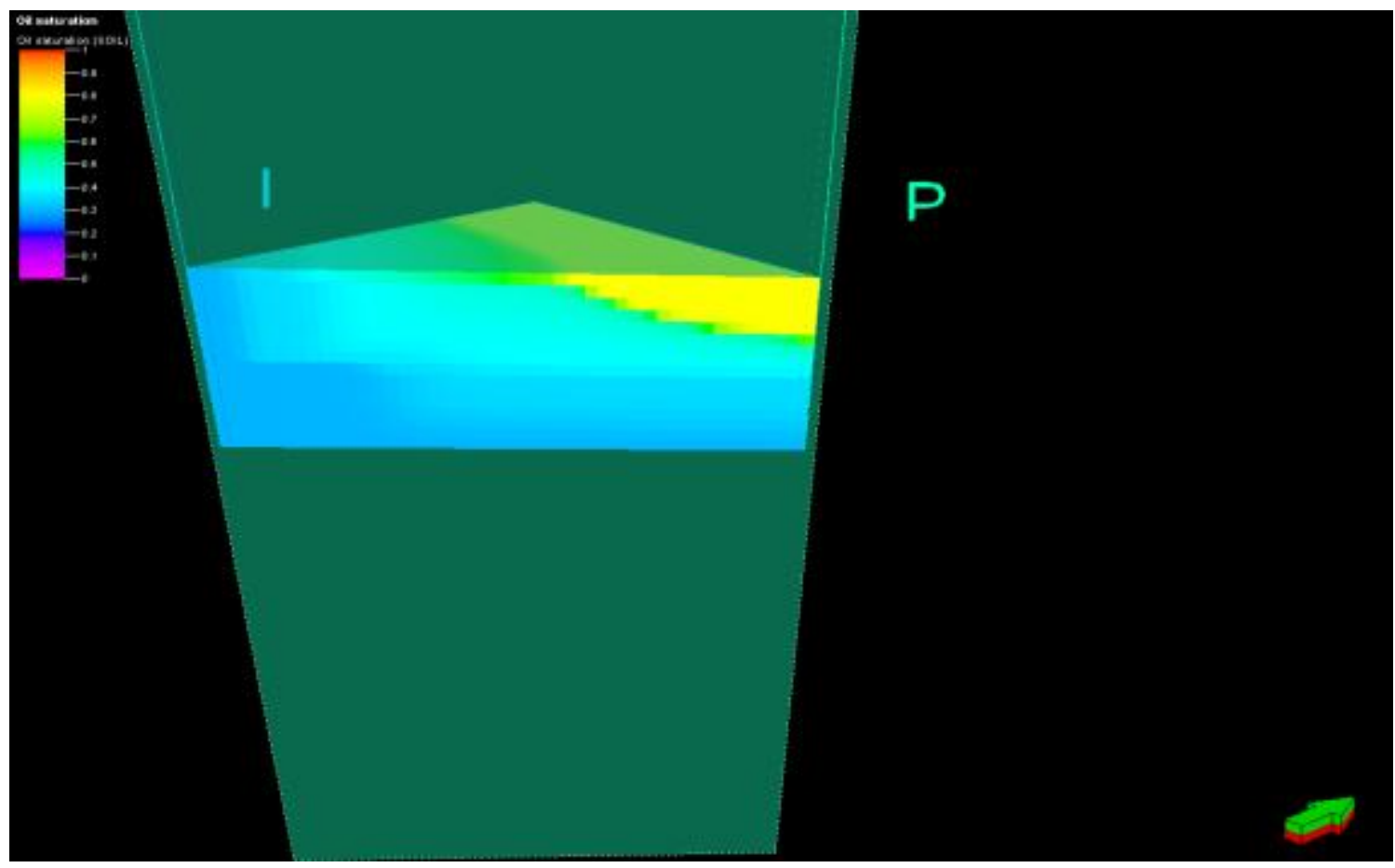

Figure 13: Waterflood [LH] - Oil Saturation at 90\% Watercut 


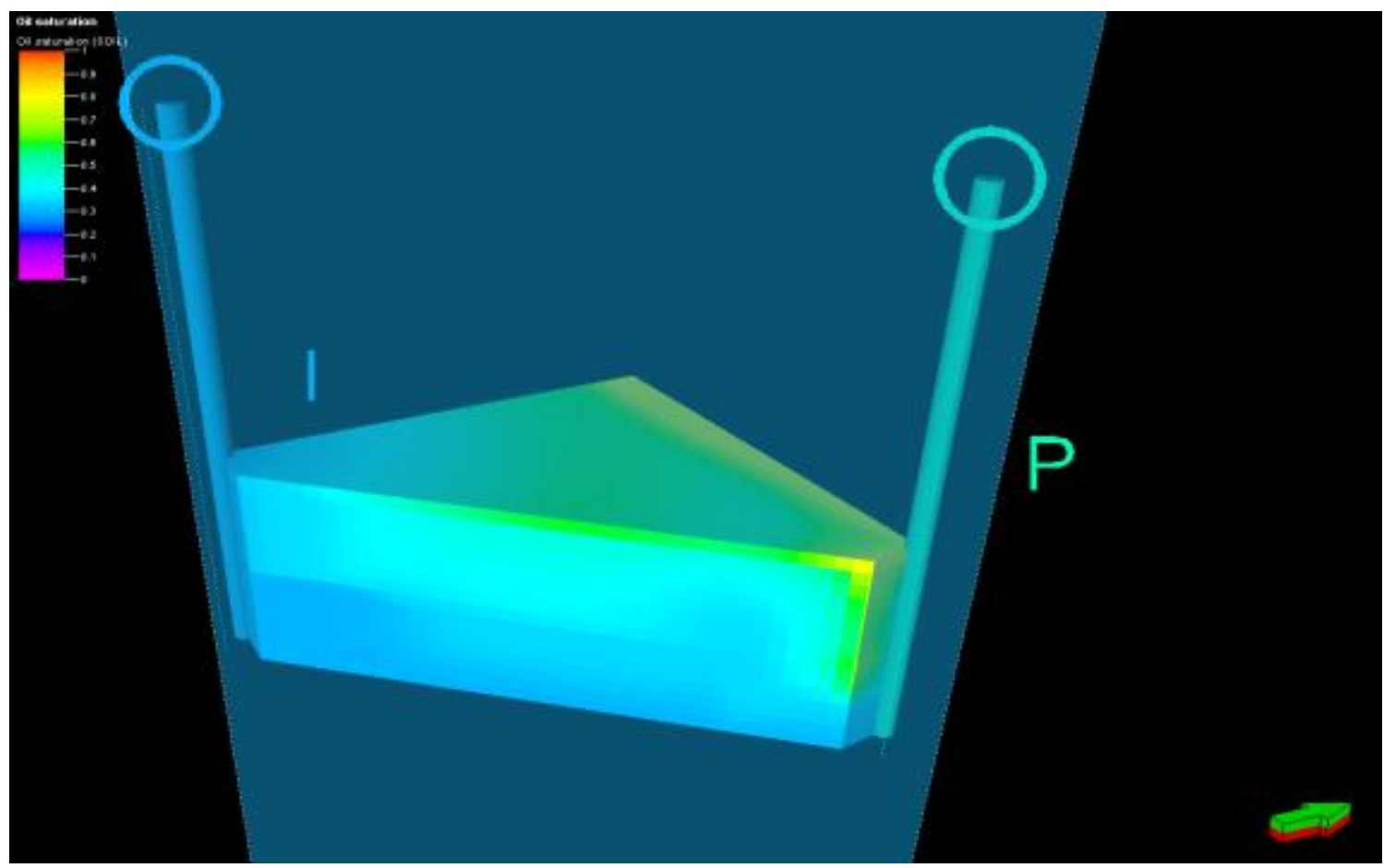

Figure 14: DDG [LH] - Oil Saturation at 90\% Watercut

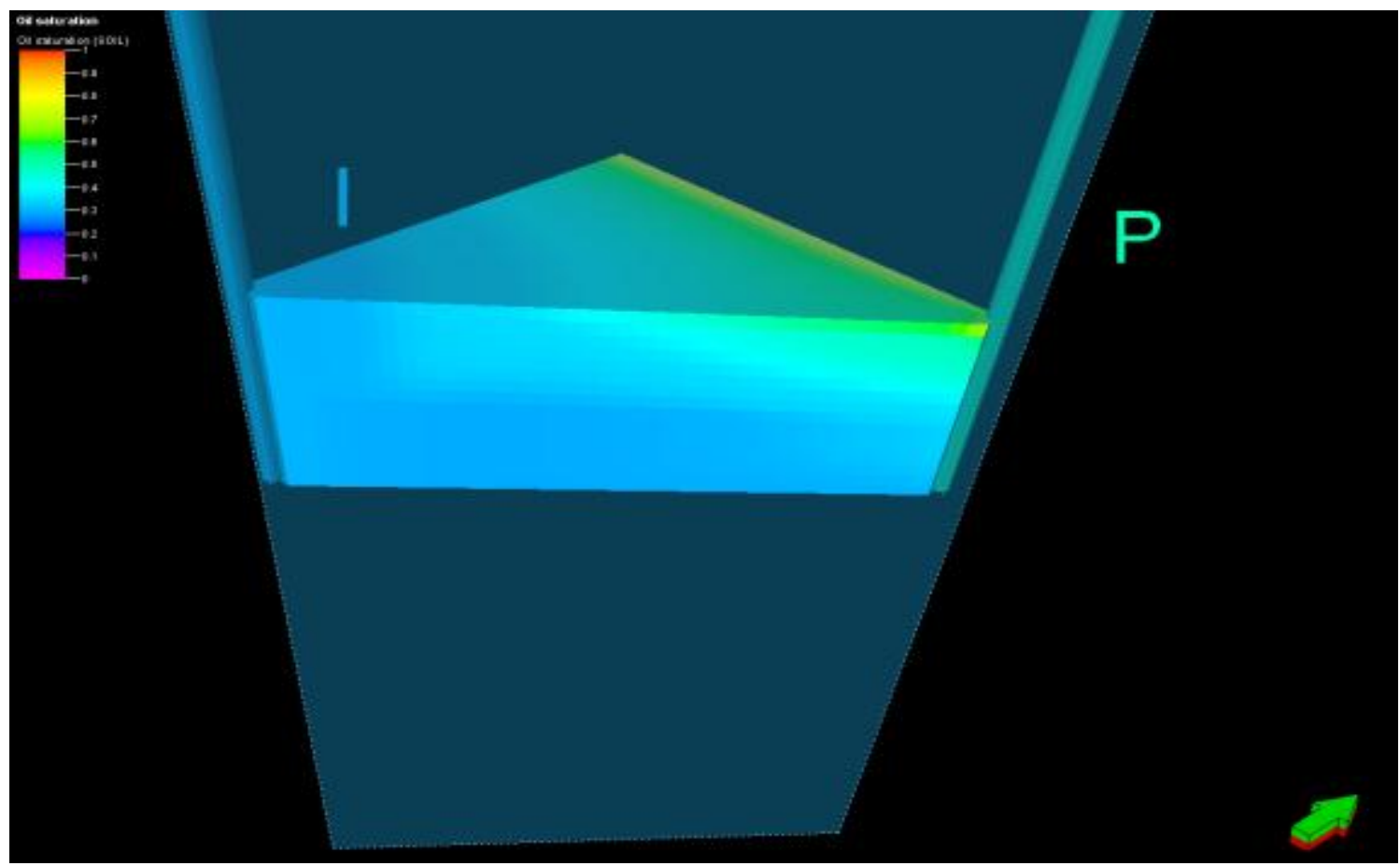

Figure 15: Polymer flood [LH] - Oil Saturation at 90\% Watercut 


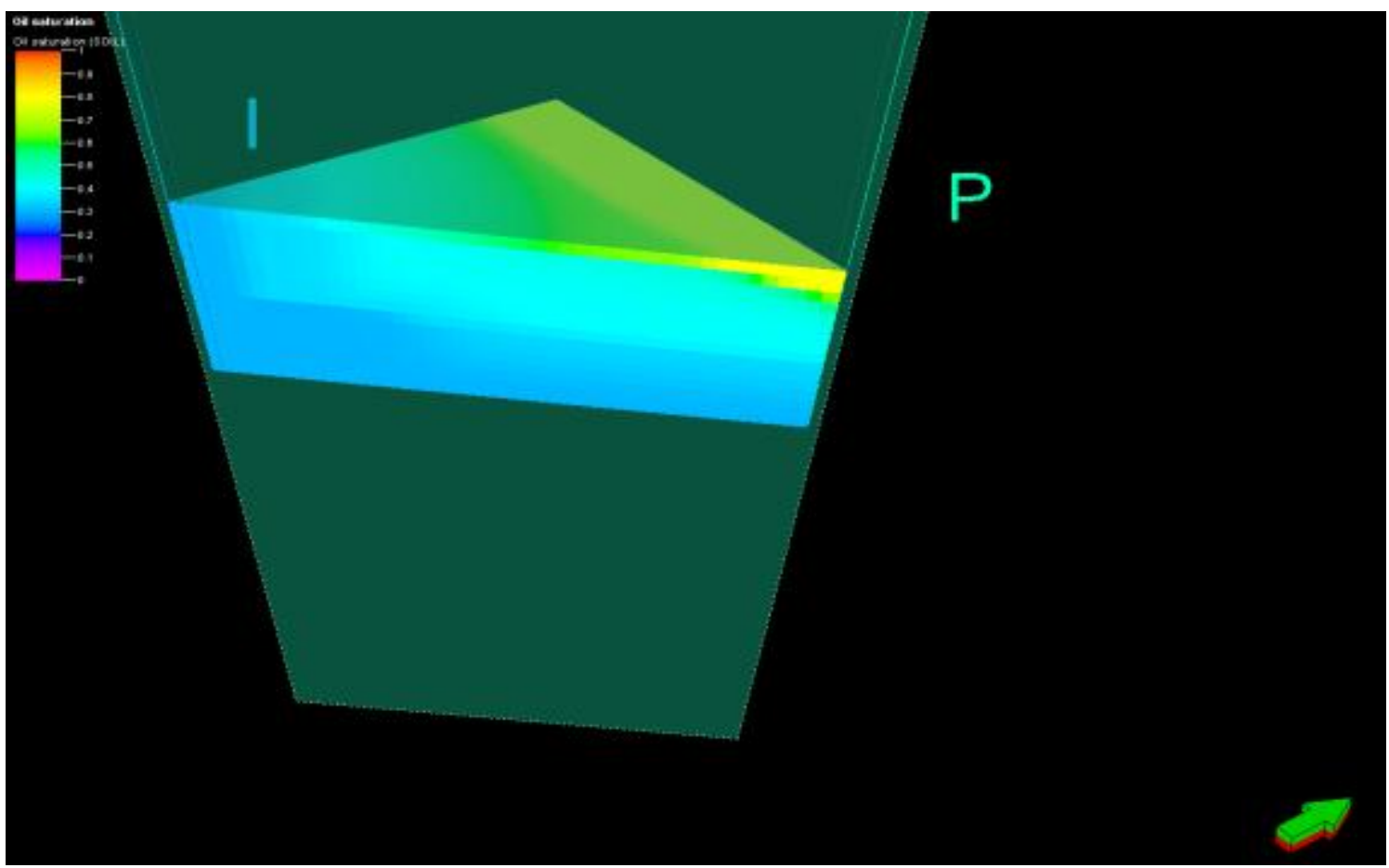

Figure 16: Waterflood [LH] - Oil Saturation at 95\% Watercut

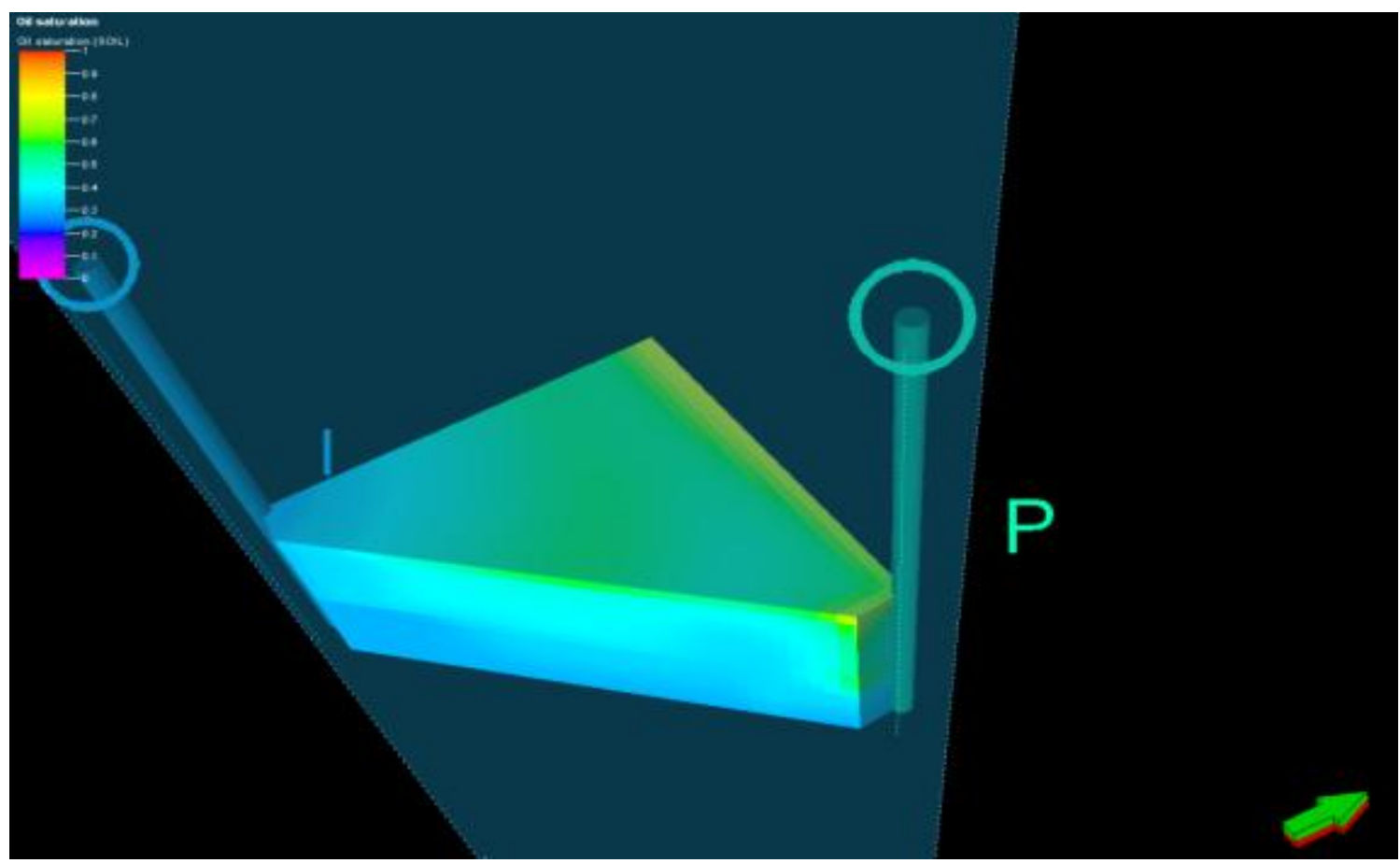

Figure 17: DDG [LH] - Oil Saturation at 95\% Watercut 


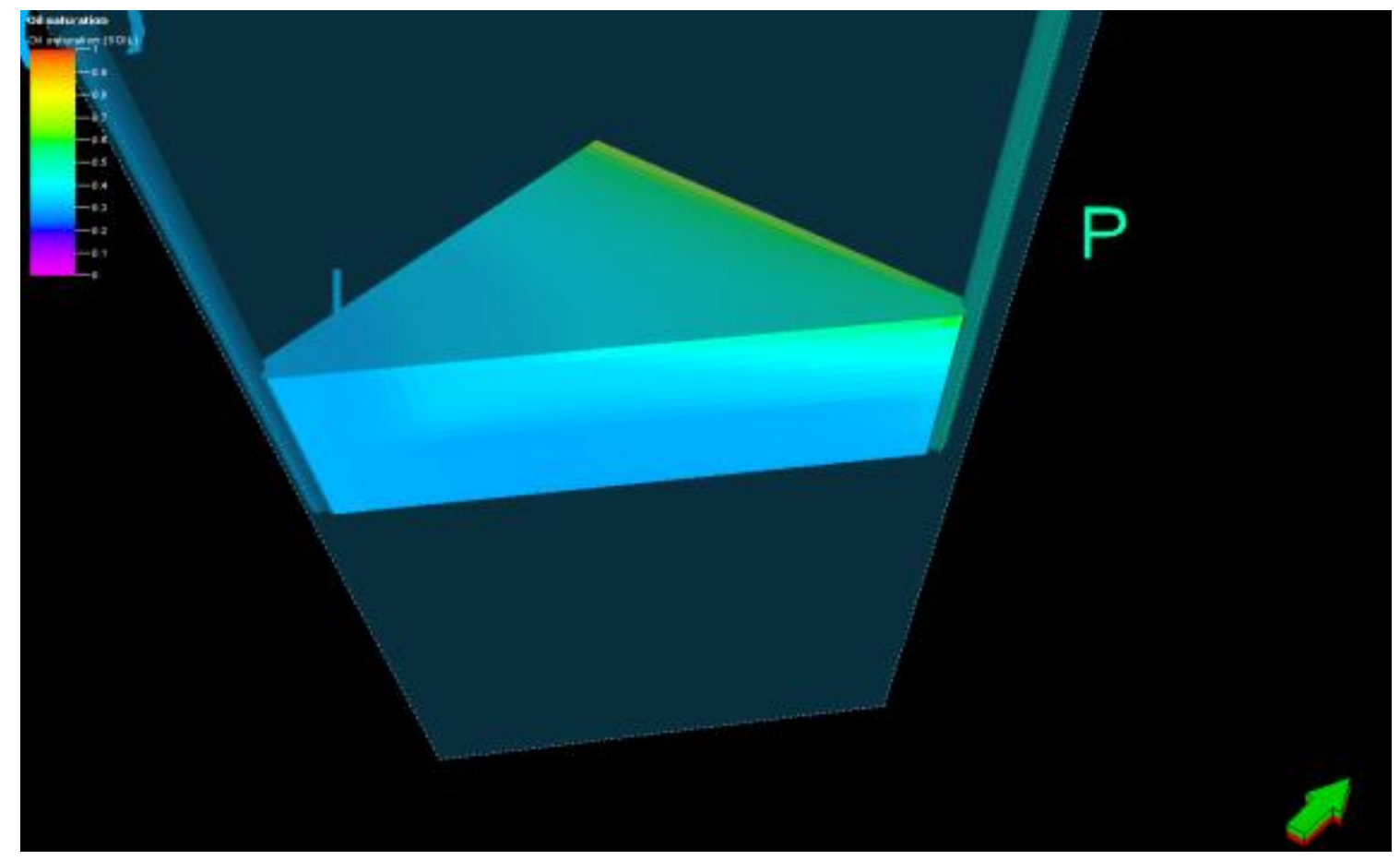

Figure 18: Polymer flood [LH] - Oil Saturation at 95\% Watercut

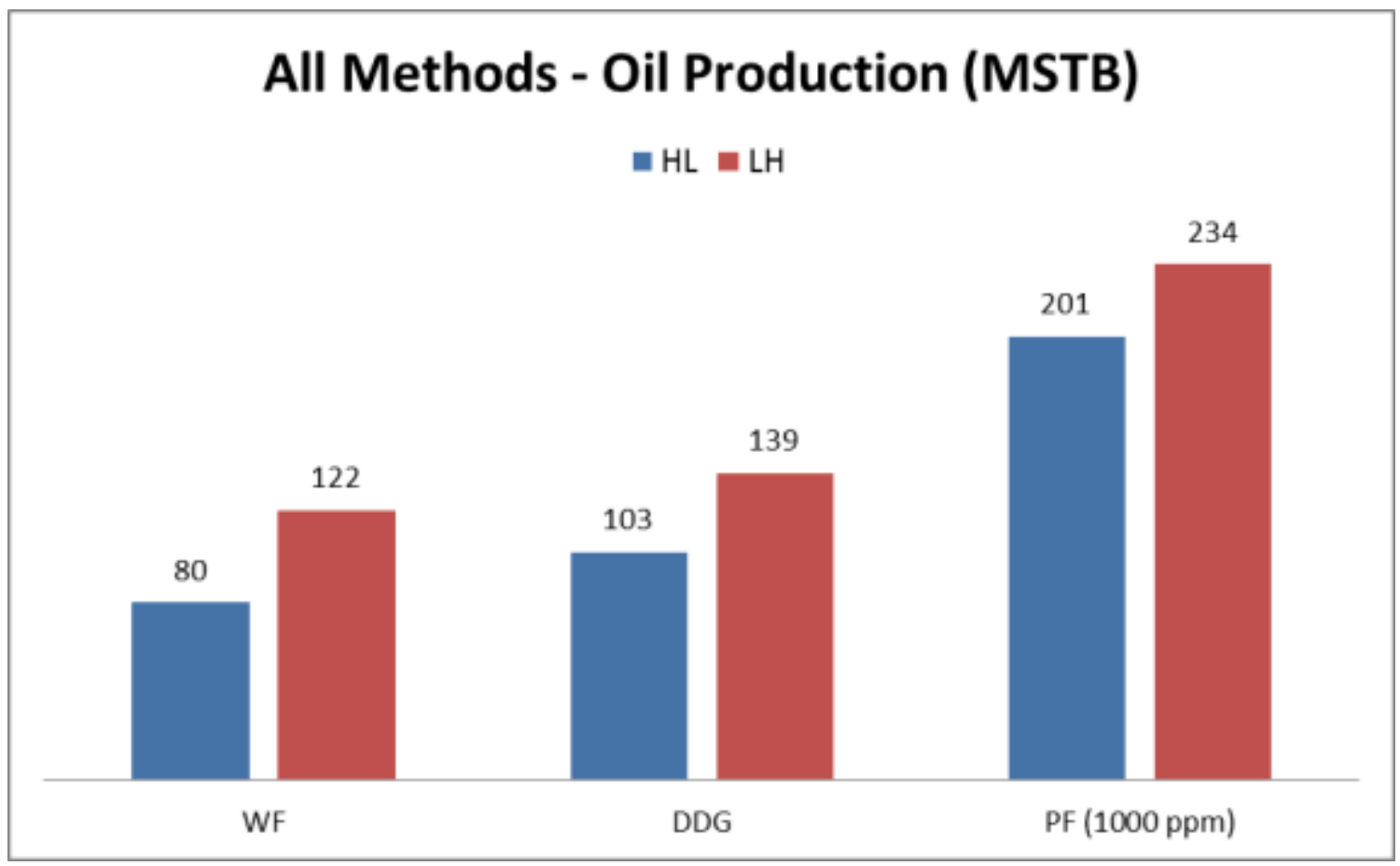

Figure 19: Base Cases - Incremental Oil Production 


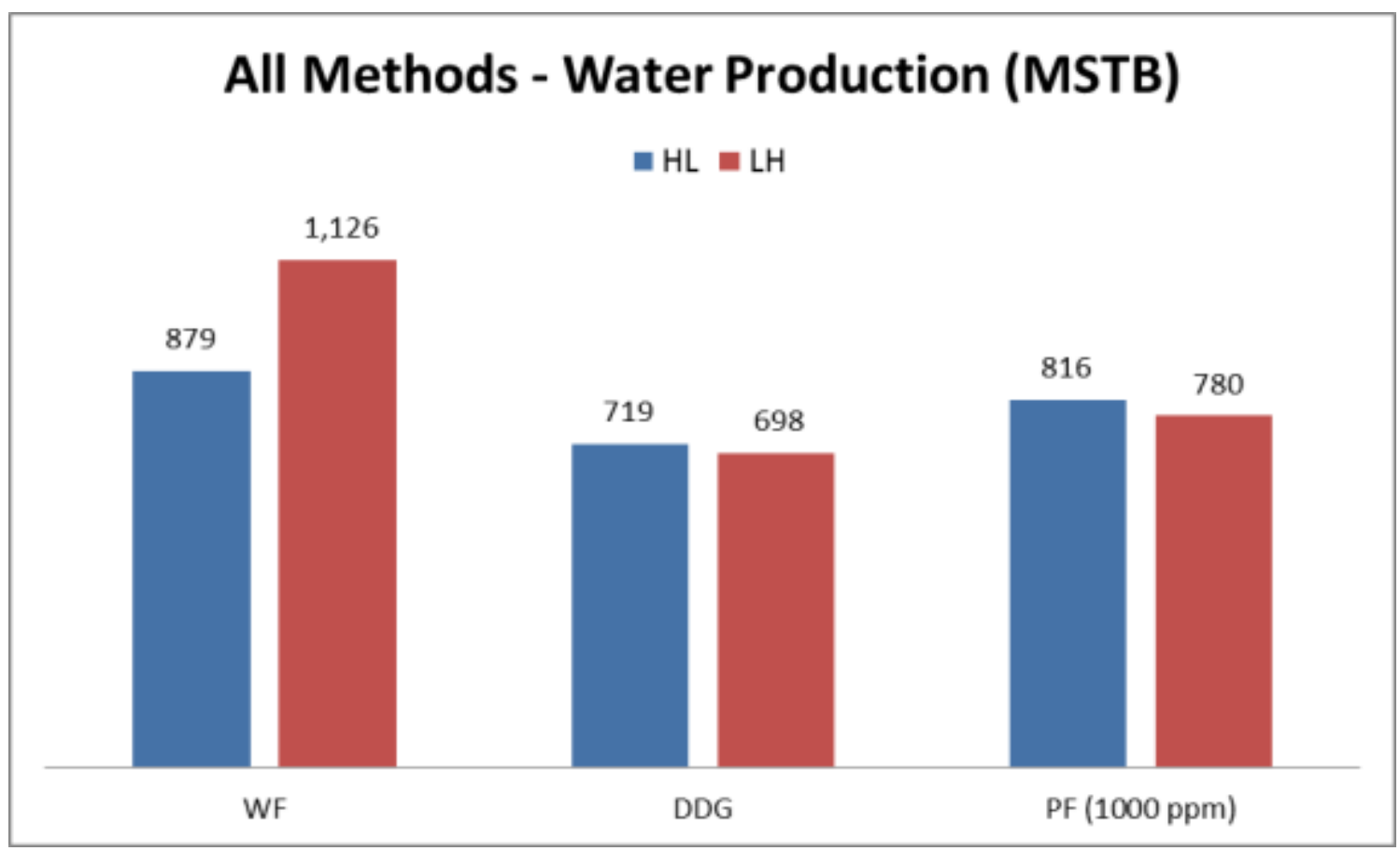

Figure 20: Base Cases - Incremental Water Production

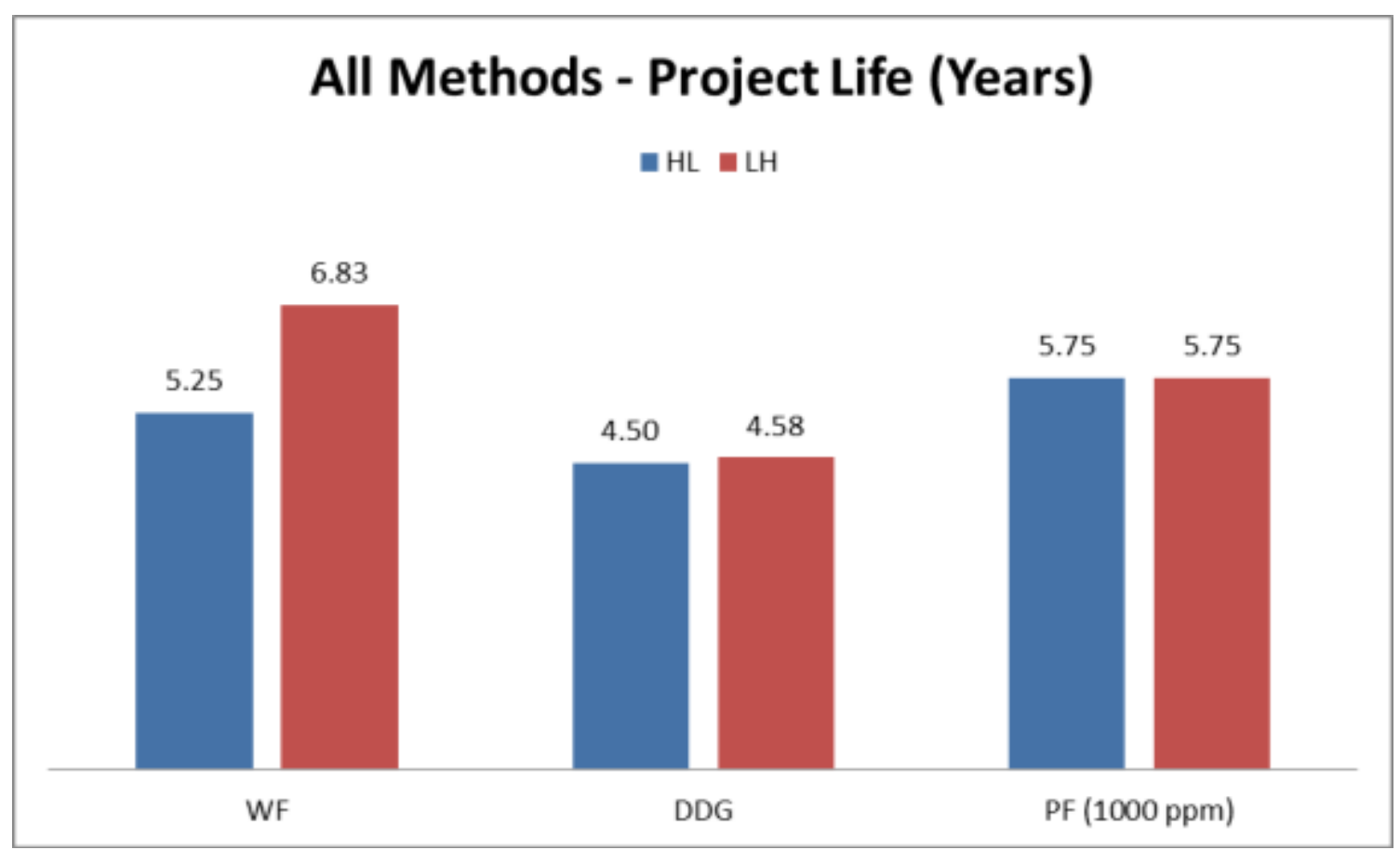

Figure 21: Base Cases - Project Life 


\subsection{Sensitivity Analysis}

In order to assess how polymer flood and DDG performed under different conditions, variables such as permeability reduction at the DDG's activation site, polymer concentration and oil viscosity were modified.

\subsubsection{Permeability Reduction}

In this run, the permeability at the plugged site was reduced to 0 from $1200 \mathrm{md}$ in the DDG model to simulate an ideal case. Recovery was only slightly improved from the case where the permeability was reduced to $40 \mathrm{md}$ in the plugged cells with an increase of less than 2000 barrels. Water production was however reduced by about 155,000 barrels with production time reduced by about 300 days. It is however unrealistic to expect the permeability to drop completely to $0 \mathrm{md}$ as no literature was found to support this. Work done by Frampton (2004) and Husband (2010) suggests that the reduction can be expected to range between 11 and 350 times that of the original value. 


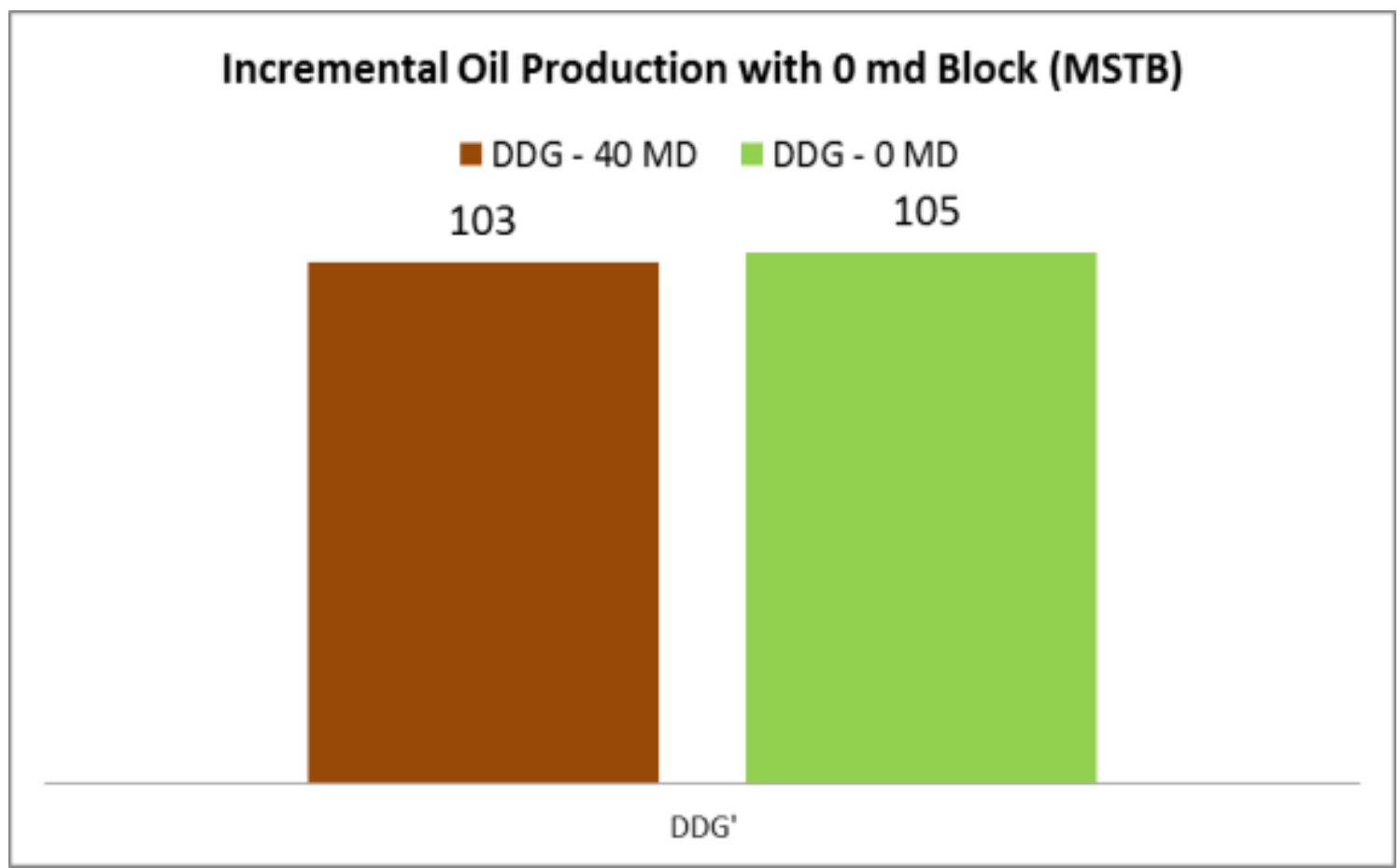

Figure 22: DDG - Incremental Oil Production with 0 md Block

\section{Water Production with 0 md Block (MSTB)}

EDG - $40 \mathrm{MD}=\mathrm{DDG}$ - $0 \mathrm{MD}$

719

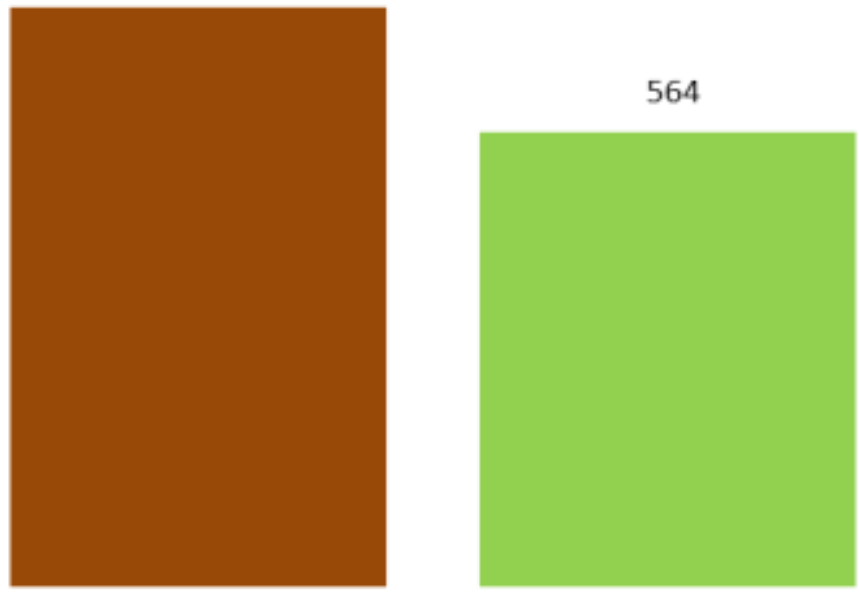

Figure 23: DDG - Incremental Water Production with 0 md Block 


\subsubsection{Polymer Concentration}

To get a better idea of the effect of the concentrations used on polymer floods performance, simulations were performed at concentrations of $285 \mathrm{ppm}(0.10 \mathrm{lb} / \mathrm{stb})$, $600 \mathrm{ppm}(0.21 \mathrm{lb} / \mathrm{stb})$ and $1500 \mathrm{ppm}(0.525 \mathrm{lb} / \mathrm{stb})$. For both $\mathrm{H}-\mathrm{L}$ and L-H arrangements, oil recovery increased slightly at the higher concentration with more marked reductions observed as concentration was reduced. Water production was however more substantially reduced at $1500 \mathrm{ppm}$.

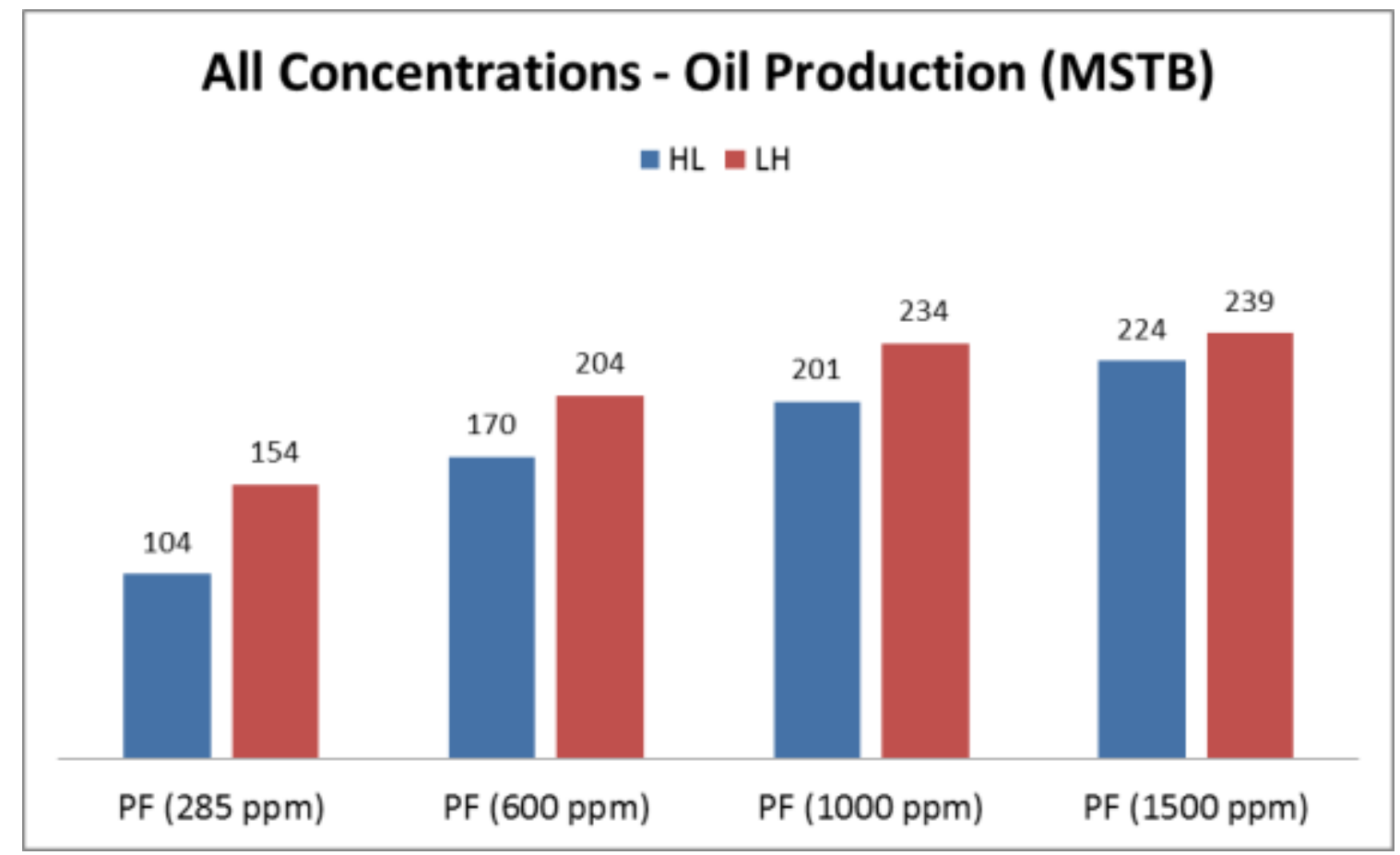

Figure 24: Polymer Flood - Oil Production at Different Concentrations 


\section{All Concentrations - Water Production (MSTB)}

EL $=\mathrm{LH}$

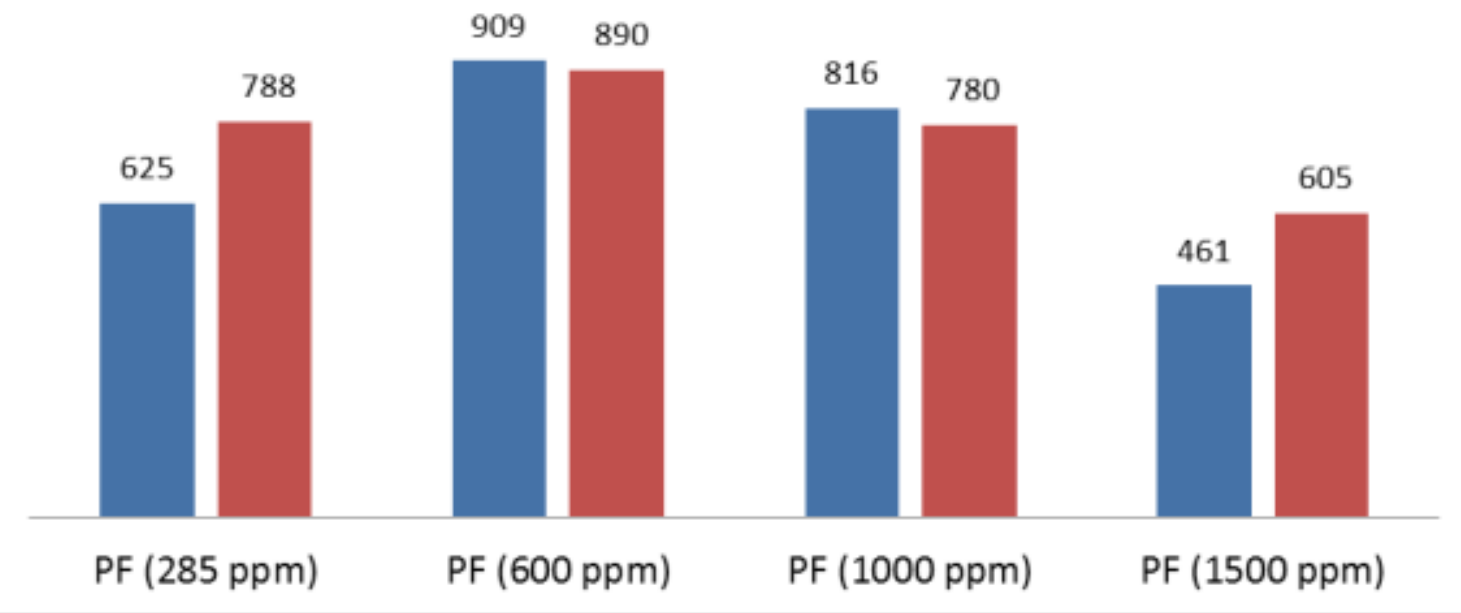

Figure 25: Polymer Flood - Water Production at Different Concentrations

\section{All Concentrations - Project Life (Years)}

$\square \mathrm{HL}=\mathrm{LH}$

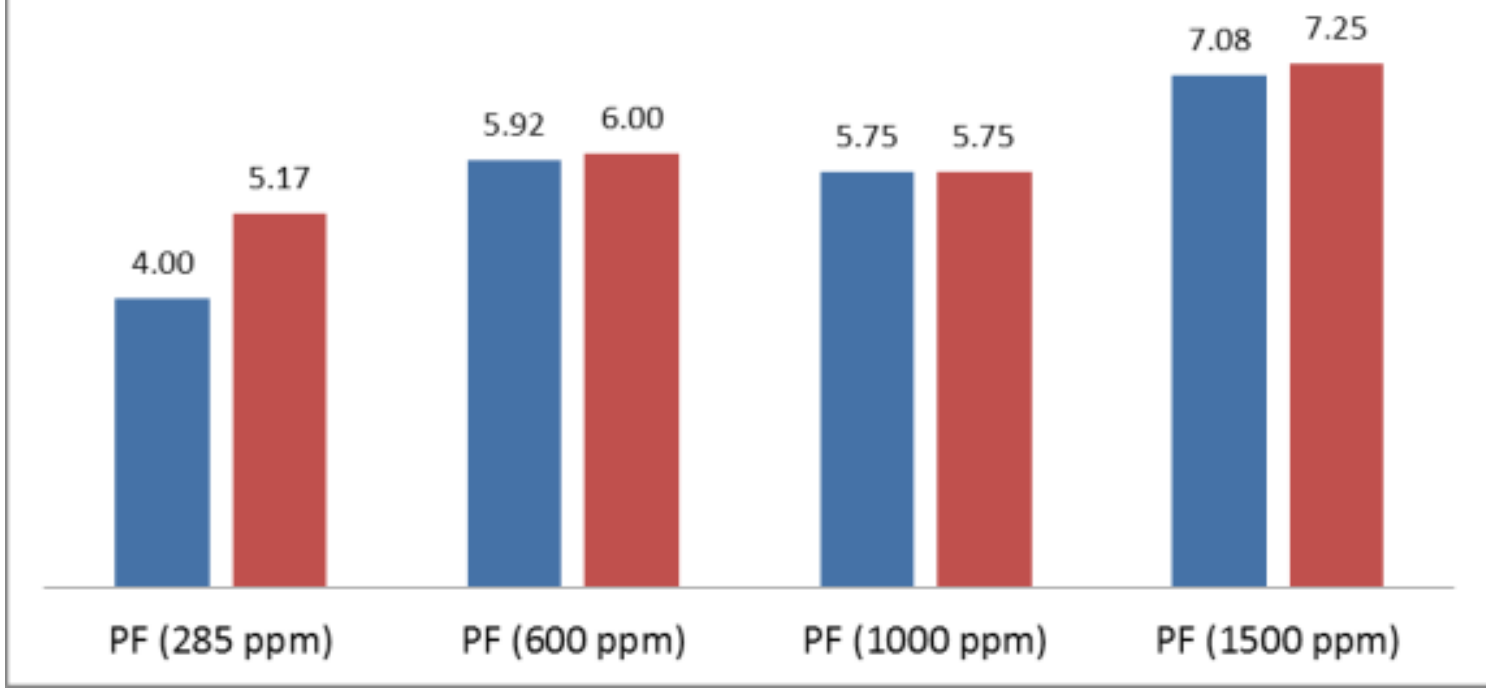

Figure 26: Polymer Flood - Project Life at Different Concentrations 


\subsubsection{DDG Production Pressure}

One of the assumptions made in the DDG process is that the viscosity of the added slurry be as close to that of water as possible. As such the pressure responses at the injection and production wells are only slightly different from the base case waterflood. To better compare this method to the polymer flood, it was decided to artificially increase the pressure drop at the production well in the DDG runs to simulate the drop observed during polymer flood. This was done by reducing the injection rate in one set of simulations by 100 barrels per day while keeping production rate constant and increasing the liquid production rate by the same amount in a second with injection rate held constant.

Oil recovery increased $90-96 \%$ in the H-L configuration and by $60 \%$ in the L$\mathrm{H}$ arrangement compared to the DDG base case results. This was however followed by increases in project life of 3 to 4 years and in water production ranging from $60-90 \%$ for both configurations. 


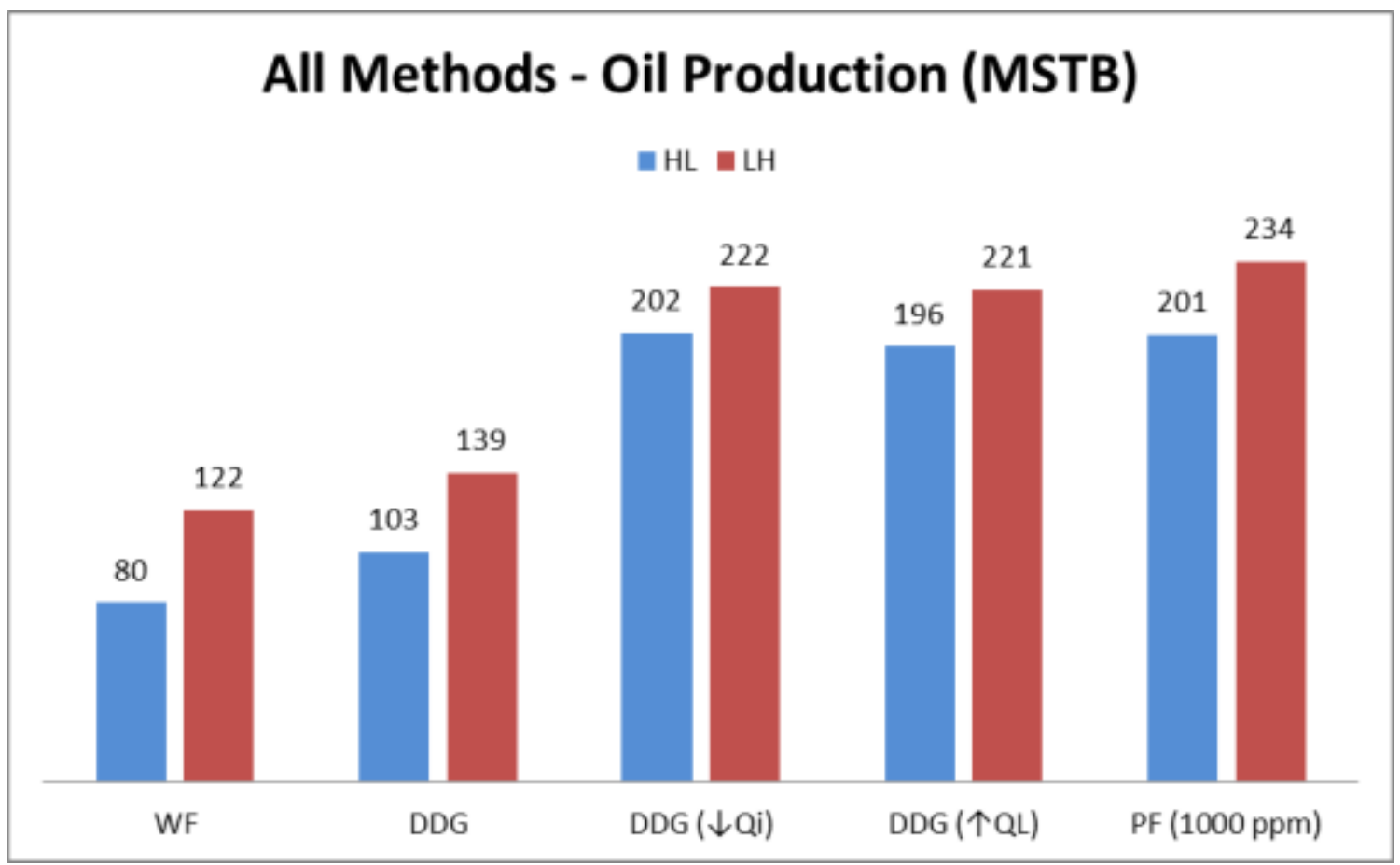

Figure 27: DDG - Oil Production with lowered Production Pressure

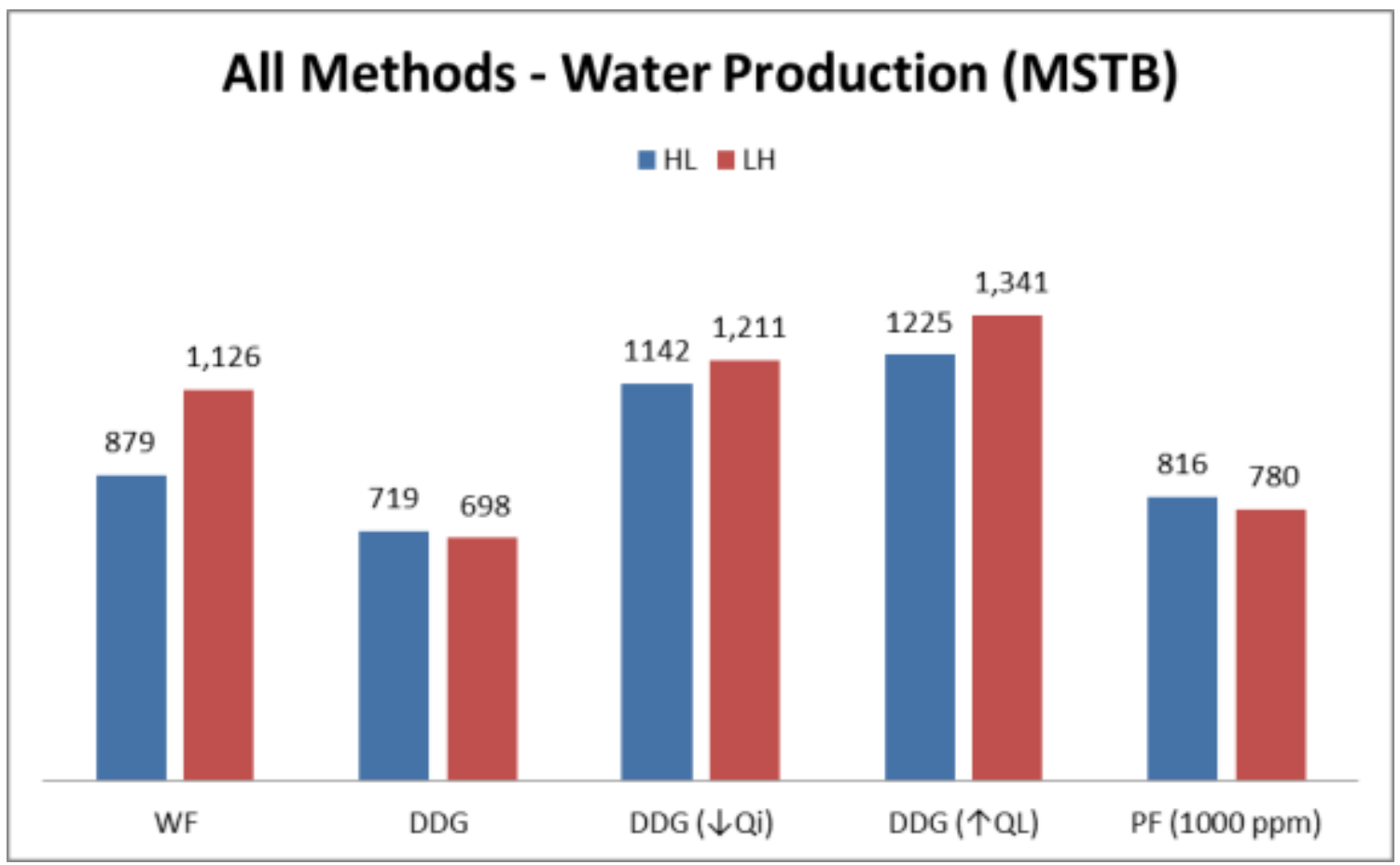

Figure 28: DDG - Water Production with lowered Production Pressure 


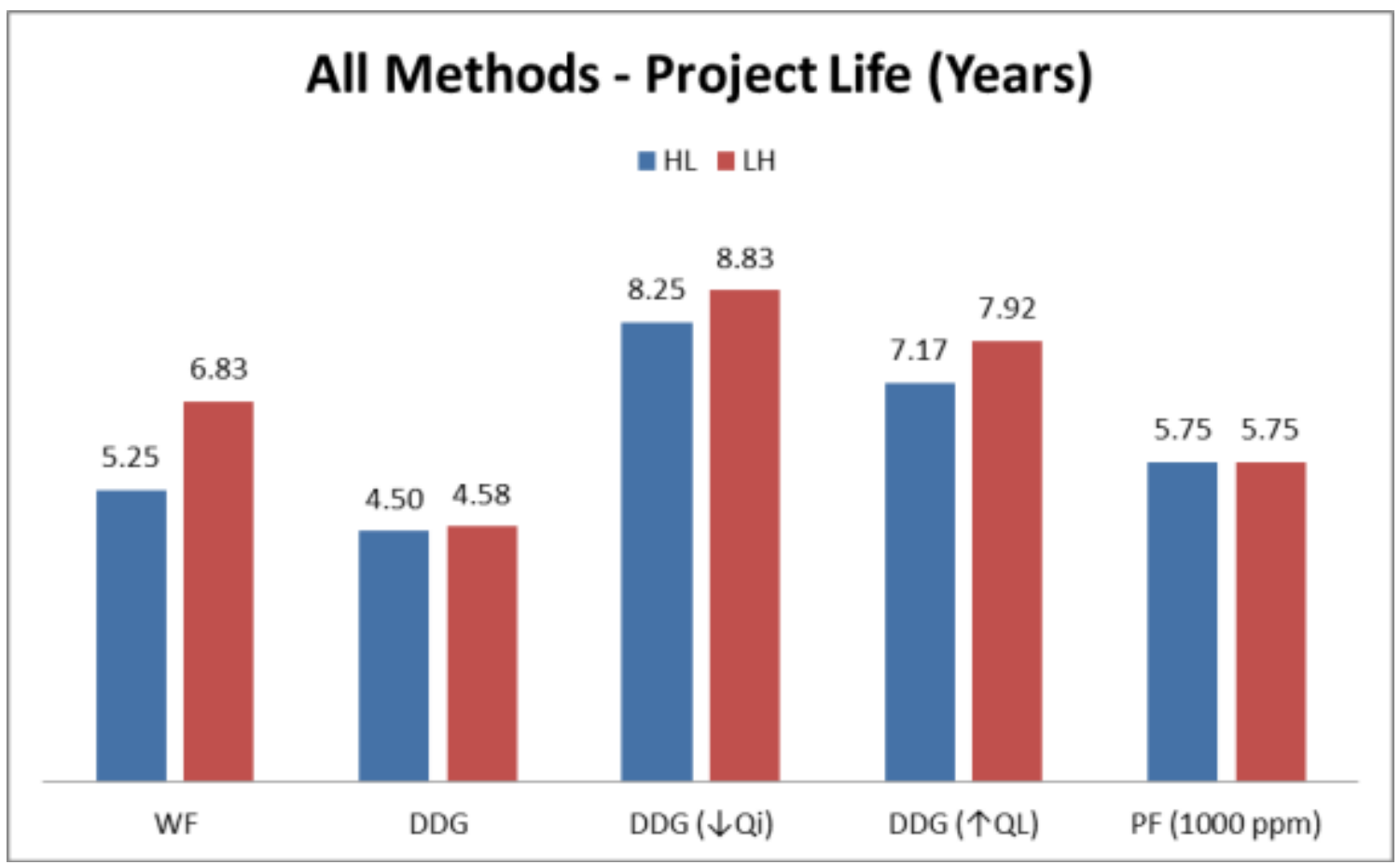

Figure 29: DDG - Project Life with lowered Production Pressure

\subsubsection{Oil Viscosity}

The oil viscosity in the H-L layer configuration was increased from $2 \mathrm{cp}$ to $10 \mathrm{cp}$ and $100 \mathrm{cp}$ in all three methods. The waterflooding model was run first to obtain the time at which $85 \%$ water-cut was reached. As expected, with an even worse mobility ratio, sweep efficiency was poorer and water production started earlier with the watercut increasing faster than in the base case. These new times were used to determine the new time it would take the DDG to reach the activation site and to begin injection in the Polymer flood for the 600 ppm, 1000 ppm and 1500 ppm models. Figures 30 - 32 show the results of these runs. 


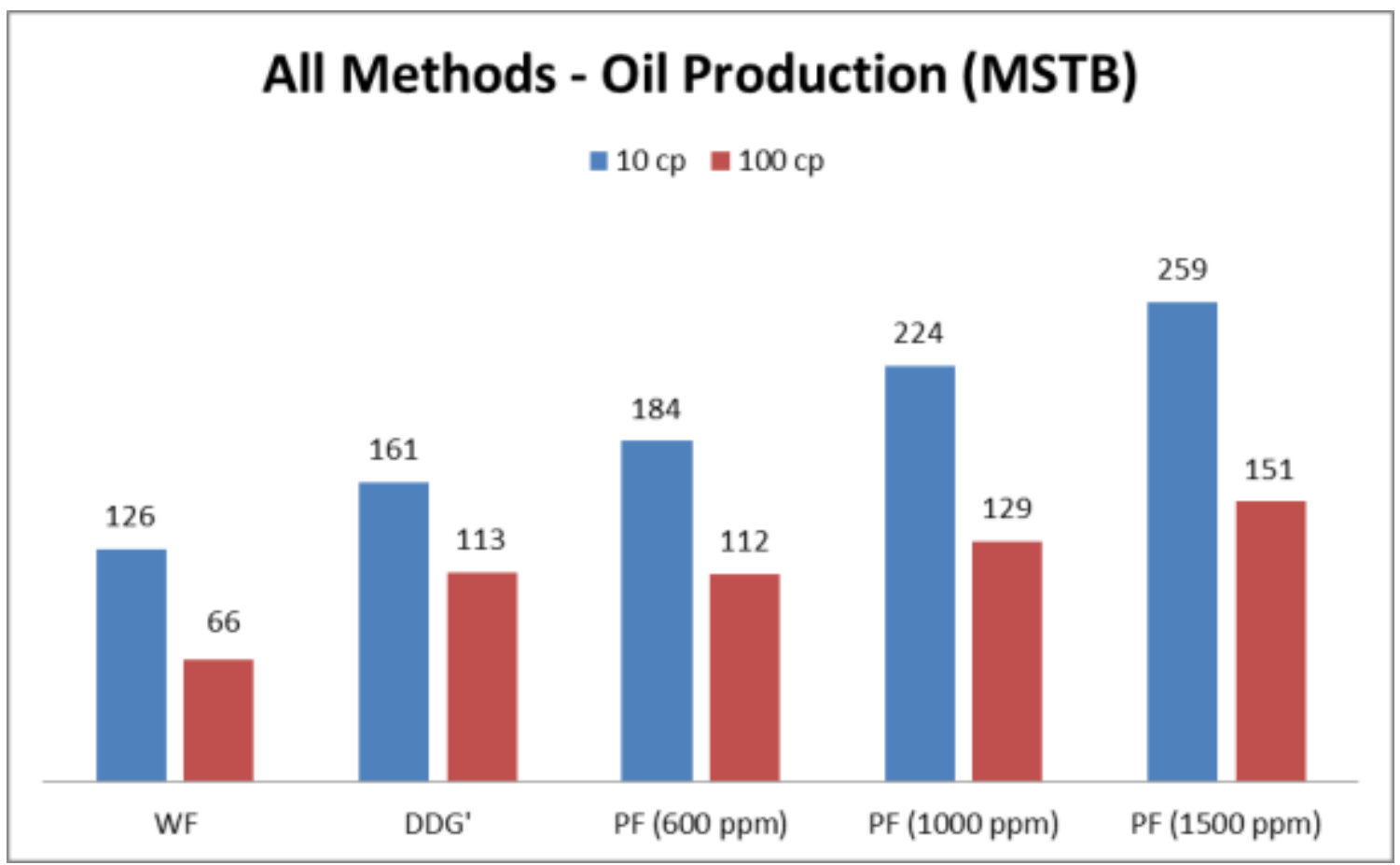

Figure 30: Incremental Oil Production for 10 and $100 \mathrm{cp}$ Oil

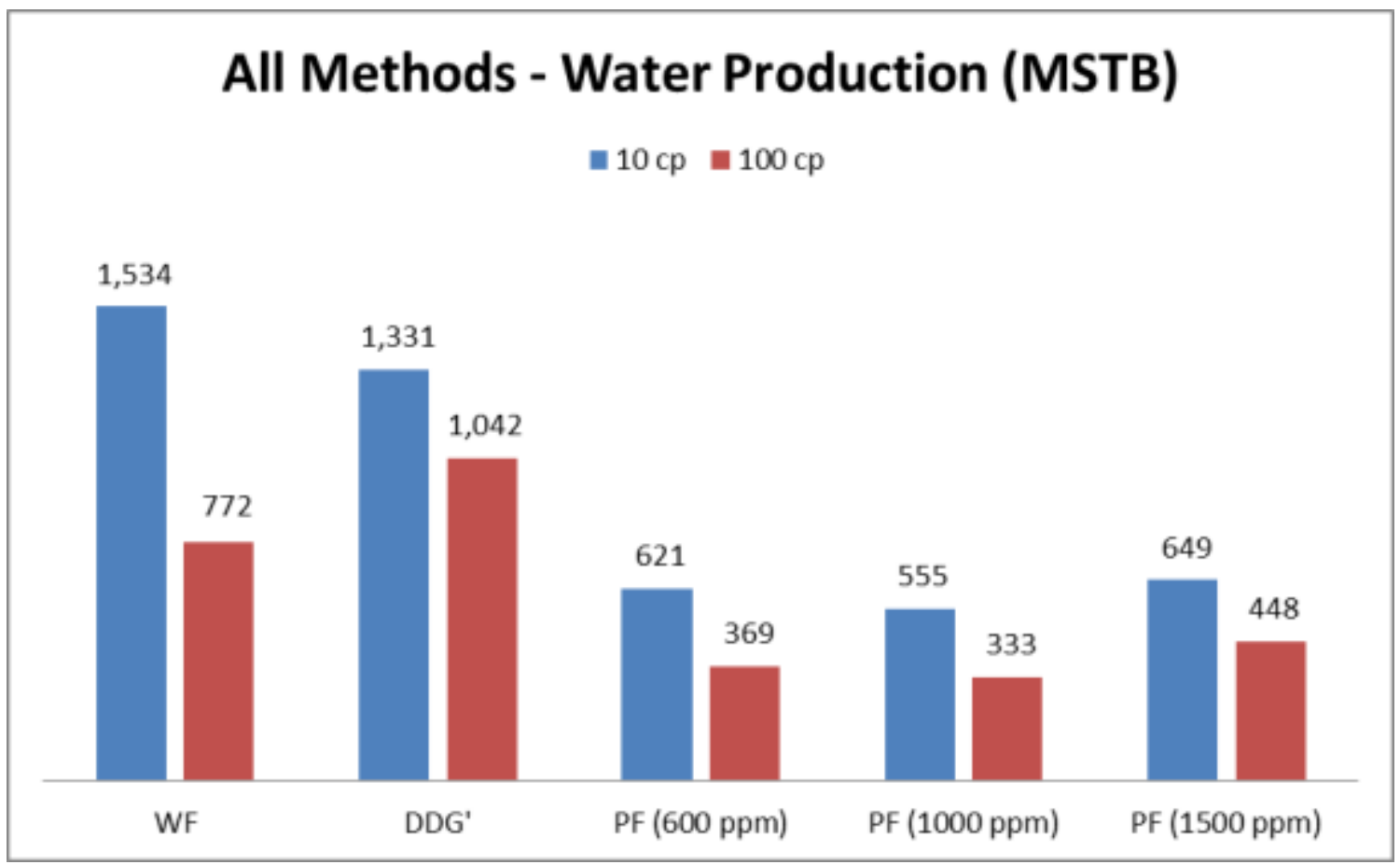

Figure 31: Incremental Water Production for 10 and $100 \mathrm{cp}$ Oil 


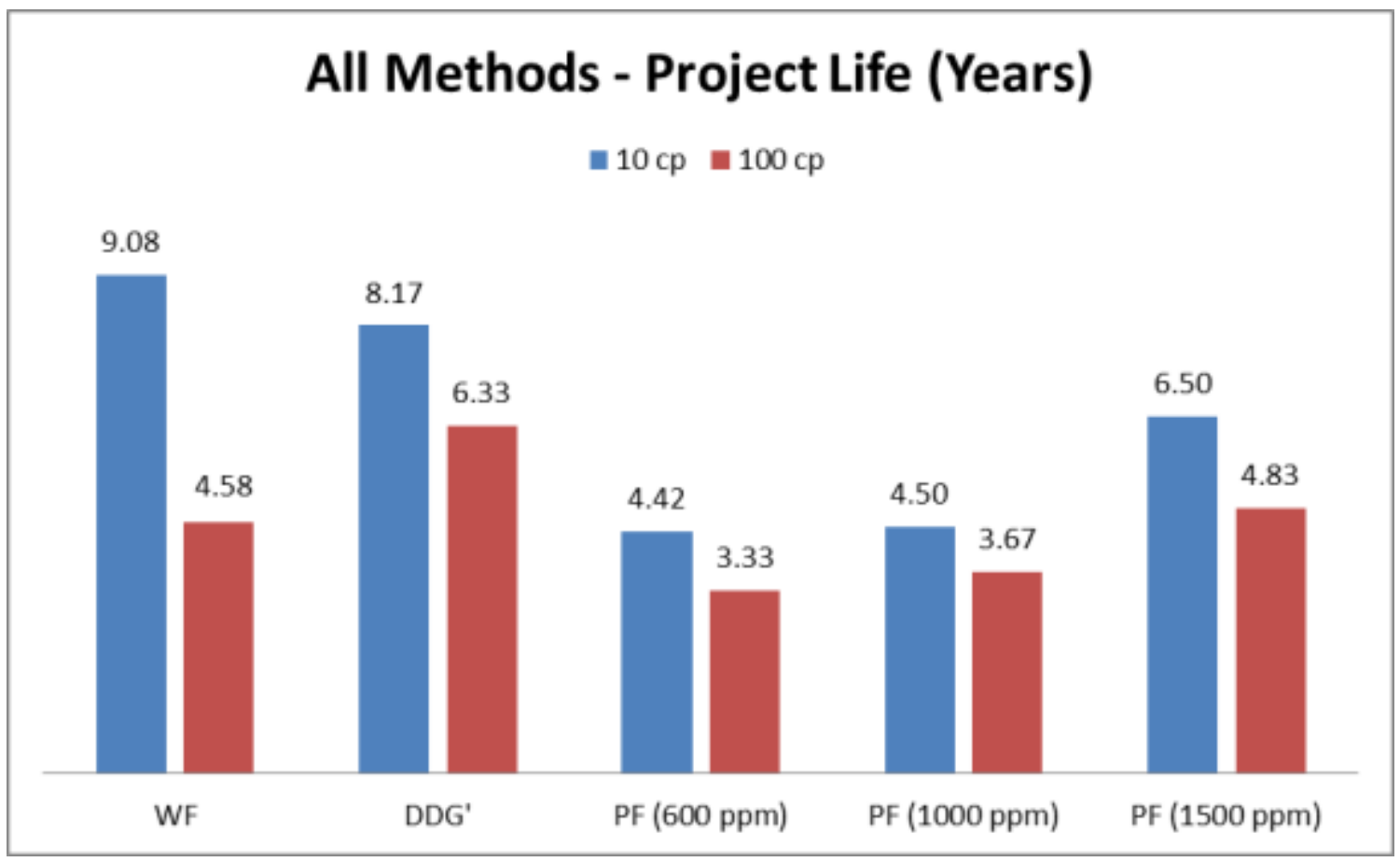

Figure 32: Project Life for 10 and $100 \mathrm{cp}$ Oil

As can be seen in the figures above, DDG performed better in terms of oil recovery at higher viscosities when compared to polymer flood than in the base case. This however came at the cost of much higher water production relative to polymer production.

\subsubsection{Polymer Flood Pressure Control}

Two approaches to polymer flooding are commonly recognized with the first, and approach taken here, being to inject and produce at the maximum allowable rates. (Wang et al. 2008) The second approach is one involving a strategy of long term sustainable development whereby production rate is controlled by reducing injection rates to prolong the oil production period. 
With this in mind, simulations were carried out where the production rate was kept equal to, or as close to the injection rate. This approach also reduces the pressure drop observed at the producer well and across the reservoir to more closely simulate the pressure profile observed during the DDG treatment.

The results show that for this reservoir, matching injection rates to production rate besides extending the field life leads to reduced oil production and NPV both of which, while lower than the results from the approach that favors maximizing production, are still higher than those from the DDG treatment.

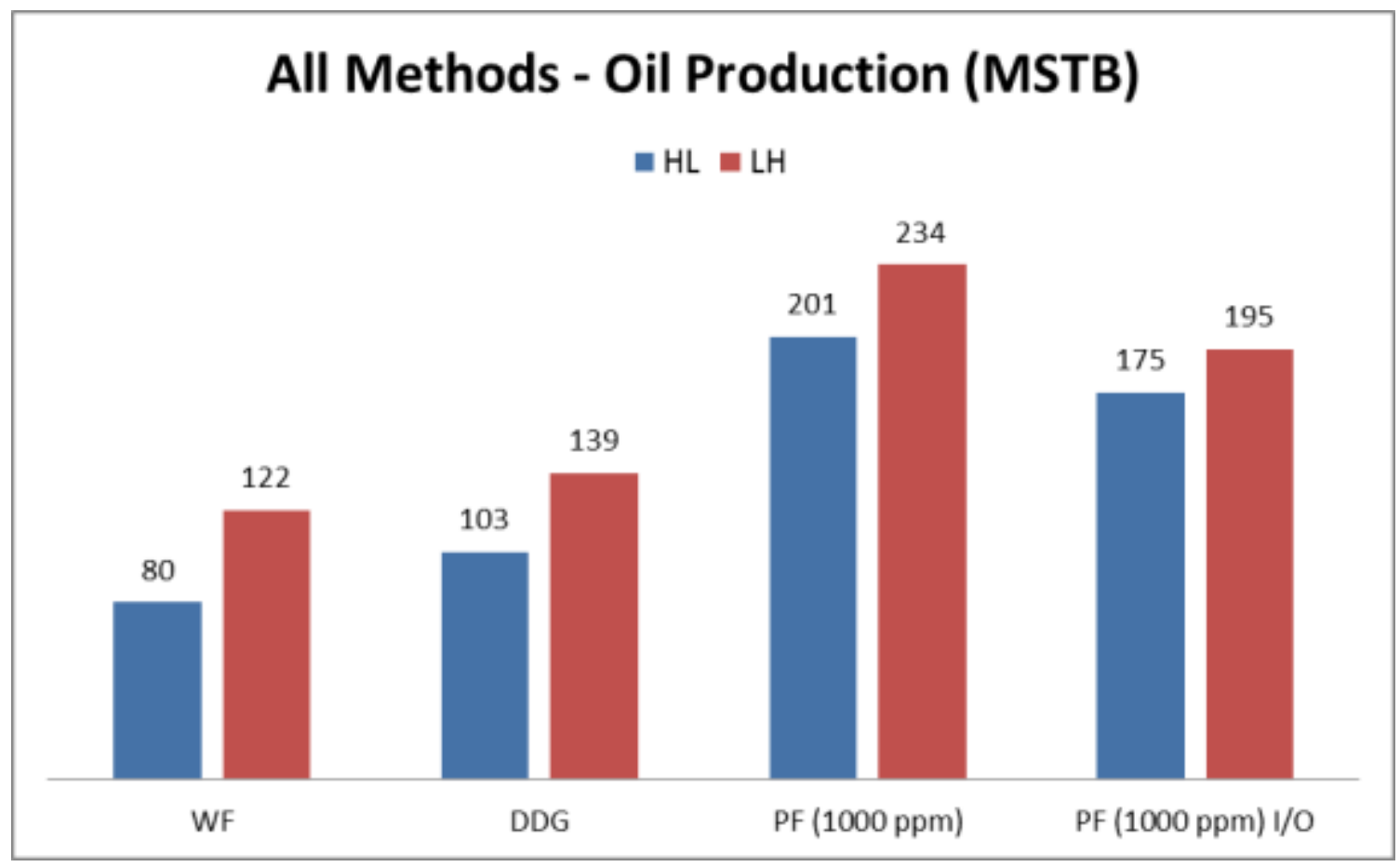

Figure 33: Oil Production when $\mathrm{Q}_{\mathrm{L}}=\mathrm{Q}_{\mathrm{i}}$ 


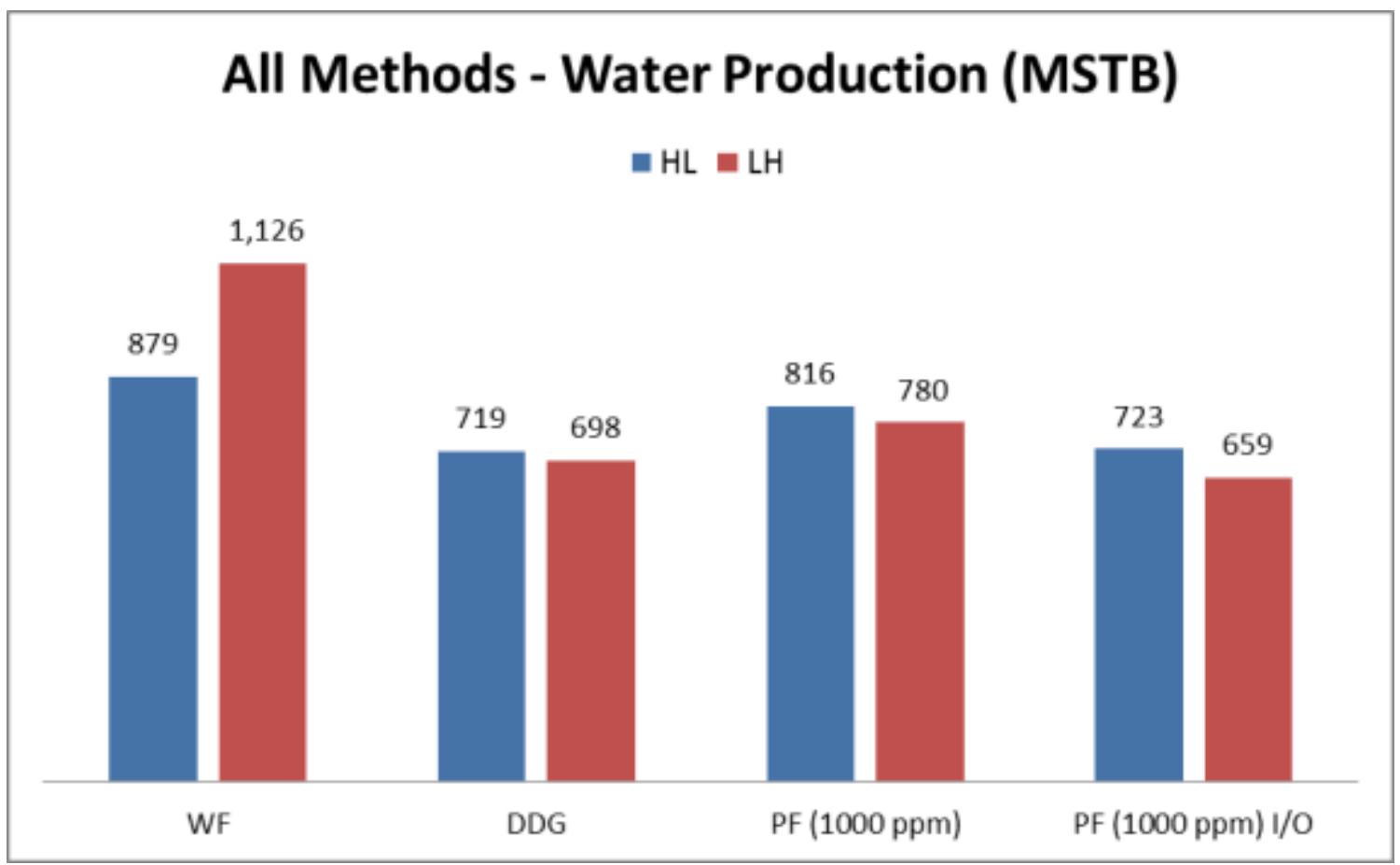

Figure 34: Water Production when $\mathrm{Q}_{\mathrm{L}}=\mathrm{Q}_{\mathrm{i}}$

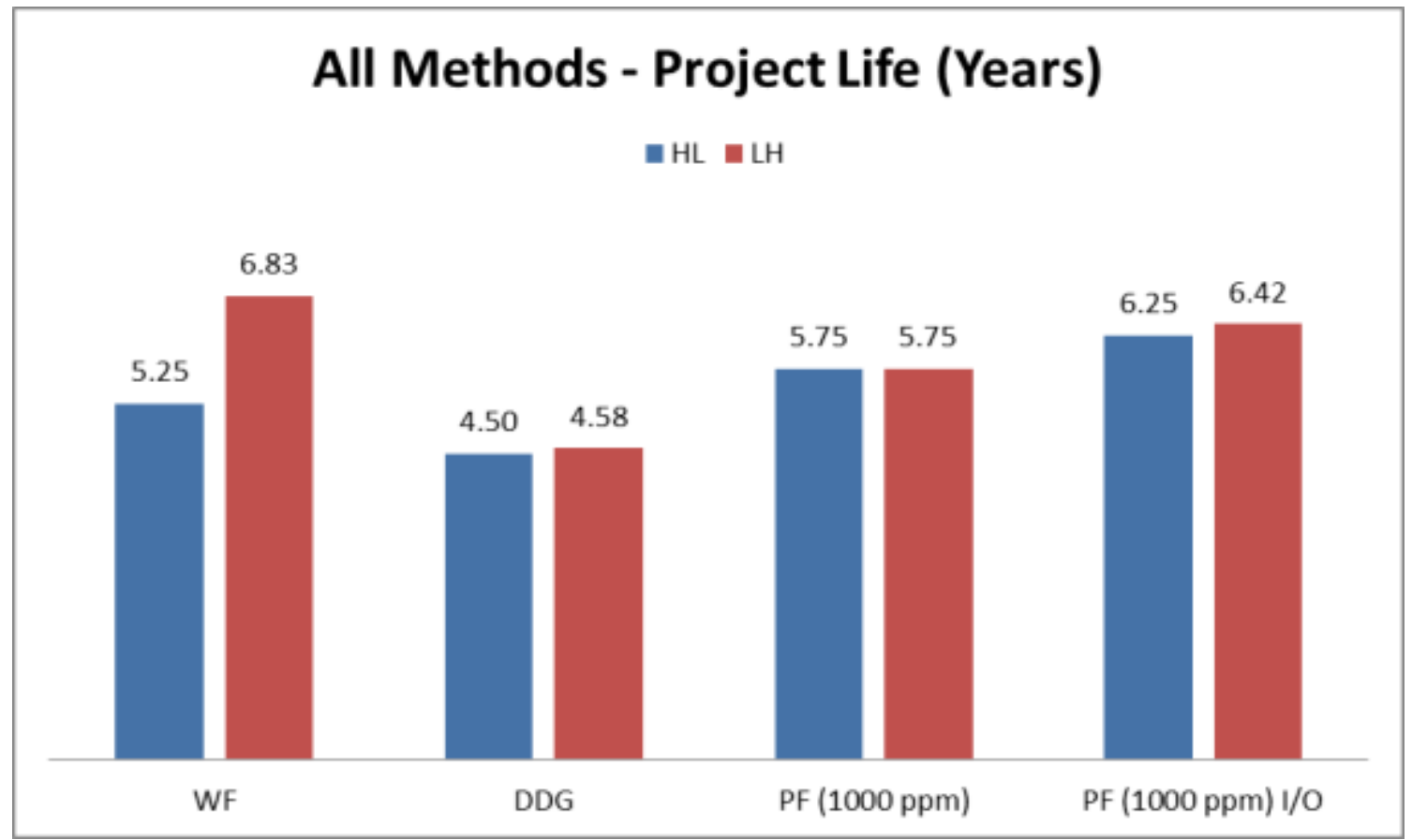

Figure 35: Project Life when $\mathrm{Q}_{\mathrm{L}}=\mathrm{Q}_{\mathrm{i}}$ 


\subsubsection{Calculation of Polymer Viscosity}

As previously stated, the default model in Eclipse used to calculate polymer viscosity in the base case focuses on the shear thinning behavior of polymers. The assumption may prove to be invalid in heterogeneous reservoirs such as ours with regions of different permeability in that shear rate would be higher in low permeability rock than in high permeability rock. Seright also stated that an overly optimistic injectivity may be calculated if shear thinning is assumed for HPAM polymer. Results were therefore verified using the Herschel-Bulkley model which calculates viscosity as a function of rheology, flow rate, pressure drop along a given length, and rock properties such as permeability and porosity.

The figures below show the results using both models for the LH configuration of the polymer flood. Figure 36 shows the calculated polymer viscosities in the low and high perm layers at the midpoint between the injection and production well for the base case polymer flood. The difference between the viscosities calculated using the two methods is negligible and this is also reflected in the production rates and field life with slightly higher differences observed with the highest viscosity polymer. 


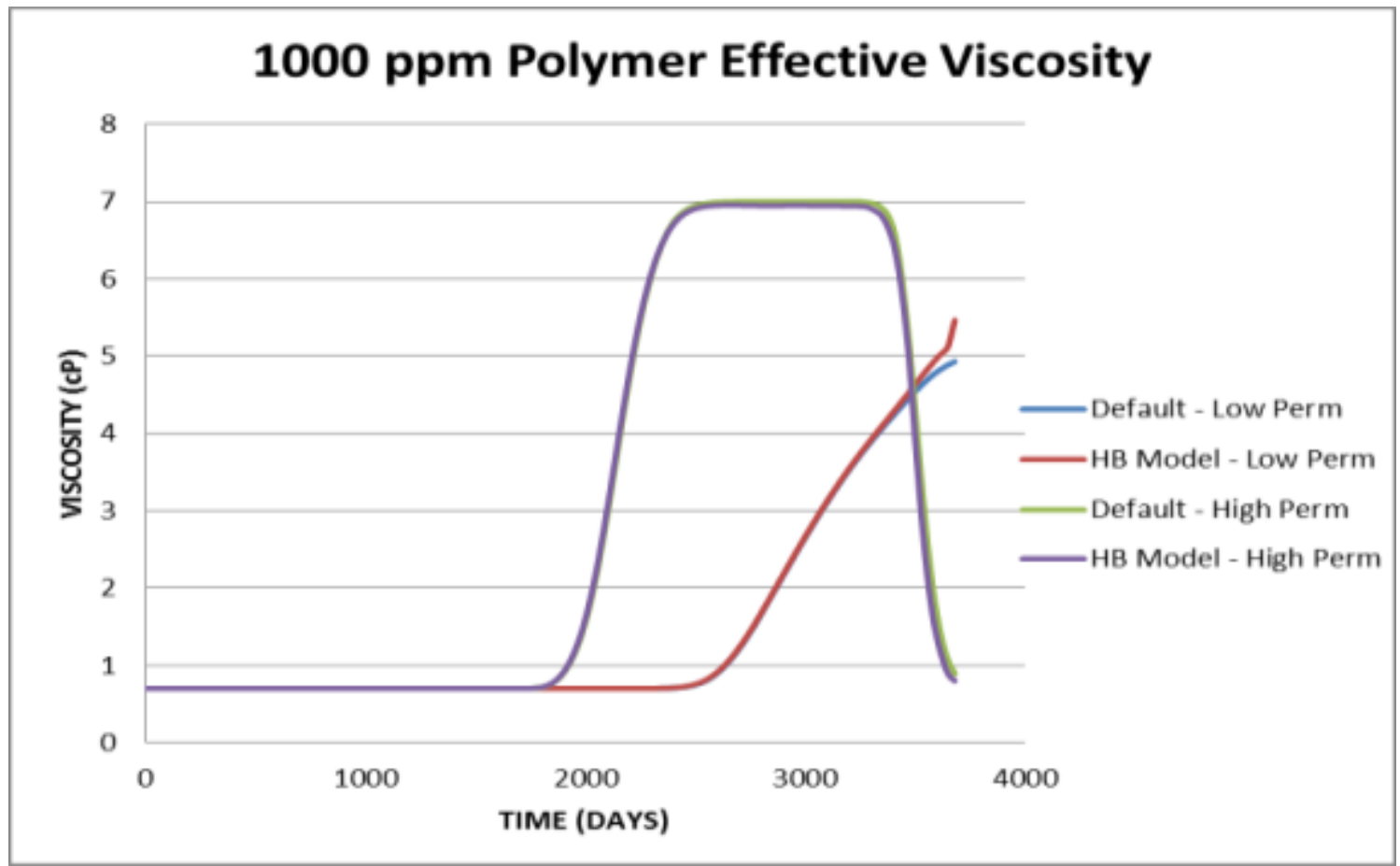

Figure 36: 1000 ppm PF Viscosity using Default \& Herschel-Bulkley Models

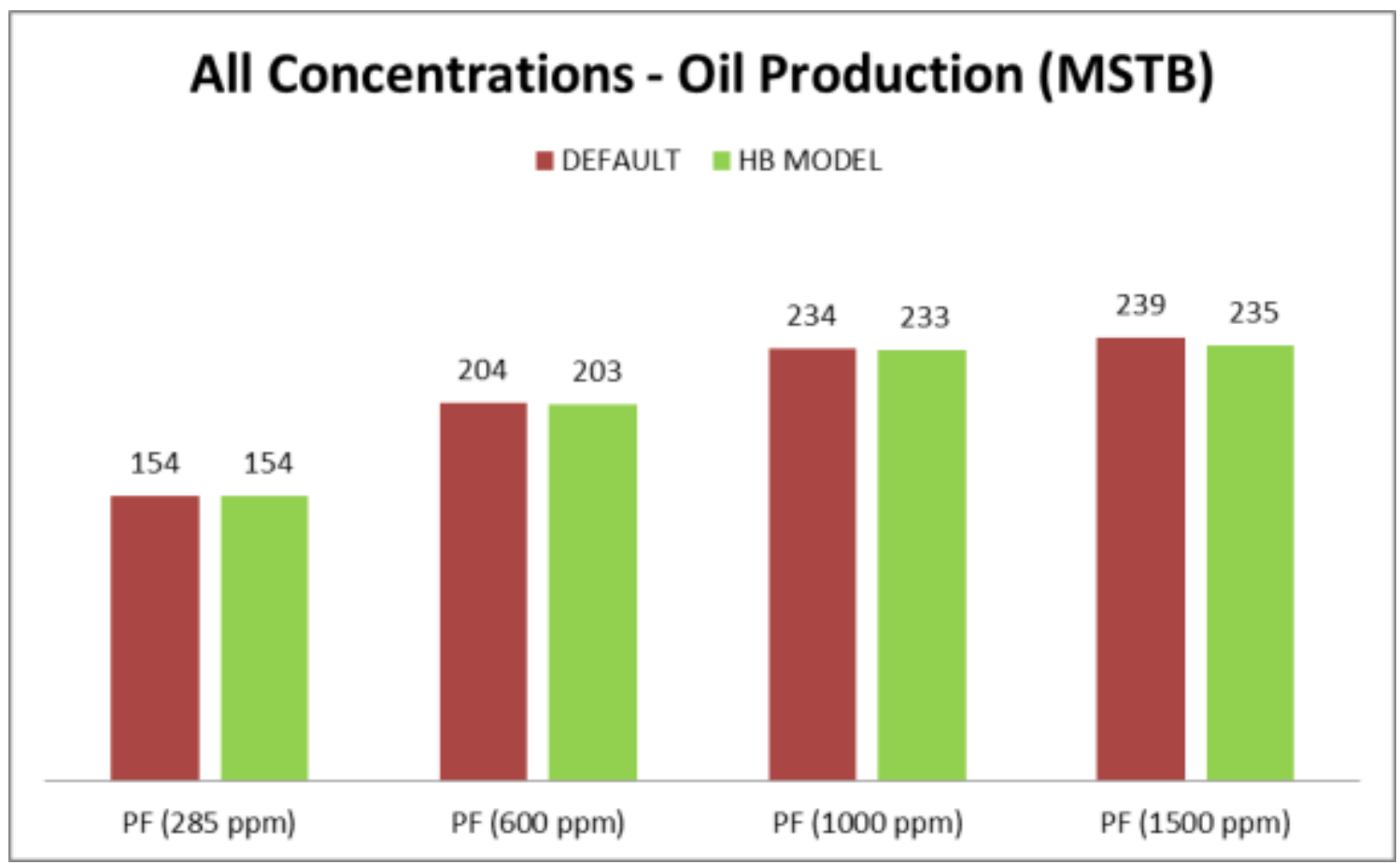

Figure 37: PF [LH] Oil Production using Default \& Herschel-Bulkley Models 


\section{All Concentrations - Water Production (MSTB)}

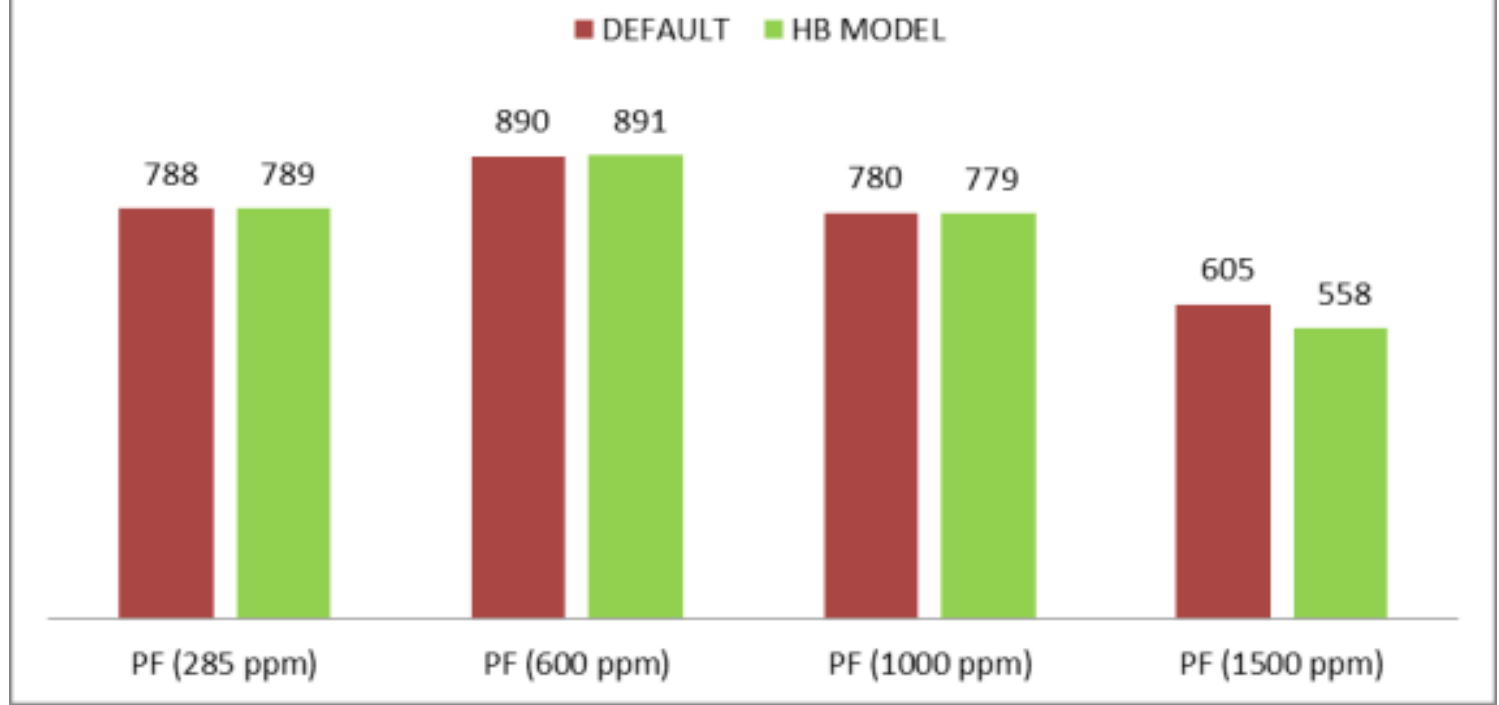

Figure 38: PF [LH] Water Production using Default \& Herschel-Bulkley Models

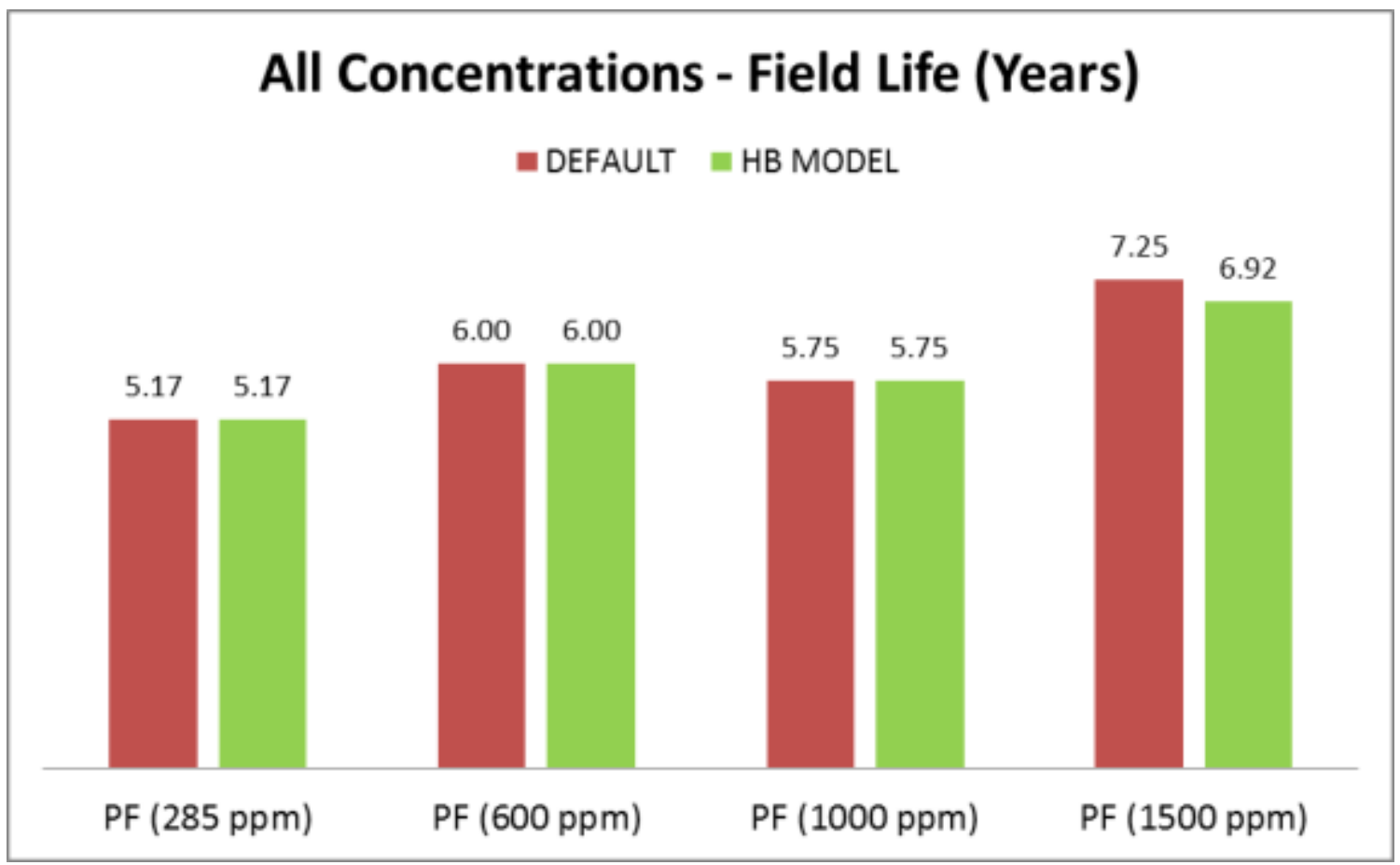

Figure 39: PF [LH] Field Life using Default \& Herschel-Bulkley Models 
The tables below shows the results, i.e. oil and water production rates, the project life and recovery factors of simulations performed.

Table 3: Results from H-L Simulations

\begin{tabular}{|c|c|c|c|c|}
\hline & Oil (MSTB) & Water (MSTB) & Life (Years) & $\mathrm{RF}$ \\
\hline WF & 80 & 879 & 5.25 & $51.3 \%$ \\
\hline DDG & 103 & 719 & 4.50 & $53.6 \%$ \\
\hline $\mathrm{DDG}^{\prime}(0 \mathrm{md})$ & 105 & 564 & 3.67 & $53.8 \%$ \\
\hline $\operatorname{DDG}\left(\downarrow Q_{i}\right)$ & 201 & 1,142 & 8.25 & $63.7 \%$ \\
\hline $\operatorname{DDG}\left(\uparrow \mathrm{Q}_{\mathrm{L}}\right)$ & 195 & 1,225 & 7.17 & $63.0 \%$ \\
\hline PF (285 ppm) & 104 & 625 & 4.00 & $53.7 \%$ \\
\hline PF (600 ppm) & 170 & 909 & 5.92 & $60.4 \%$ \\
\hline PF (1000 ppm) & 201 & 816 & 5.75 & $63.6 \%$ \\
\hline PF (1500 ppm) & 224 & 461 & 7.08 & $65.9 \%$ \\
\hline$P F(1000 \mathrm{ppm}) Q_{L}=Q_{i}$ & 175 & 723 & 6.25 & $61.0 \%$ \\
\hline
\end{tabular}

Table 4: Results from L-H Simulations

\begin{tabular}{|c|c|c|c|c|}
\hline & Oil (MSTB) & Water (MSTB) & Life (Years) & RF \\
\hline WF & 122 & 1,126 & 6.83 & $52.5 \%$ \\
\hline DDG & 139 & 698 & 4.58 & $54.3 \%$ \\
\hline $\operatorname{DDG}\left(\downarrow Q_{i}\right)$ & 222 & 1,211 & 8.83 & $62.7 \%$ \\
\hline $\operatorname{DDG}\left(\uparrow Q_{L}\right)$ & 221 & 1,341 & 7.92 & $62.6 \%$ \\
\hline PF (285 ppm) & 154 & 788 & 5.17 & $55.7 \%$ \\
\hline PF (600 ppm) & 204 & 890 & 6.00 & $60.8 \%$ \\
\hline PF (1000 ppm) & 234 & 780 & 5.75 & $63.8 \%$ \\
\hline PF (1500 ppm) & 239 & 605 & 7.25 & $65.4 \%$ \\
\hline$P F(1000 \mathrm{ppm}) \mathrm{Q}_{\mathrm{L}}=\mathrm{Q}_{\mathrm{i}}$ & 195 & 659 & 6.42 & $59.9 \%$ \\
\hline
\end{tabular}

Table 5: Results from $10 \mathrm{cp}$ Oil Simulations

\begin{tabular}{|c|c|c|c|c|}
\hline & Oil (MSTB) & Water (MSTB) & Life (Years) & RF \\
\hline WF & 126 & 1,534 & 9.08 & $41.2 \%$ \\
\hline DDG & 161 & 1,331 & 8.17 & $44.9 \%$ \\
\hline PF (600 ppm) & 184 & 621 & 4.42 & $47.1 \%$ \\
\hline PF (1000 ppm) & 224 & 555 & 4.50 & $51.3 \%$ \\
\hline PF (1500 ppm) & 259 & 649 & 6.50 & $54.8 \%$ \\
\hline
\end{tabular}


Table 6: Results from $100 \mathrm{cp}$ Oil Simulations

\begin{tabular}{|c|c|c|c|c|}
\hline & Oil (MSTB) & Water (MSTB) & Life (Years) & RF \\
\hline WF & 66 & 772 & 4.58 & $21.5 \%$ \\
\hline DDG & 113 & 1,042 & 6.33 & $26.5 \%$ \\
\hline PF (600 ppm) & 112 & 369 & 3.33 & $26.2 \%$ \\
\hline PF (1000 ppm) & 129 & 333 & 3.67 & $27.9 \%$ \\
\hline PF (1500 ppm) & 151 & 448 & 4.83 & $30.1 \%$ \\
\hline
\end{tabular}




\section{ECONOMICS}

In this section, the primary objective is to compare the polymer flood to the DDG treatment method in terms of value and economic feasibility using the Net Present Value of each configuration as a yardstick. The model used to perform this analysis was developed using Microsoft Excel ${ }^{\circledR}$ and kept simple and flexible to allow for any modifications that needed to be made.

The input data, i.e. oil and water production, water injection and quantities of DDG and polymer used will be imported starting from the time-step immediately after the base case reaches $85 \%$ water cut. This assumes then that all activity up to that point is a sunk cost.

To measure the profitability of each method required taking the cost of capital into consideration by calculating the Present Value of future cash flows at each monthly time-step. This was done by applying a discount factor derived from the annual interest rate for the cost of capital to the net cash flow per period after operating costs and taxes had been deducted.

NPV is therefore given by

$$
N P V=\sum\left\{\text { Cash Flow } *\left[\frac{1}{\left(1+\frac{i}{12}\right)^{n}}\right]\right\}
$$

where Cash Flow $=$ Revenue - Operating Costs - Taxes

$$
\begin{gathered}
i=\text { Annual Interest Rate } \\
n=\text { Number of months }
\end{gathered}
$$


Revenue was calculated by multiplying the oil produced by the assumed price of crude oil. The operating costs included assumed values for a monthly fixed cost, the costs associated with injecting water and its disposal, the cost of polymer; here Hydrolyzed Polyacrylamide HPAM and the DDG. Table 6 below includes the values used for these calculations. The operating costs, except the cost of the DDG, were taken from a recent economic analysis on polymer flooding and data from polymer flooding operations in the Daqing Oil Field in China. (Alusta et al. 2011; Demin et al. 2003) The price of the DDG is a conservative estimate based on industry prices for other similar complex polymers. The economics of both methods will be impacted by the price of chemicals and water handling costs which, while reasonable estimates based on market prices, are still assumptions. Two additional scenarios were considered where the prices of polymer and the DDG were changed and these will be discussed below.

Table 7: Economic Analysis Input Data

\begin{tabular}{|c|c|}
\hline Effective Starting Date & January 2000 \\
\hline Oil Price $(\$ / \mathrm{bbl})$ & 50 \\
\hline CAPEX (\$) at 85\% WCT & - \\
$-\quad$ Waterflooding & $-250,000$ \\
$-\quad$ Polymer Flood & $-25,000$ \\
$-\quad$ DDG & 12.50 \\
\hline Production Tax Rate (\%) & 1750 \\
\hline Fixed Operating Costs (\$/month) & 50,000 \\
\hline Abandonment $(\$)$ & 2.00 \\
\hline Water Injection $(\$ / \mathrm{bbl})$ & 2.00 \\
\hline Water Disposal $(\$ / \mathrm{bbl})$ & 10 \\
\hline Discount Rates $(\%)$ & 0.05 \\
\hline Variable Oil Cost $(\$ / \mathrm{bbl})$ & 1.50 \\
\hline Polymer Cost $(\$ / \mathrm{lb})$ & 3.00 \\
\hline DDG Cost $(\$ / \mathrm{lb})$ & \\
\hline
\end{tabular}




\subsection{Waterflooding}

These results are for the two different layer arrangements and constitute the base case for each of these configurations as used in the DDG treatment and polymer flooding. The monthly incomes and annualized economic variables are presented below. The steady decline in cash flow reflects the decreasing production of oil and steady high water production.

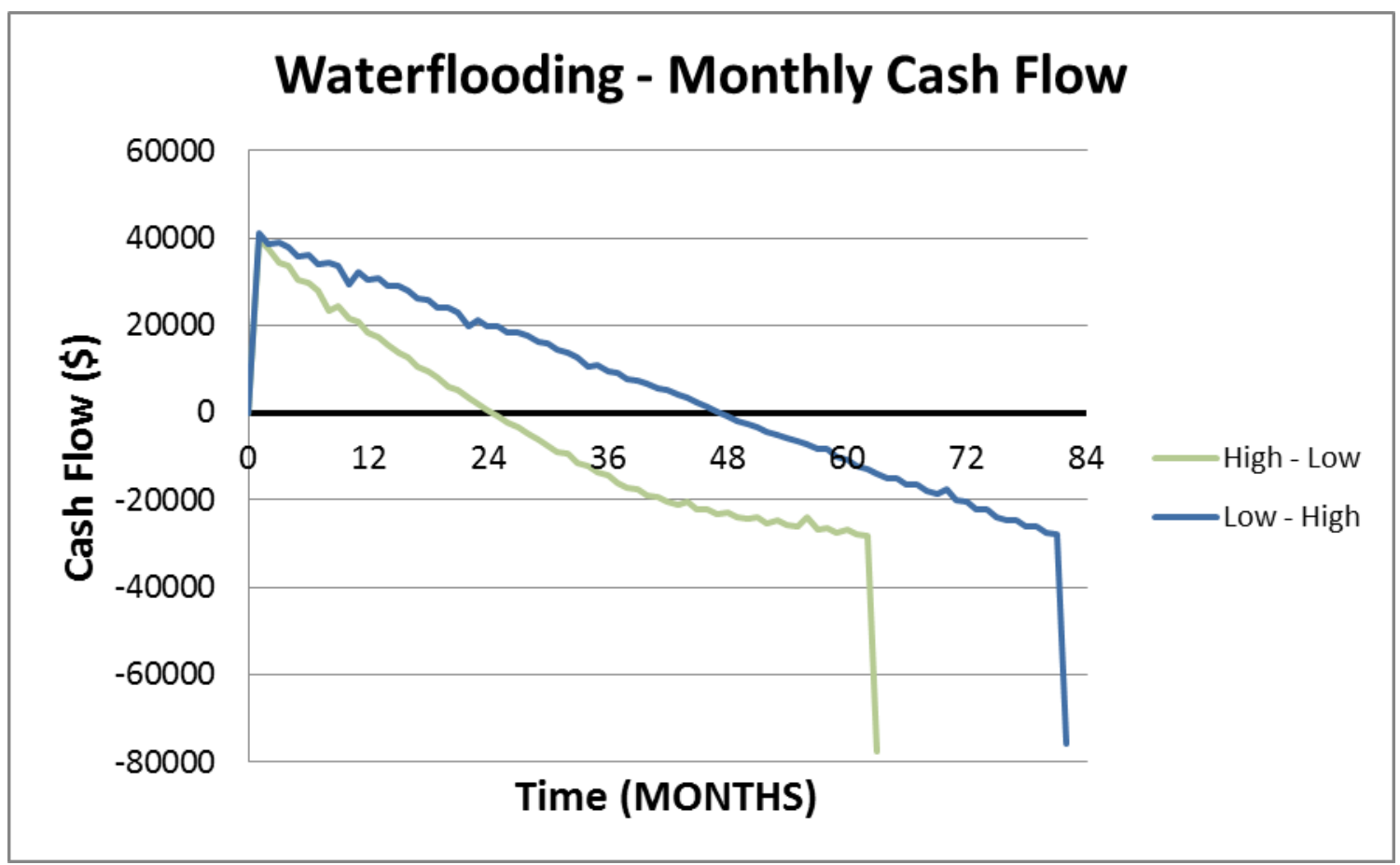

Figure 40: Waterflooding - Monthly Income 


\subsection{Polymer Flooding}

The results for the polymer simulations in both the H-L and the L-H arrangement are given below for the concentrations under study. These results are compared to those obtained from the waterflooding simulations at the end of this section. It should be pointed out that the amount of polymer injected is constrained by the polymer concentration in the injected solution, given in pounds per barrel of water injected. The price of the polymer remained the same at different concentrations because it was assumed that the type of polymer being used remained the same with the only change being in the concentrations and amount used.

Injection only starts after a water-cut of $85 \%$ is reached with an initial negative cash flow when the CAPEX for the polymer flood facilities and equipment are added. Income begins to increase as the improvement in sweep efficiency leads to improved oil recovery. The accompanying reductions in water injection and production also help to increase cash flow. The loss incurred by the cost of the polymer needed was however offset by the returns obtained as oil production increased. 


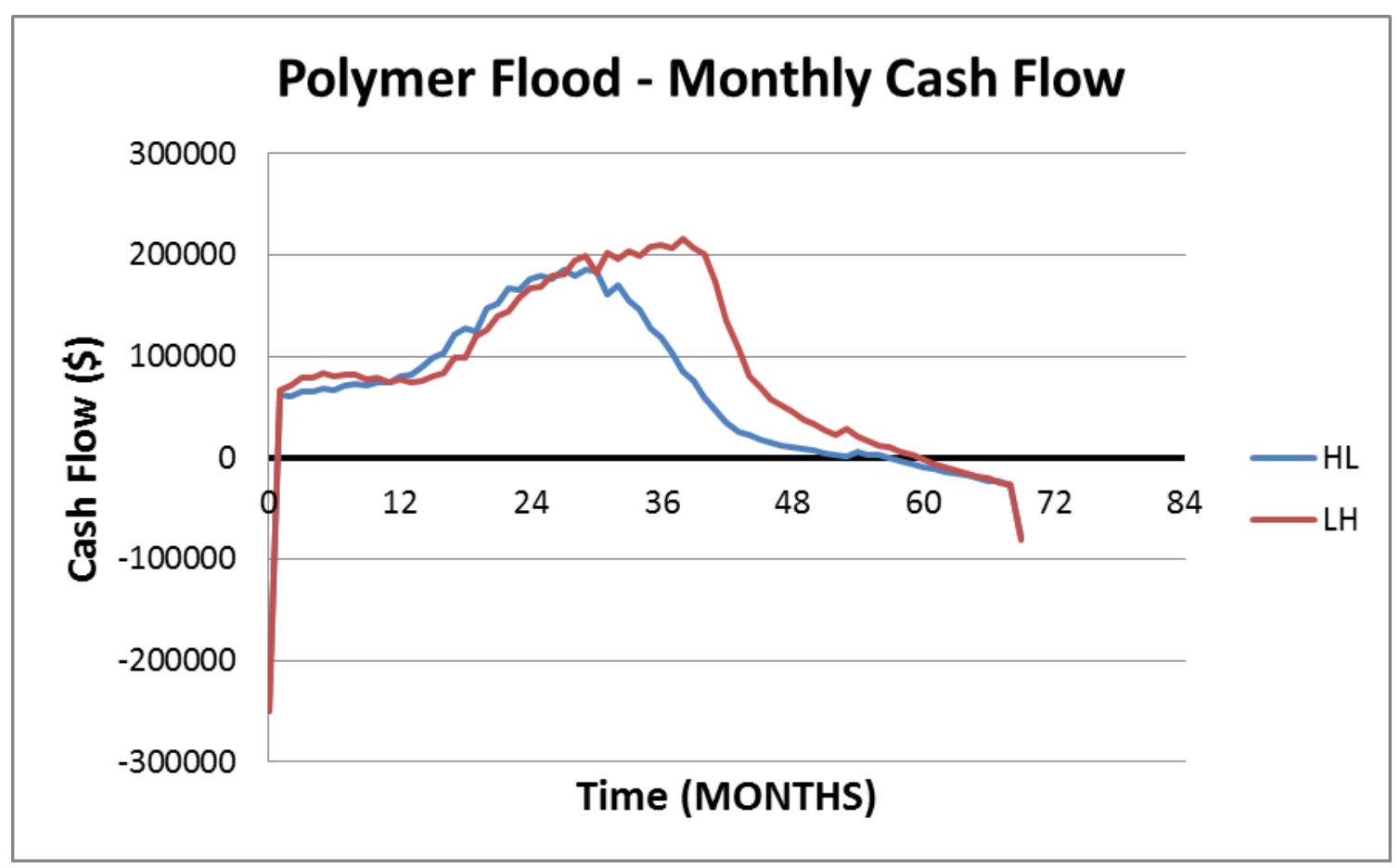

Figure 41: 1000 ppm Polymer Flood - Monthly Income

\subsection{Deep Diverting Gel}

One of the key steps in performing an economic analysis on the DDG treatment was estimating the amount of the polymer to be used. This was performed using a rule of thumb proposed by the DDG supplier which relates the amount of DDG to the effective pore volume of the thief zone to be blocked. A treatment size of $3 \%$ of this pore volume was recommended and a supply concentration of polymer between $1.5-1.7 \%$ (Roussennac et al. 2010).

Therefore in our case where by the time $85 \%$ water-cut has been reached, the high permeability layer is considered the thief zone with a pore volume of 621,000 barrels, the amount of treated water to be injected was 18,600 barrels with about 317 
barrels of the DDG mixed in. A weight conversion factor also from work done by Roussennac et al (2010) was used to obtain the mass of this volume in pounds. Care was taken to ensure that the cost of this treatment was applied to the economic analysis starting from the month injection began and not from the beginning of the project at Month 0. Using this cost at the beginning of the project depressed the value of the project's NPV since there was no discounting and it was assumed to be a part of the initial sunk cost and capital expenditure. The figures below show the results from these runs.

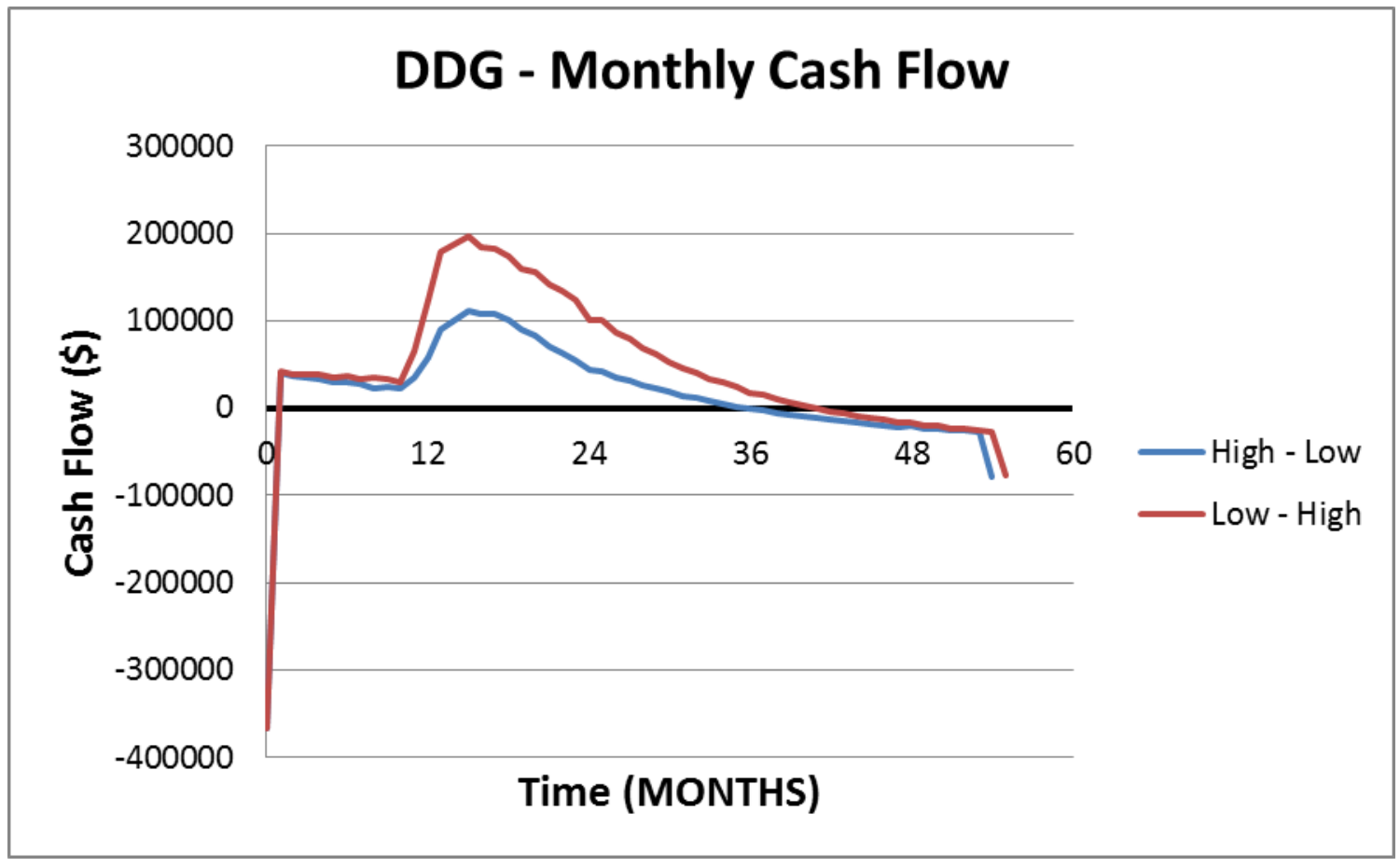

Figure 42: Deep Diverting Gel - Monthly Income 


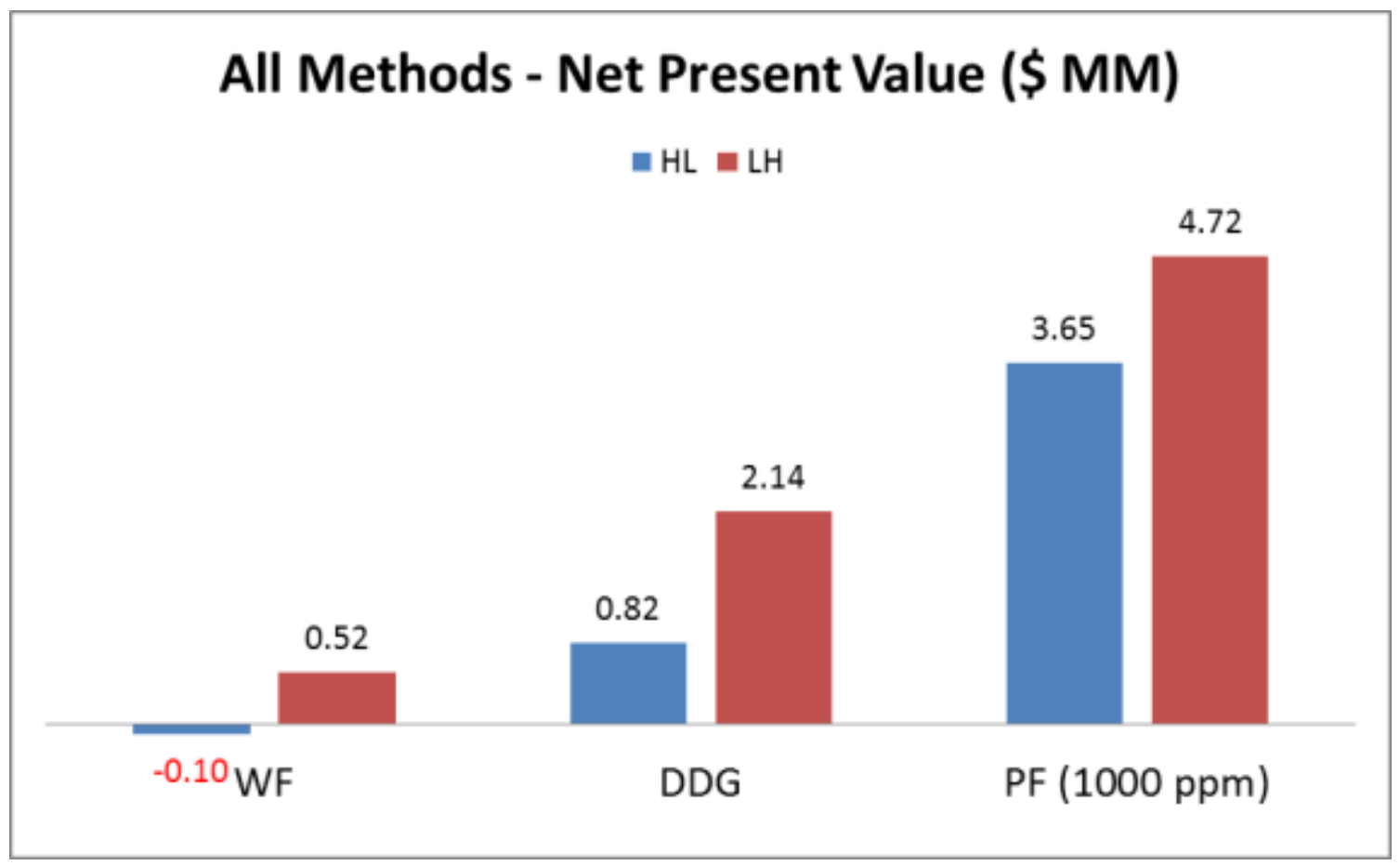

Figure 43: Base Cases - NPV

Table 8: Base Case (HL) - Economic Results Summary

\begin{tabular}{|c|c|c|}
\hline & Cash Flow (\$) & NPV (\$) \\
\hline WF & 329,000 & 98,000 \\
\hline DDG & 905,000 & 821,000 \\
\hline PF (1000 ppm) & $4,408,000$ & $3,650,000$ \\
\hline
\end{tabular}

Table 9: Base Case (LH) - Economic Results Summary

\begin{tabular}{|c|c|c|}
\hline & Cash Flow (\$) & NPV (\$) \\
\hline WF & 384,000 & 522,000 \\
\hline DDG & $2,487,000$ & $2,144,000$ \\
\hline PF (1000 ppm) & $5,927,000$ & $4,723,000$ \\
\hline
\end{tabular}




\subsection{Sensitivity Analysis}

The results from the runs in the sensitivity analyses performed in the section above are also shown below.

\subsubsection{Permeability Reduction}

Due to the increase in oil recovery and reduced water production observed when the permeability at the plugged site was dropped to $0 \mathrm{md}$, there is a higher return after the activation of the DDG in this scenario than in the base case as can be seen in the figure below.

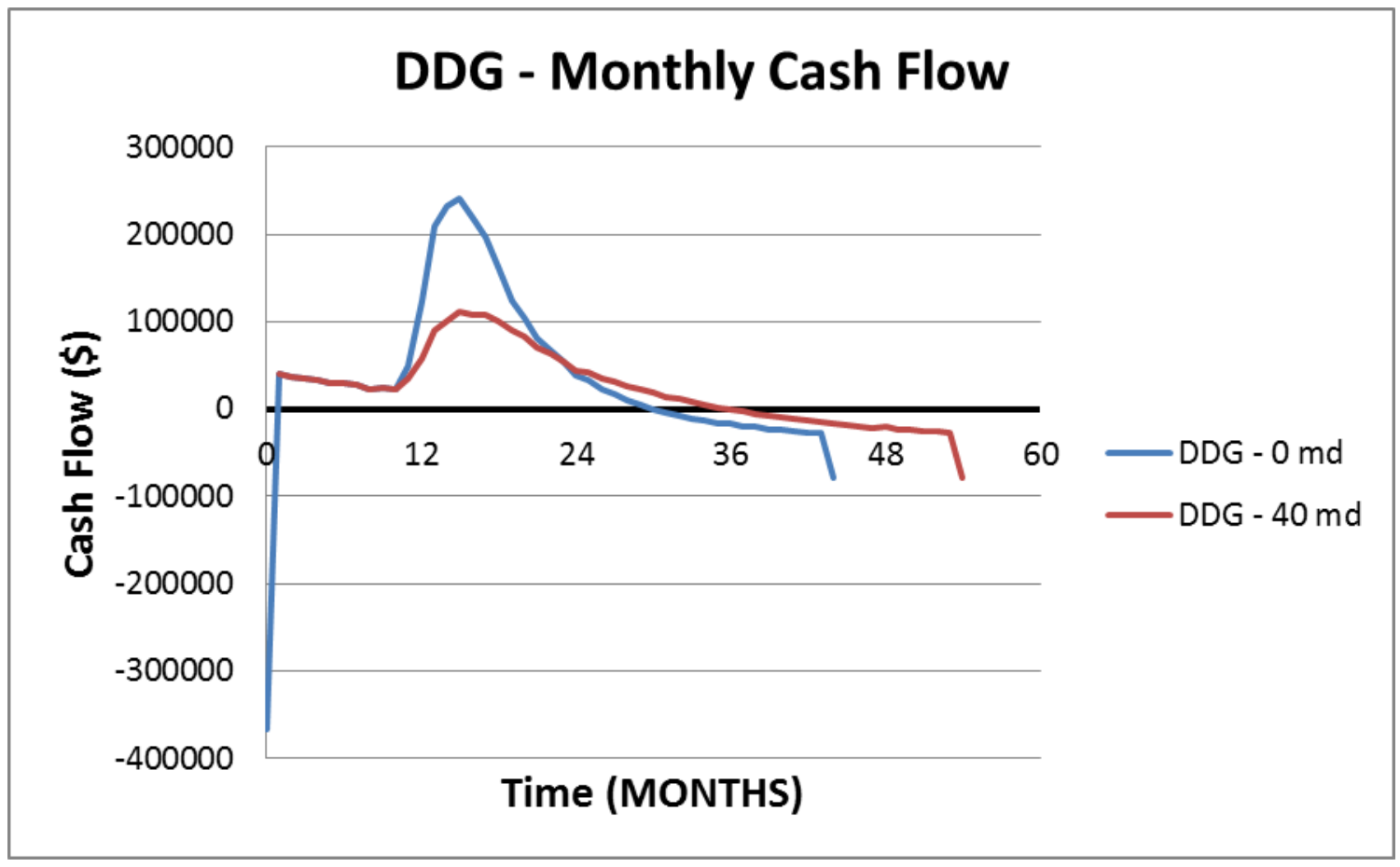

Figure 44: Deep Diverting Gel - Monthly Income 


\section{NPV with 0 md Block (\$ MM)}

DDG - $40 \mathrm{MD} \quad \mathrm{DDG}$ - $0 \mathrm{MD}$

1.43
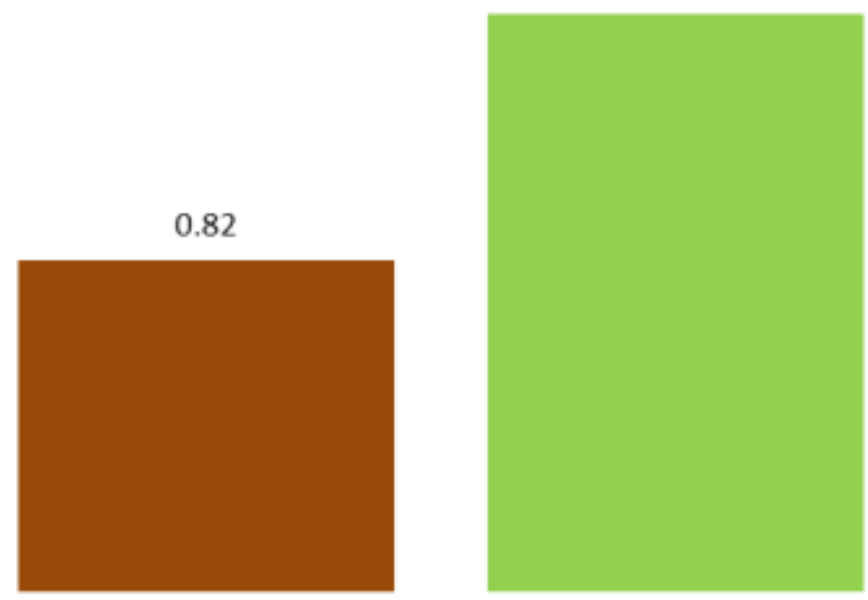

Figure 45: DDG - NPV with 0 md Block

Table 10: DDG (0 \& 40 md $)$ - Economic Results Summary

\begin{tabular}{|c|c|c|}
\hline & Cash Flow (\$) & NPV (\$) \\
\hline DDG (40 md) & 905,000 & 821,000 \\
\hline DDG (0 md) & $1,617,000$ & $1,434,000$ \\
\hline
\end{tabular}

\subsubsection{Polymer Concentration}

The same behavior as in the base case was observed at lower polymer concentrations although returns were lower due to the lower volumes of oil produced. When a polymer concentration of $1500 \mathrm{ppm}$ is used, a period of steady cash flow is observed that corresponds to the time it takes for the injected polymer slug to flow through the reservoir. It remains steady because although both wells are flowing at their 
maximum rates, these rates are much lower than the design rates due to the reduction in injectivity that occurs because of the increased viscosity of the polymer solution.

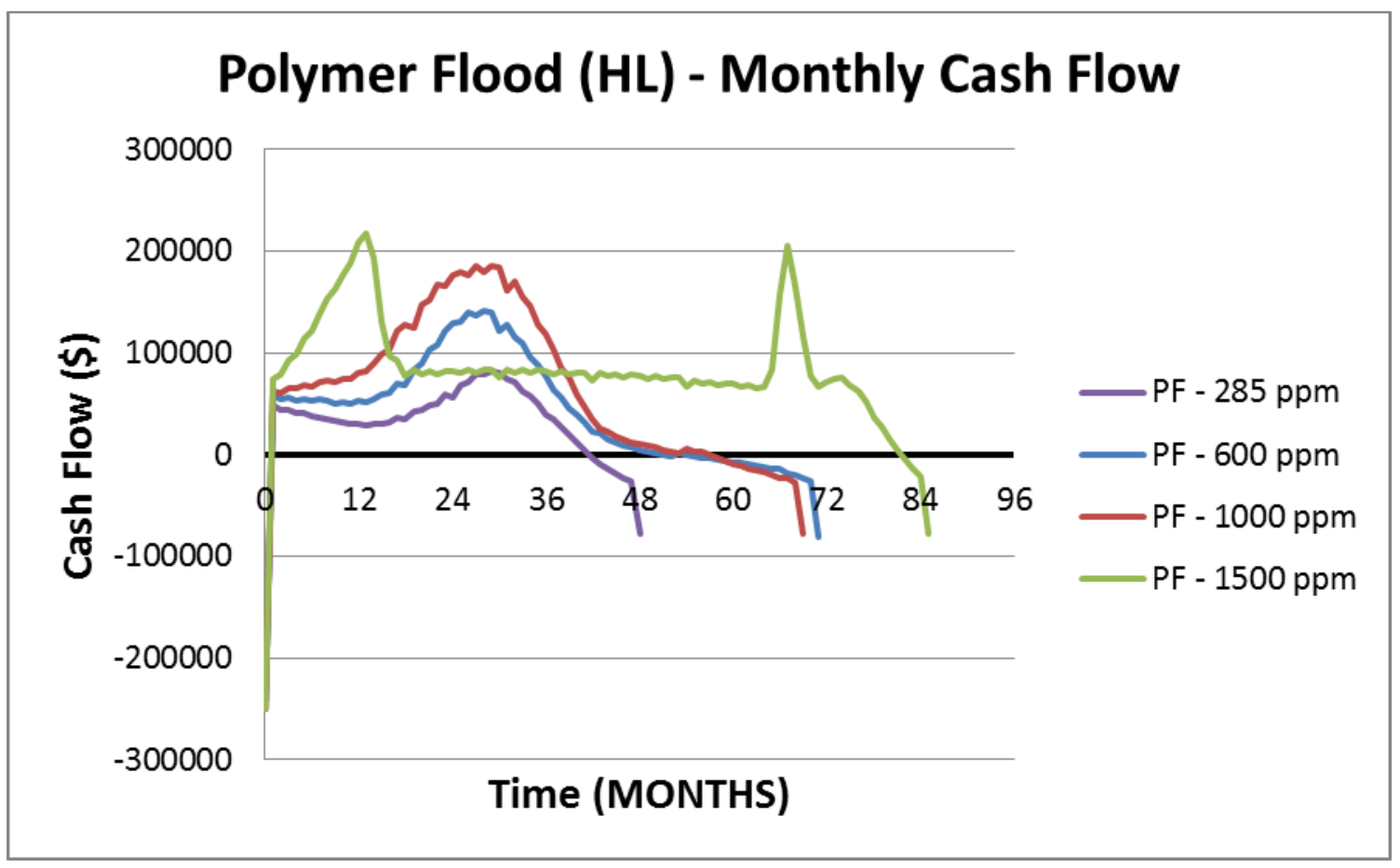

Figure 46: Polymer Flood (HL) - Monthly Income 


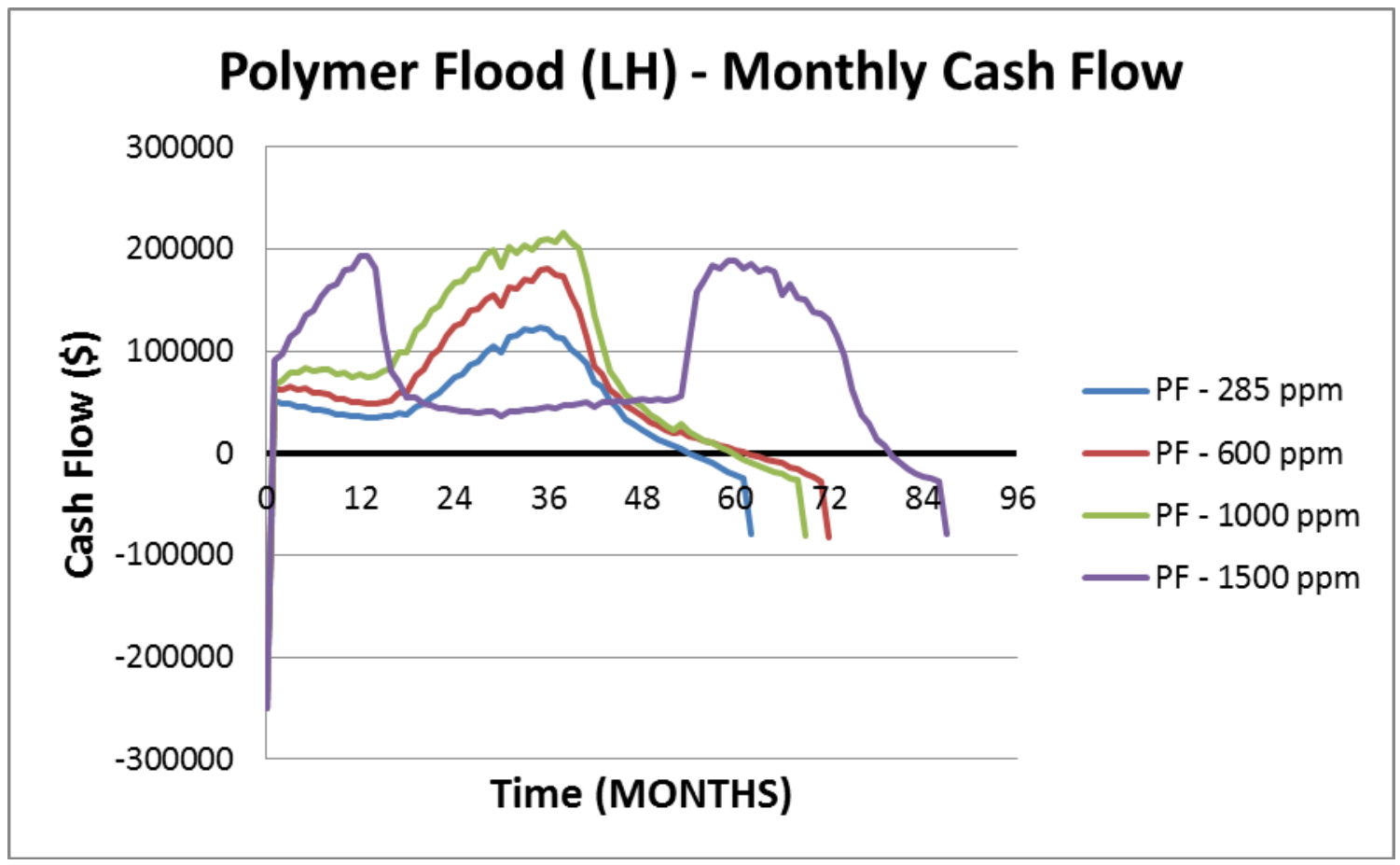

Figure 47: Polymer Flood (LH) - Monthly Income

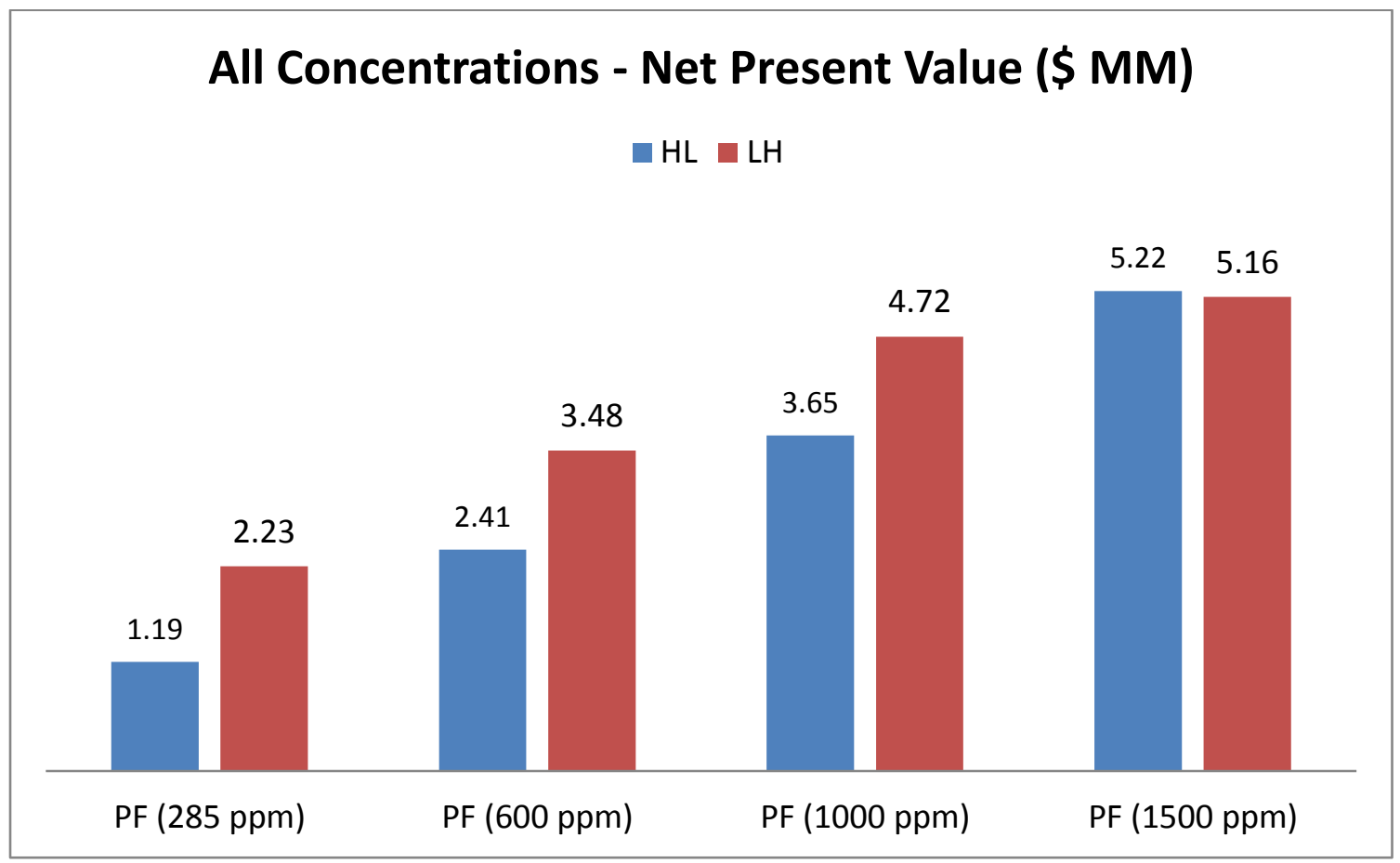

Figure 48: Polymer Flood - NPV at Different Concentrations 
Table 11: Polymer Flood (HL) - Economic Results Summary

\begin{tabular}{|c|c|c|}
\hline & Cash Flow (\$) & NPV (\$) \\
\hline PF (285 ppm) & $1,430,000$ & $1,186,000$ \\
\hline PF (600 ppm) & $2,881,000$ & $2,406,000$ \\
\hline PF (1000 ppm) & $4,409,000$ & $3,646,000$ \\
\hline PF (1500 ppm) & $6,954,000$ & $5,220,000$ \\
\hline
\end{tabular}

Table 12: Polymer Flood (LH) - Economic Results Summary

\begin{tabular}{|c|c|c|}
\hline & Cash Flow (\$) & NPV (\$) \\
\hline PF (285 ppm) & $2,812,000$ & $2,227,000$ \\
\hline PF (600 ppm) & $4,388,000$ & $3,484,000$ \\
\hline PF (1000 ppm) & $5,927,000$ & $4,723,000$ \\
\hline PF (1500 ppm) & $7,088,000$ & $5,157,000$ \\
\hline
\end{tabular}

\subsubsection{DDG Production Pressure}

The figures below illustrate the increased cash flow of the DDG project when the production pressure is forced to reduce. In the first simulation, where the injection rate is reduced by 100 barrels per day, the increase in cash flow is due to the reduced operating expenses as less water is injected. The second simulations results closely mirror those of the first although in this instance the cash flow increases as oil production is ramped up by an extra 100 barrels a day. 


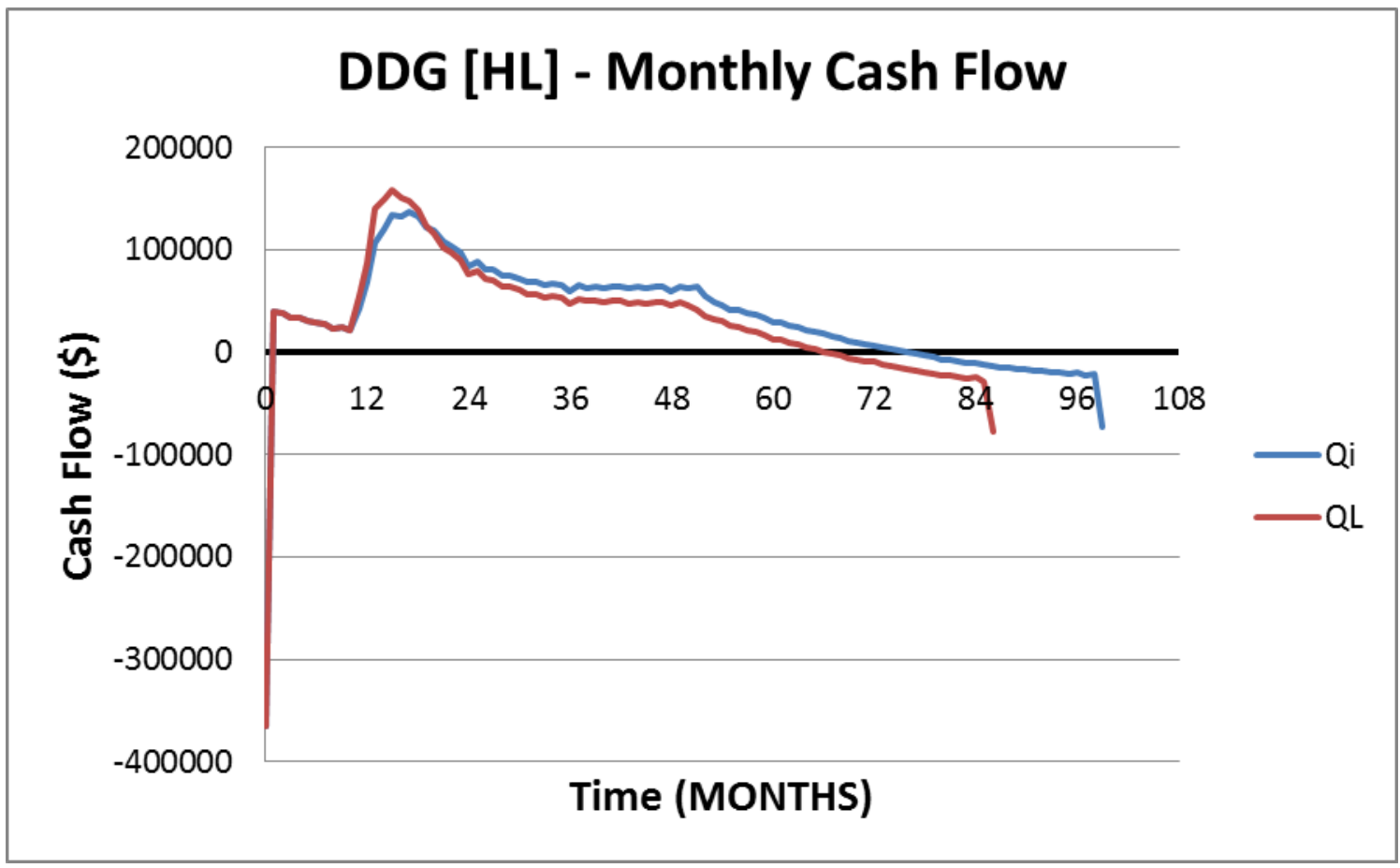

Figure 49: DDG (HL) - Monthly Income with lowered Production Pressure

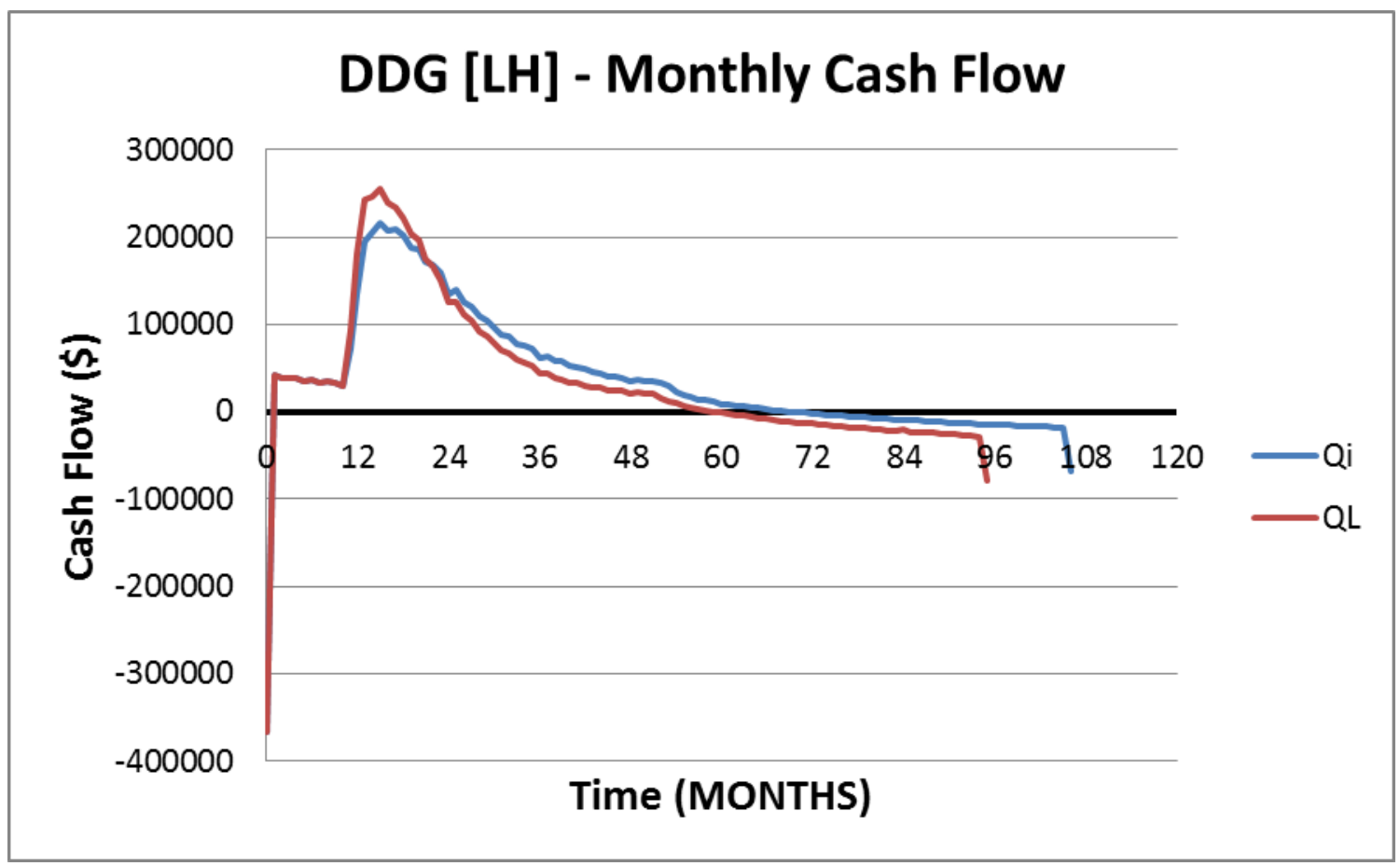

Figure 50: DDG (LH) - Monthly Income with lowered Production Pressure 


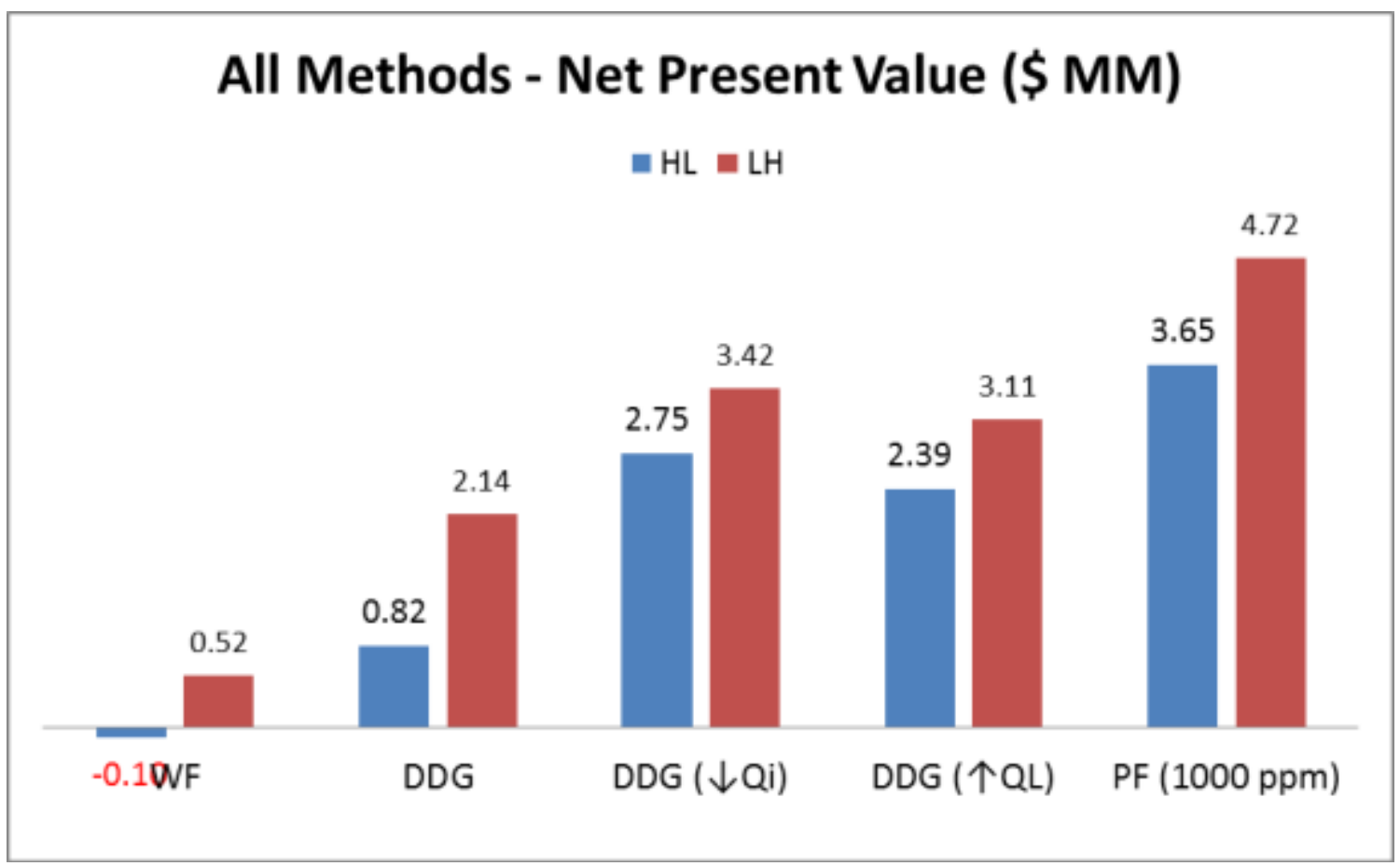

Figure 51: DDG - NPV with lowered Production Pressure

\subsubsection{Oil Viscosity}

In the case of the oil viscosity being changed from $2 \mathrm{cp}$ to 10 and $100 \mathrm{cp}$, the effect of well life and incremental water and oil production can be seen in the figures below. The trends shown by the NPV followed those observed in the monthly cash flows in the $10 \mathrm{cp}$ and $100 \mathrm{cp}$ oil simulations with the DDG's NPV lower than those of the polymer floods at all concentrations. 


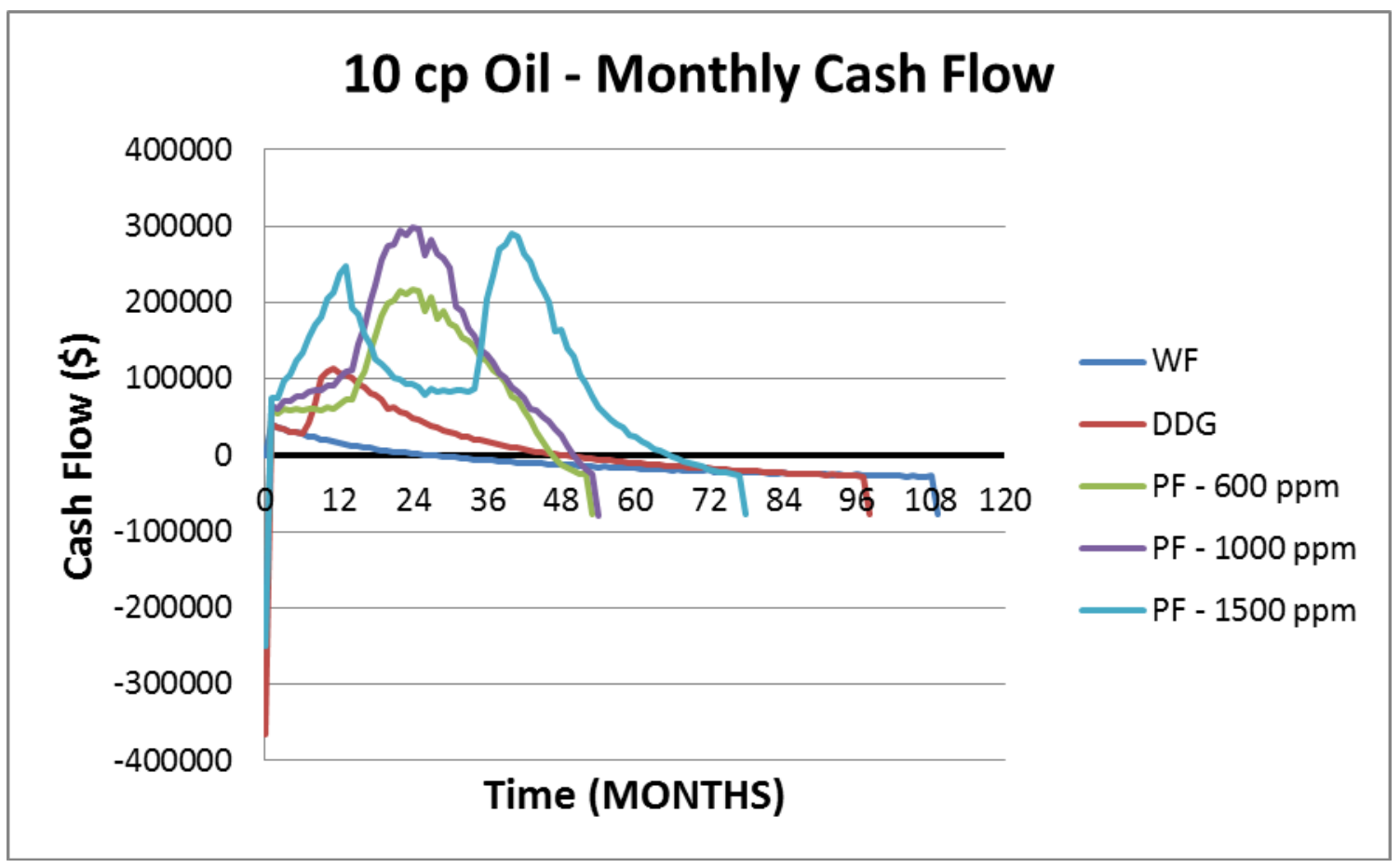

Figure 52: Monthly Income from simulations using $10 \mathrm{cp}$ Oil

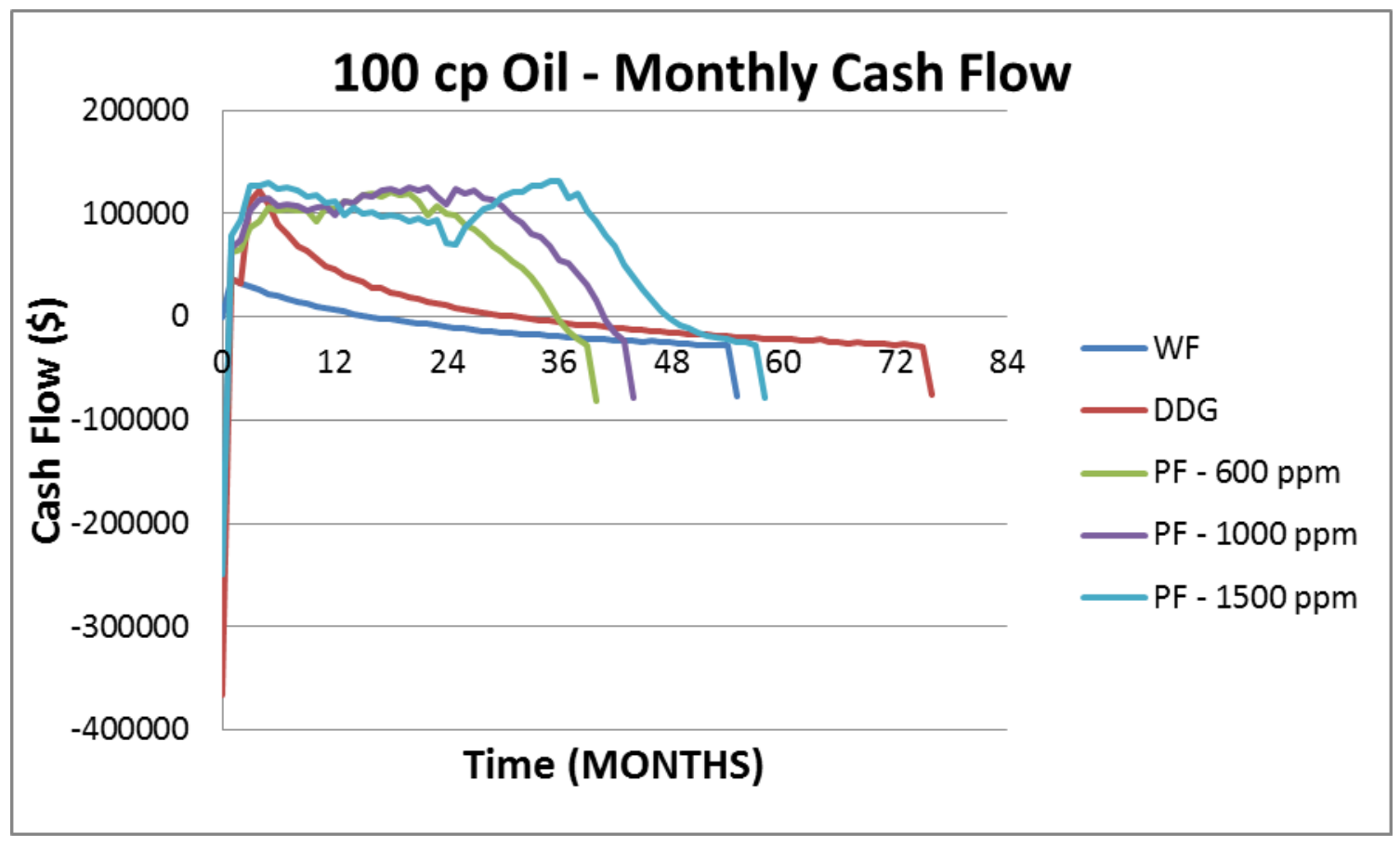

Figure 53: Monthly Income from simulations using $100 \mathrm{cp}$ Oil 


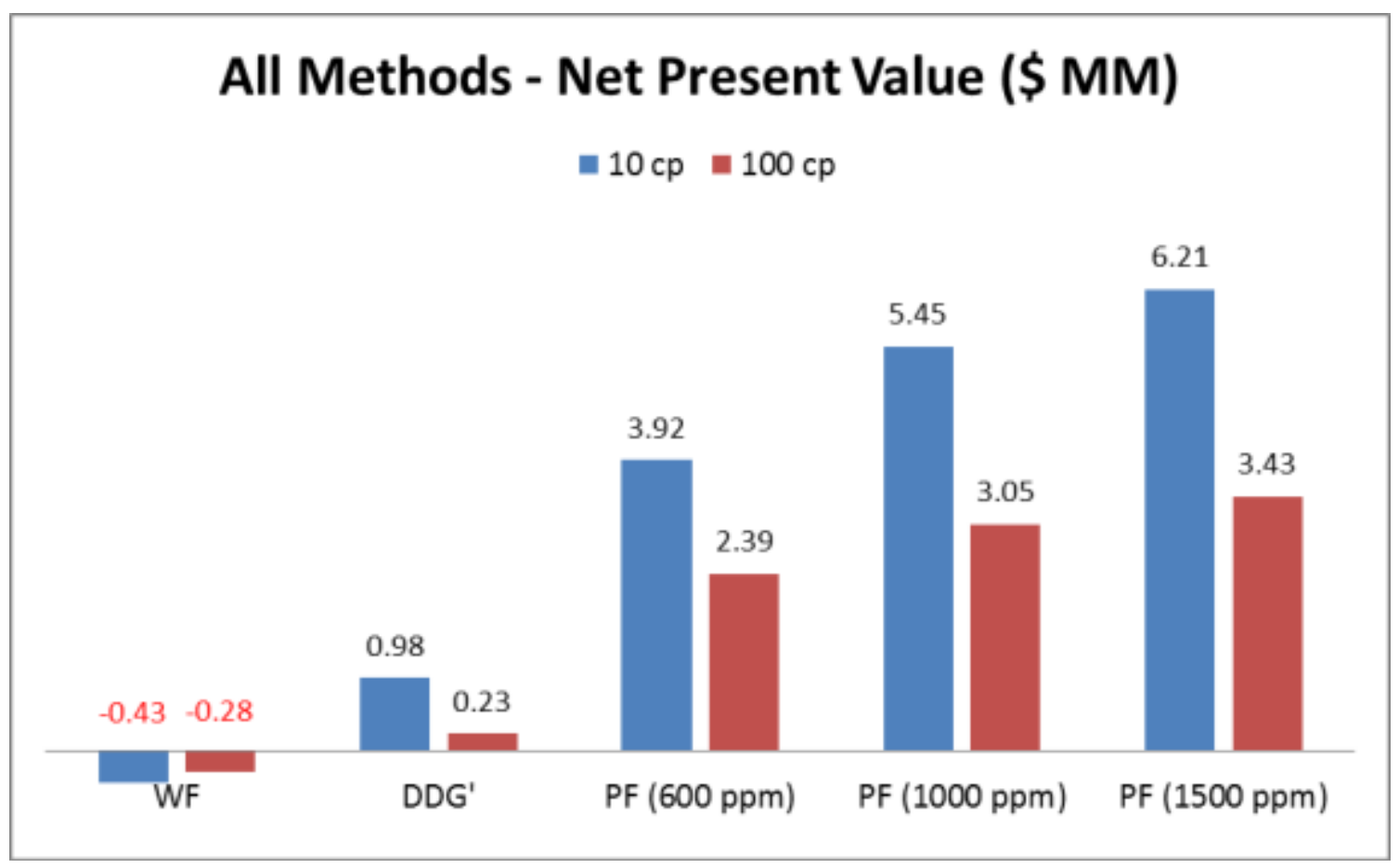

Figure 54: NPV for 10 and $100 \mathrm{cp}$ Oil

Table 13: $10 \mathrm{cp}$ Oil - Economic Results Summary for All Methods

\begin{tabular}{|c|c|c|}
\hline & Cash Flow (\$) & NPV (\$) \\
\hline WF & $(1,141,000)$ & $(433,000)$ \\
\hline DDG' $^{\prime}$ & 813,000 & 981,000 \\
\hline PF (600 ppm) & $4,789,000$ & $3,917,000$ \\
\hline PF (1000 ppm) & $6,665,000$ & $5,451,000$ \\
\hline PF (1500 ppm) & $7,840,000$ & $6,208,000$ \\
\hline
\end{tabular}

Table 14: $100 \mathrm{cp}$ Oil - Economic Results Summary for All Methods

\begin{tabular}{|c|c|c|}
\hline & Cash Flow (\$) & NPV (\$) \\
\hline WF & $(483,000)$ & $(281,000)$ \\
\hline DDG' $^{\prime}$ & $(5,000)$ & 233,000 \\
\hline PF (600 ppm) & $2,739,000$ & $2,388,000$ \\
\hline PF (1000 ppm) & $3,572,000$ & $3,047,000$ \\
\hline PF (1500 ppm) & $4,082,000$ & $3,434,000$ \\
\hline
\end{tabular}




\subsubsection{Polymer Flood Pressure Control}

Although the field life was extended in this run, the choking back of production ultimately led to a lower cumulative oil production than in the base case. This is also reflected in the NPV.

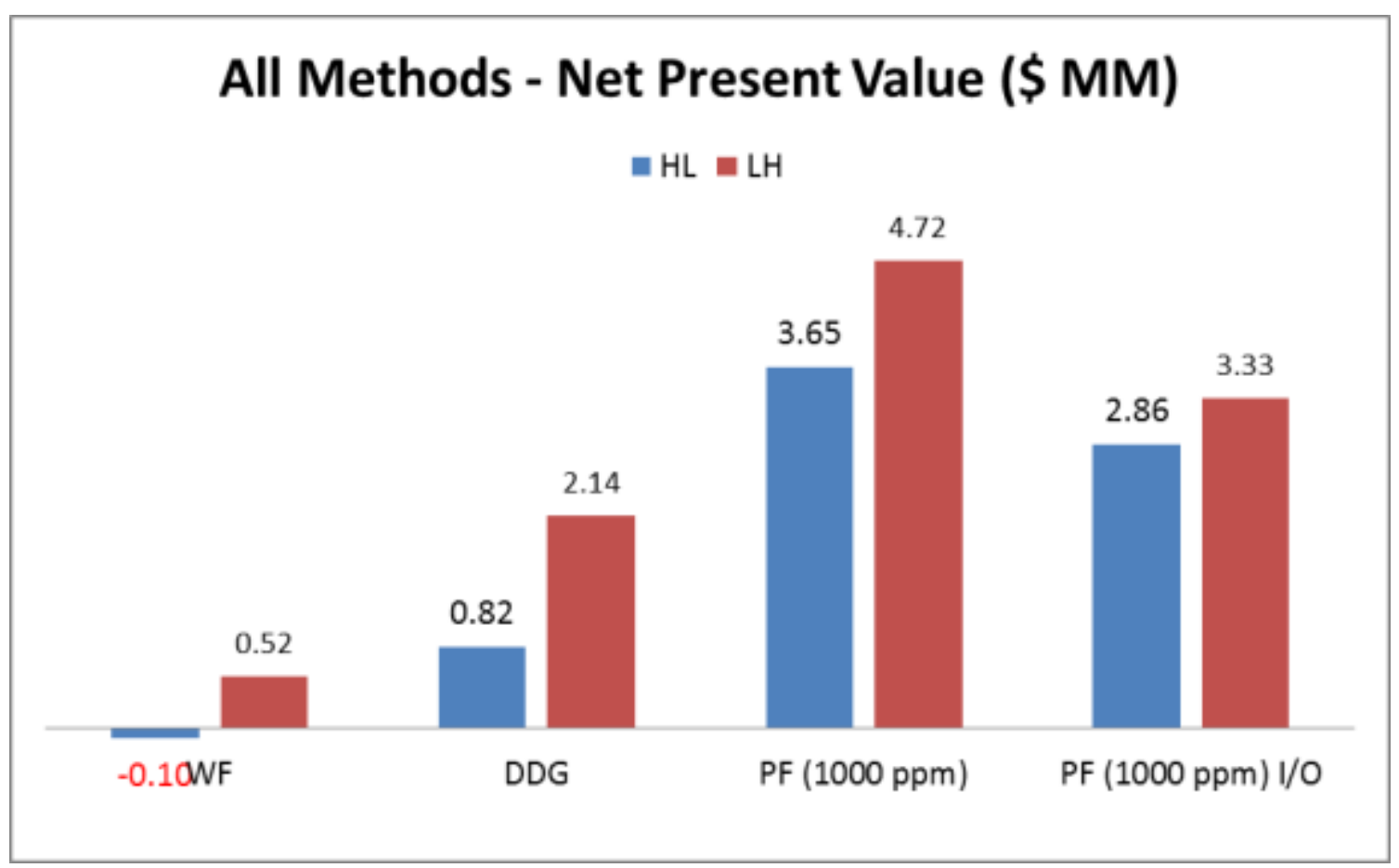

Figure 55: NPV when $\mathrm{Q}_{\mathrm{L}}=\mathrm{Qi}$

\subsubsection{Cost of Polymers}

The effect of the cost of polymer and DDG on cash flow and NPV was examined by reducing the price of DDG to $\$ 1.50$ per pound and for the scenario where the price of polymer increases to $\$ 3.00$ per pound with all other variables held constant. Based on 
the figures below, the cost of polymer would have to be unreasonably high for the economics of both methods to be equal.

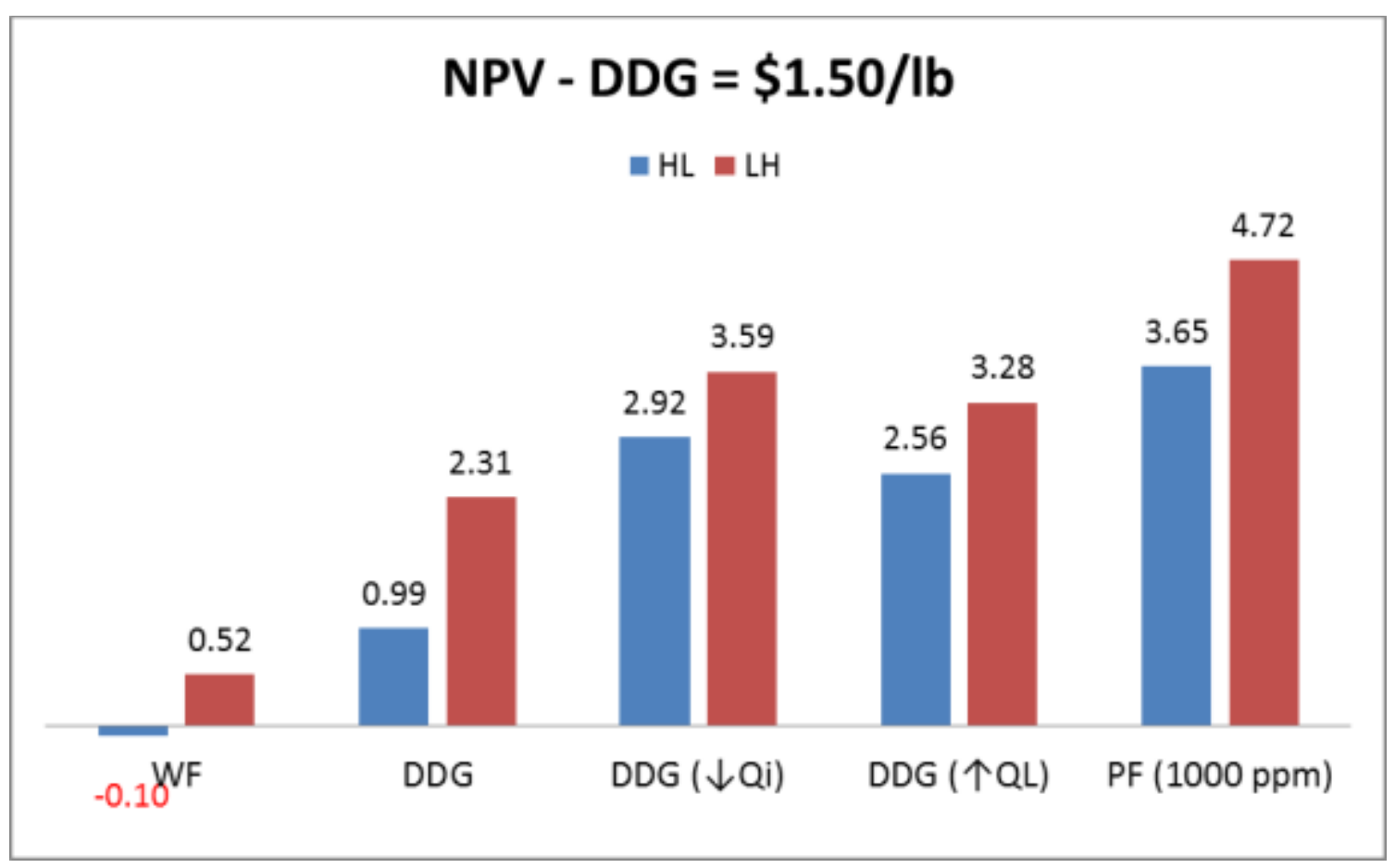

Figure 56: NPV at DDG $=\$ 1.50 / \mathrm{lb}$ 


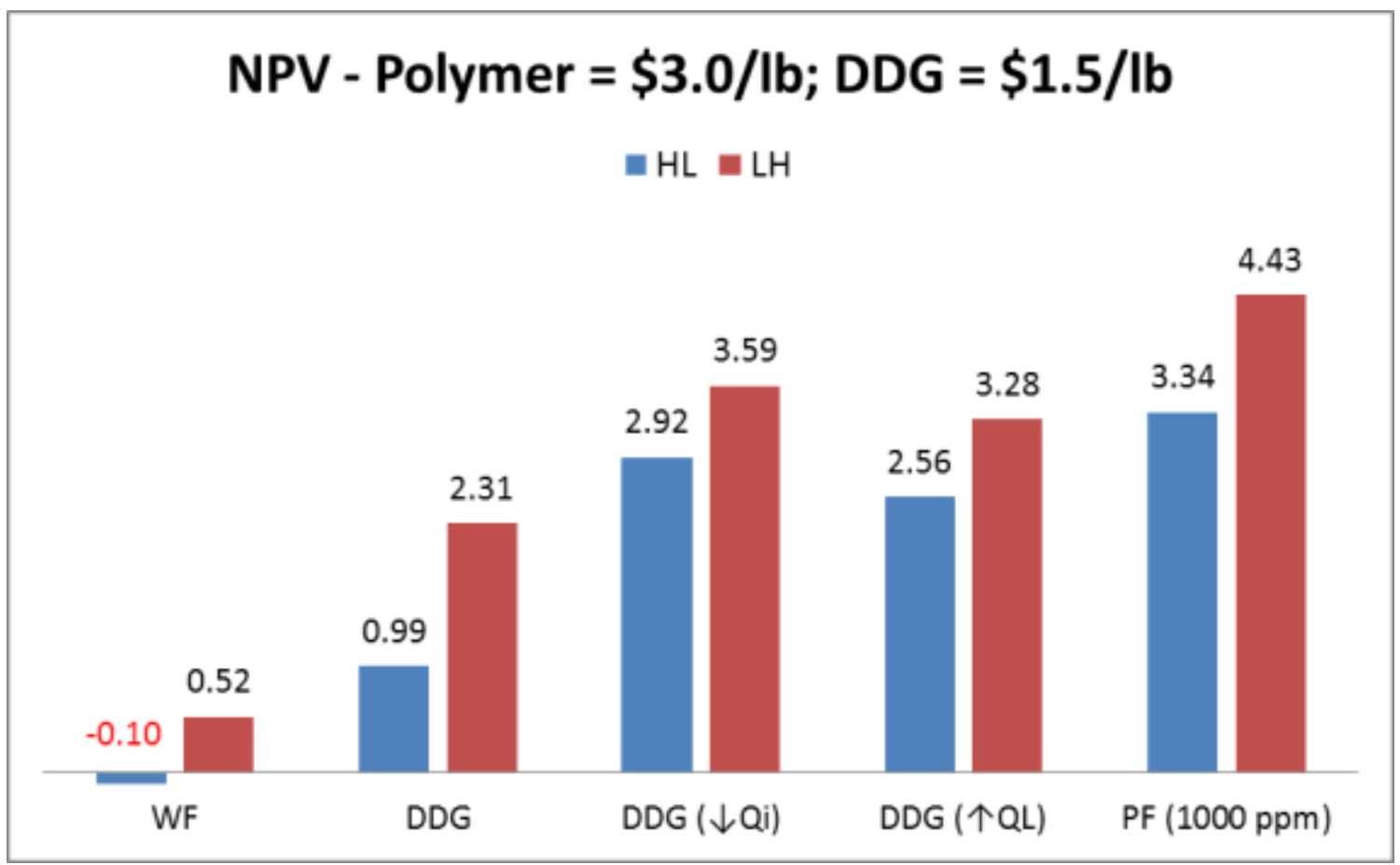

Figure 57: NPV at Polymer $=\$ 3.0 / \mathrm{lb}$ and DDG $=\$ 1.50 / \mathrm{lb}$ 


\section{CONCLUSIONS AND RECOMMENDATIONS}

\subsection{Conclusions}

Both polymer flooding and the DDG have their limitations, some of which have been made obvious in the preceding chapters. The use of deep diverting gels as an effective recovery method is constrained by cost, reservoir characteristics such as permeability, porosity and temperature, minimal reservoir fracturing to prevent loss of the particles, vertical communication between layers, and an injector-producer transit time that needs to be more than thirty days. Polymer floods on the other hand are limited by injectivity concerns due to the possibility of having viscous slugs forming too close to the injection well if improperly designed and the risk of formation damage, maximum allowable viscosities, reservoir properties like temperature and salinity. These factors and more need to be taken into consideration when evaluating either of these two methods as potential candidates for secondary recovery.

The results and economic analysis presented above however show that a properly designed polymer flood program has a decided advantage over the use of the DDG both in terms of oil recovery and monetary value. Incremental oil recovery for the DDG treatment over waterflooding was $2.3 \%$ in the $\mathrm{HL}$ configuration and $1.8 \%$ in the $\mathrm{LH}$ configuration while the polymer flood resulted in increments of 12.3 and $11.4 \%$ respectively. The factors with the largest impact on the economics were the amount of oil produced and the extent of reduction in water production and are the main reason polymer flooding is more attractive than the DDG treatment. 
The economic limit of a project is typically determined by excessive water production. 95\% water-cut was chosen arbitrarily and in reality would depend on project specifics. Based on the monthly cash flows for all three methods, it can be deduced that a water-cut of $95 \%$ which was picked as the economic limit in the simulations may be a poor choice because cash flow is negative in the last two years or more in all configurations. This has the effect of reducing the Net Present Value of the projects from their ideal values if each project was terminated when monthly cash flow became 0 .

\subsection{Recommendations}

One of the major shortcomings of previous work done on comparing the DDG's performance to that of Polymer flooding has been in the accuracy of the assumptions used. This is particularly obvious in the areas of estimating the amount of DDG used in any treatment, in pinpointing the exact location of its activation and estimating the area and volume plugged.

In this work it was assumed that the DDG treatment had the same viscosity as water to provide an optimal environment although based on work by Pritchett et al (2003), the slurry viscosity could actually be two to seven times higher than that of the injection water. Akanni (2010) also reported discrepancies between the results obtained using a commercial simulator and those based on analytical calculations and attributed it to the possible effect of gravity although the reasons for this are still open to investigation.

More precise work could be performed on these areas to more accurately simulate the DDG's performance. 


\section{REFERENCES}

Akanni, O.O. 2010. Analysis of Bright Water Reservoir Sweep Improvement and Comparison with Polymer Flooding for Improved Oil Recovery. MS thesis. New Mexico Institute of Mining and Technology, Soccorro, New Mexico.

Alusta, G.A., Mackay, E.J., Fennema, J., and Collins, I. 2011. EOR Vs. Infill Well Drilling: How to Make the Choice? Paper SPE 143300 presented at the SPE Enhanced Oil Recovery Conference, Kuala Lumpur, Malaysia. 19-21 July 2011.

Bai, B., Li, L., Liu, Y., Wang, Z., and Liu, H. 2004. Preformed Particle Gel for Conformance Control: Factors Affecting Its Properties and Applications. Paper SPE 89389 presented at the SPE/DOE Symposium on Improved Oil Recovery, Tulsa, Oklahoma. 17-21 April 2004.

Brown, L.R., Pittman Jr., C.U., Lynch, F.L., and Vadie, A.A. 2003. Augmenting a Microbial Selective Plugging Technique with Polymer Flooding to Increase the Efficiency of Oil Recovery - a Search for Synergy. Fifth Semi-Annual Progress Report, Contract No. DE-AC26-99BC15210, US DOE, Washington, DC (January 2002).

Chang, E.A. 2006. Composition and Method for Recovering Hydrocarbon Fluids from a Subterranean Reservoir. US Patent No. 6,984,705.

Chang, E.A. 2007. Composition for Recovering Hydrocarbon Fluids from a Subterranean Reservoir. US Patent No. 7,300,973.

Chang, H.L., Sui, X., Xiao, L., Guo, Z., Yao, Y. et al. 2006. Successful Field Pilot of InDepth Colloidal Dispersion Gel (CDG) Technology in Daqing Oil Field. Paper SPE 89460 presented at the SPE/DOE Symposium on Improved Oil Recovery, Tulsa, Oklahoma. 17-21 April 2004.

Demin, W., Lanshui, Z., Jiecheng, C., and Junzheng, W. 2003. Actual Field Data Show That Production Costs of Polymer Flooding Can Be Lower Than Water Flooding. Paper SPE 84849 presented at the SPE International Improved Oil Recovery Conference in Asia Pacific, Kuala Lumpur, Malaysia. 20-21 October 2003.

Fethi, G., Kaddour, K., Tesconi, M., Alberto, B., Carlo, C., and Angelo, G.G. 2010. El Borma - Bright Water - Tertiary Method of Enhanced Oil Recovery for a Mature Field. Paper SPE 136140 presented at the SPE Production and Operations Conference and Exhibition, Tunis, Tunisia. 8-10 June 2010. 
Frampton, H., Morgan, J.C., Cheung, S.K., Munson, L., Chang, K.T., and Williams, D. 2004. Development of a Novel Waterflood Conformance Control System. Paper SPE 89391 presented at the SPE/DOE Symposium on Improved Oil Recovery, Tulsa, Oklahoma. 17-21 April 2004.

Husband, M.E., Ohms, D.S., Frampton, H., Carhart, S.R., Carlson, B.H. et al. 2010. Results of a Three-Well Waterflood Sweep Improvement Trial in the Prudhoe Bay Field Using a Thermally Activated Particle System. Paper SPE 129967 presented at the SPE Improved Oil Recovery Symposium, Tulsa, Oklahoma. 2428 April 2010.

Mack, J.C. and Smith, J.E. 1994. In-Depth Colloidal Dispersion Gels Improve Oil Recovery Efficiency. Paper SPE 27780 presented at the SPE/DOE Improved Oil Recovery Symposium, Tulsa, Oklahoma. 17-20 April 1994.

Morgan, N. 2007. Pop Goes the Polymer. Frontiers: 6-9.

Mungan, N. 1970. Water Flooding with Polymer Solutions. Paper SPE 3172.

Muruaga, E., Flores, M.V., Norman, C., and Romero, J.L. 2008. Combining Bulk Gels and Colloidal Dispersion Gels for Improved Volumetric Sweep Efficiency in a Mature Waterflood. Paper SPE 11334 presented at the SPE/DOE Symposium on Improved Oil Recovery, Tulsa, Oklahoma. 20-23 April 2008.

Mustoni, J.L., Denyer, P., and Norman, C. 2010. Deep Conformance Control by a Novel Thermally Activated Particle System to Improve Sweep Efficiency in Mature Waterfloods of the San Jorge Basin. Paper SPE 129732 presented at the SPE Improved Oil Recovery Symposium, Tulsa, Oklahoma. 24-28 April 2010.

Ohms, D.S., McLeod, J.D., Graff, C.J., Frampton, H., Morgan, J. et al. 2009. Incremental Oil Success from Waterflood Sweep Improvement in Alaska. Paper SPE 121761 presented at the SPE International Symposium on Oilfield Chemistry, The Woodlands, Texas. 20-22 April 2009.

Pritchett, J., Frampton, H., Brinkman, J., Cheung, S., Morgan, J. et al. 2003. Field Application of a New In-Depth Waterflood Conformance Improvement Tool. Paper SPE 84897 presented at the SPE International Improved Oil Recovery Conference in Asia Pacific, Kuala Lumpur, Malaysia. 20-21 October 2003.

Ranganathan, R., Lewis, R., McCool, C.S., Green, D.W., and Willhite, G.P. 1998. Experimental Study of the Gelation Behavior of a Polyacrylamide/Aluminum Citrate Colloidal-Dispersion Gel System. SPE Journal 3 (4): 337-343. SPE52503-PA. DOI: 10.2118/52503-PA 
Roussennac, B.D. and Toschi, C. 2010. Brightwater Trial in Salema Field (Campos Basin, Brazil). Paper SPE 131299 presented at the SPE EUROPEC/EAGE Annual Conference and Exhibition, Barcelona, Spain. 14-17 June 2010.

Eclipse Reservoir Engineering Software. 2010. Schlumberger, http://www.slb.com/services/software/reseng/eclipse

Seright, R.S. 2010. Potential for Polymer Flooding Reservoirs with Viscous Oils. Paper SPE 129899 presented at the SPE Improved Oil Recovery Symposium, Tulsa, Oklahoma. 24-28 April 2010.

Seright, R.S., Lane, R.H., and Sydansk, R.D. 2003. A Strategy for Attacking Excess Water Production. Paper SPE 84966 presented at the SPE Permian Basin Oil and Gas Recovery Conference, Midland, Texas. 15-16 May 2001.

Seright, R.S., Zhang, G., Akanni O.O. and Wang, D. 2011. A Comparison of Polymer Flooding with In-Depth Profile Modification. Paper SPE 146087 presented at the Canadian Unconventional Resources Conference, Calgary, Alberta. 15-17 November 2011.

Sorbie, K.S. and Seright, R.S. 1992. Gel Placement in Heterogeneous Systems with Crossflow. Paper SPE 24192 presented at the SPE/DOE Enhanced Oil Recovery Symposium, Tulsa, Oklahoma. 22-24 April 1992.

Wang, D., Seright, R.S., Shao, Z., and Wang, J. 2008. Key Aspects of Project Design for Polymer Flooding at the Daqing Oilfield. Paper SPE 109682 presented at the SPE Annual Technical Conference and Exhibition, Anaheim, California. 11-14 November 2007.

Yanez, P.A., Mustoni, J.L., Frampton, H., Relling, M.F., Chang, K.-T. et al. 2007. New Attempt in Improving Sweep Efficiency at the Mature Koluel Kaike and Piedra Clavada Waterflooding Projects of the S. Jorge Basin in Argentina. Paper SPE 107923 presented at the Latin American \& Caribbean Petroleum Engineering Conference, Buenos Aires, Argentina. 15-18 April 2007. 


\section{APPENDIX}

\section{A Waterflooding Data File}

-- Area of the pattern is 40 acres. Quarter of 5-spot represents 10 acres.

-- Two wells, one injector and one producer, on opposite sides of the 10 ac-pattern

-- Grid dimensions are $660 \mathrm{ft}$ by $660 \mathrm{ft}$ by $60 \mathrm{ft}$

-- Grid represents a 110x110x16 Cartesian model of a quarter of a 40 acre 5-spot

RUNSPEC

TEMP

-- Specifies the dimensions of the grid: $44 \times 44 \times 16$

DIMENS

$444416 /$

-- Specifies phases present: oil, water

OIL

WATER

-- Field units to be used

FIELD

-- Specifies dimensions of saturation and PVT tables

TABDIMS

$\begin{array}{llllll}1 & 1 & 30 & 30 & 1 & 30\end{array} /$

-- Specifies maximum number of well and groups of wells WELLDIMS

2162 2/

-- Specifies start of simulation

START

1 'JAN' 2000 /

-- Specifies the size of the stack for Newton iterations

NSTACK

90 / 


\section{GRID}

-- Specifies the length of the cell in the $\mathrm{X}$ and Y direction: $10 \mathrm{ft}$

DXV

$242 * 15.619052 /$

DYV

$242 * 15.619052 /$

-- Specifies the length of the cell in the $\mathrm{X}$ and $\mathrm{Y}$ direction: $4 \mathrm{ft}$

DZ

$30976 * 4$ /

-- Specifies permeabilities in X direction: $100 \mathrm{md}$ on low perm layer and 1200 on high perm layer

BOX

$14414418 /$

PERMX

$15488 * 1200 /$

BOX

$144144916 /$

PERMX

$15488 * 100 /$

ENDBOX

-- Specifies permeabilities in Y direction: $100 \mathrm{md}$ on low perm layer and 1200 on high perm layer

BOX

$14414418 /$

PERMY

15488*1200 /

BOX

144144916 /

PERMY

$15488 * 100$ /

ENDBOX 
-- Specifies permeabilities in $\mathrm{Z}$ direction: $10 \mathrm{md}$ on low perm layer and $100 \mathrm{on}$ high perm layer

BOX

$14414418 /$

PERMZ

$15488 * 100 /$

BOX

$144144916 /$

PERMZ

$15488 * 10 /$

ENDBOX

-- Specifies Porosity 25\%

BOX

14414418 /

PORO

$15488 * 0.25$ /

BOX

$144144916 /$

PORO

$15488 * 0.25$ /

ENDBOX

-- Specifies the depth of the top cells: $8000 \mathrm{ft}$

TOPS

$1936 * 8000.0 /$

-- Specifies what is to be written in the GRID output file RPTGRID

$11111000 /$

-- Allows for creating a GRID output file GRIDFILE

$21 /$

-- Allows for creating an INIT output file INIT 
PROPS

-- Specifies water saturation tables: Water saturation, Water relative permeability, Oil relative permeability

-- and Oil-Water capillary pressure

SWOF

-- Sw krw $\quad$ kro $\quad$ Pcow

$\begin{array}{llll}0.2 & 0 & 1 & 0 \\ 0.25 & 0.004346481 & 0.751314732 & 0 \\ 0.3 & 0.013763162 & 0.545761134 & 0 \\ 0.35 & 0.027010896 & 0.379858861 & 0 \\ 0.4 & 0.043581146 & 0.249999989 & 0 \\ 0.45 & 0.063161081 & 0.152424743 & 0 \\ 0.5 & 0.08553019 & 0.083187501 & 0 \\ 0.55 & 0.110520981 & 0.038106184 & 0 \\ 0.6 & 0.138000001 & 0.012679833 & 0 \\ 0.65 & 0.167857295 & 0.00193272 & 0 \\ 0.7 & 0.2 & 0 & 0 /\end{array}$

-- Specifies PVT properties of water: $\mathrm{Bw}=1.063 ; \mathrm{Cw}=3.03 \mathrm{E}-06$; watervisc $=.8$. All values at 3480 psia and $280 \mathrm{DegF}$

PVTW

$346413.03 \mathrm{E}-06 \quad .70 .0 /$

-- Specifies PVT properties of the oil: pressure, Bo and oilvisc PVDO

$\begin{array}{rll}\text {-- Pressure } & \text { Bo } & \text { Oil visc } \\ 3480 & 1.01 & 2.0 \\ 3600 & 1.00 & 2.0 /\end{array}$

-- Specifies surface densities: Oil API: 34.2; Water spec. gravity: 1.07;

GRAVITY

$34.21 .07 /$

-- Specifies rock compressibility: 5.0E-06 psi -1@3480 psia

ROCK

3480.0 5.0E-06/

SPECHEAT

$\begin{array}{llll}0.0 & 0.48 & 0.94 & 0.5\end{array}$ 
$300.00 .520 .950 .5 /$

SPECRock

0.025

$30025 /$

RTEMP

$210 /$

REGIONS

-- Specifies the number of saturation regions (only one for this case)

SATNUM

$30976 * 1 /$

SOLUTION

-- Specifies initial equilibration conditions. Datum depth $=8060 \mathrm{ft}$; Reference pressure at datum $=3480$ psia

-- WOC depth $=15000 \mathrm{ft}$ (out of the reservoir means no initial contact present)

-- GOC depth $=0 \mathrm{ft}$ (out of the reservoir means no initial contact present)

EQUIL

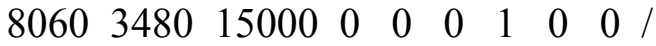

-- Specifies parameters to be written in the SOLUTION section of the RESTART file: pressure, water saturation

-- gas saturation and oil saturation

RPTSOL PRESSURE SWAT SOIL FIP /

-- Specifies that RESTART files are to written every timestep RPTRST

BASIC $=2$ /

SUMMARY

-- Specifies that a SUMMARY file with neat tables is to be written in text format RUNSUM

BTCNFHEA

1444 /

14412 / 
$15304 /$

$153012 /$

$30154 /$

$301512 /$

$4414 /$

$44112 /$

I

-- Specifies that the SUMMARY file is to be created as a separate file in addition from the text file with neat tables

SEPARATE

-- Specifies that reports are to be written only at the timesteps sepcified in the DATA file. Avoids reports to

-- be created at chopped timesteps (to avoid excessive data and clutter). RPTONLY

-- Specifies that a group of parameters specific to ECLIPSE are going to be written in the SUMMARY files.

ALL

EXCEL

separate

ALL

FOE

SCHEDULE

-- Specifies what is to written to the SCHEDULE file

RPTSCHED FIELD 16:55 18 APR 86

$\begin{array}{lllllllllllllllll}1 & 0 & 1 & 0 & 0 & 0 & 2 & 0 & 0 & 0 & 0 & 2 & 0 & 0 & 0 & 0 & 0\end{array}$

$\begin{array}{lllllllllllllllll}0 & 0 & 0 & 0 & 0 & 0 & 0 & 0 & 0 & 0 & 0 & 0 & 0 & 0 & 0 & 0 & 0\end{array}$

$\begin{array}{lllllllllllllllll}0 & 0 & 0 & 0 & 0 & 0 & 0 & 0 & 0 & 0 & 0 & 0 & 0 & 0 & 0 & 0 & /\end{array}$

-- Define well specifications:

WELSPECS

'P' 'G' 4418030 'OIL' 2* SHUT /

'I' 'G' 1448030 'WAT' /

/

-- Specifies completion data

COMPDAT

$\begin{array}{lllllllllll}\text { 'P' } & 44 & 1 & 1 & 16 \\ \text { 'OPEN' } & 1 & 0 & .273^{*} \mathrm{z} /\end{array}$ 
'I' $\quad 1 \quad 44 \quad 1 \quad 16$ 'OPEN' $^{1} \quad 0 \quad .273^{*} \mathrm{z} /$

/

-- Specifies well controls for the producer

-- Name of the well: P

-- Status of the well: open to production

-- Well control mode: reservoir voidage rate

-- The final record specifies target for the control parameter: 530 reservoir barrels

WCONPROD

'P' 'OPEN' 'LRAT' 3* 500 /

/

-- Specifies well controls for the injector

-- Name of the well: I

-- Status of the well: open to injection

-- Well control mode: reservoir injection rate

-- The final record specifies target for the control parameter: 1200 reservoir barrels

WCONINJ

'I' 'WATER' 'OPEN' 'BHP' 4* 3600 /

/

WECON

'P' 2*0.95 2* WELL YES/

/

WTEMP

'I' 70 /

/

TUNING

l

I

$\begin{array}{llllll}50 & 2 & 100 & 1 & 40 /\end{array}$

-- Specifies the number and length of the timesteps required: 200 timesteps of 20 days each

TSTEP

0.10 .30 .6135212931303130313130313031

312831303130313130313031

312831303130313130313031

312831303130313130313031 
312931303130313130313031

312831303130313130313031

312831303130313130313031

312831303130313130313031

312931303130313130313031

312831303130313130313031

312831303130313130313031

312831303130313130313031

$312931303130313130313031 /$

$--0.10 .30 .613529 * 1030 * 3040 * 50 /$

END

\section{B DDG Treatment Data File}

-- Area of the pattern is 40 acres. Quarter of 5-spot represents 10 acres.

-- Two wells, one injector and one producer, on opposite sides of the 10 ac-pattern

-- Grid dimensions are $660 \mathrm{ft}$ by $660 \mathrm{ft}$ by $60 \mathrm{ft}$

-- Grid represents a 110x110x15 Cartesian model of a quarter of a 40 acre 5-spot

RUNSPEC

TEMP

-- Specifies the dimensions of the grid

DIMENS

444416 /

-- Specifies phases present: oil, water

OIL

WATER

-- Field units to be used

FIELD

-- Specifies dimensions of saturation and PVT tables

TABDIMS

$\begin{array}{llllll}1 & 1 & 30 & 30 & 1 & 30 /\end{array}$

-- Specifies maximum number of well and groups of wells WELLDIMS

$21622 /$ 
-- Specifies start of simulation

START

1 'JAN' 2000 /

-- Specifies the size of the stack for Newton iterations

NSTACK

$90 /$

GRID

-- Specifies the length of the cell in the $\mathrm{X}$ and $\mathrm{Y}$ direction: $10 \mathrm{ft}$

DXV

$242 * 15.619052 /$

DYV

$242 * 15.619052 /$

-- Specifies the length of the cell in the $\mathrm{X}$ and $\mathrm{Y}$ direction: $4 \mathrm{ft}$

DZ

$30976 * 4 /$

-- Specifies permeabilities in X direction: $100 \mathrm{md}$ on low perm layer and 1200 on high perm layer

BOX

$1295518 /$

PERMX

$232 * 40 /$

$\mathrm{BOX}$

$1316618 /$

PERMX

$248 * 40$ /

BOX

1347718 /

PERMX

$272 * 40$ /

BOX

$1368818 /$ 
PERMX

$288 * 40$ /

BOX

30379918 /

PERMX

$64 * 40$ /

BOX

3237101018 /

PERMX

$48 * 40$ /

BOX

3438111118 /

PERMX

$40 * 40$ /

BOX

3538121318 /

PERMX

$64 * 40$ /

BOX

3639141518 /

PERMX

$64 * 40$ /

BOX

3740164418 /

PERMX

$928 * 40$ /

BOX

1441418 /

PERMX

1408*1200 /

BOX

30445518 /

PERMX

$120 * 1200$ /

BOX

32446618 / 


\section{PERMX}

$104 * 1200$ /

BOX

35447718 /

PERMX

$80 * 1200$ /

BOX

37448818 /

PERMX

$64 * 1200$ /

BOX

384491018 /

PERMX

$112 * 1200$ /

BOX

3944111318 /

PERMX

$144 * 1200$ /

BOX

4044141518 /

PERMX

$80 * 1200$ /

BOX

4144164418 /

PERMX

928*1200 /

BOX

1299918 /

PERMX

$232 * 1200$ /

BOX

131101018 /

PERMX

$248 * 1200$ /

BOX

133111118 / 
PERMX

$264 * 1200$ /

BOX

134121318 /

PERMX

$544 * 1200$ /

BOX

135141518 /

PERMX

$560 * 1200$ /

BOX

136164418 /

PERMX

$8352 * 1200$ /

BOX

144144916 /

PERMX

$15488 * 100$ /

ENDBOX

-- Specifies permeabilities in Y direction: $100 \mathrm{md}$ on low perm layer and 1200 on high perm layer

$\mathrm{BOX}$

$1295518 /$

PERMY

$232 * 40 /$

BOX

$1316618 /$

PERMY

$248 * 40 /$

BOX

$1347718 /$

PERMY

$272 * 40$ /

BOX

$1368818 /$ 
PERMY

$288 * 40$ /

BOX

30379918 /

PERMY

$64 * 40$ /

BOX

$3237101018 /$

PERMY

$48 * 40$ /

BOX

$3438111118 /$

PERMY

$40 * 40$ /

BOX

$3538121318 /$

PERMY

$64 * 40$ /

BOX

$3639141518 /$

PERMY

$64 * 40$ /

BOX

$3740164418 /$

PERMY

$928 * 40$ /

BOX

1441418 /

PERMY

$1408 * 1200$ /

BOX

30445518 /

PERMY

$120 * 1200$ /

BOX

32446618 / 


\section{PERMY}

104*1200 /

BOX

35447718 /

PERMY

$80 * 1200$ /

BOX

$37448818 /$

PERMY

64*1200 /

BOX

384491018 /

PERMY

$112 * 1200$ /

BOX

$3944111318 /$

PERMY

144*1200 /

BOX

$4044141518 /$

PERMY

$80 * 1200$ /

BOX

4144164418 /

PERMY

928*1200/

BOX

$1299918 /$

PERMY

$232 * 1200 /$

BOX

131101018 /

PERMY

$248 * 1200$ /

BOX

$133111118 /$ 


\author{
PERMY \\ $264 * 1200$ / \\ BOX \\ 134121318 / \\ PERMY \\ $544 * 1200$ / \\ BOX \\ $135141518 /$ \\ PERMY \\ $560 * 1200$ / \\ BOX \\ 136164418 / \\ PERMY \\ $8352 * 1200$ / \\ BOX \\ 144144916 / \\ PERMY \\ $15488 * 100$ / \\ ENDBOX
}

-- Specifies permeabilities in $\mathrm{Z}$ direction: $10 \mathrm{md}$ on low perm layer and 100 on high perm layer

$\mathrm{BOX}$

$1295518 /$

PERMZ

$232 * 10 /$

$\mathrm{BOX}$

$1316618 /$

PERMZ

$248 * 10 /$

BOX

1347718 /

PERMZ

$272 * 10 /$

BOX

$1368818 /$ 


\section{PERMZ \\ $288 * 10$ / \\ BOX}

30379918 /

PERMZ

$64 * 10$ /

BOX

3237101018 /

PERMZ

$48 * 10$ /

BOX

3438111118 /

PERMZ

$40 * 10 /$

BOX

3538121318 /

PERMZ

$64 * 10$ /

BOX

3639141518 /

PERMZ

$64 * 10 /$

BOX

3740164418 /

PERMZ

$928 * 10$ /

BOX

1441418 /

PERMZ

1408*100 /

BOX

30445518 /

PERMZ

$120 * 100$ /

BOX

32446618 / 


\author{
PERMZ \\ $104 * 100$ / \\ BOX \\ 35447718 / \\ PERMZ \\ $80 * 100$ / \\ BOX \\ 37448818 / \\ PERMZ \\ $64 * 100$ / \\ BOX \\ 384491018 / \\ PERMZ \\ $112 * 100 /$ \\ BOX \\ 3944111318 / \\ PERMZ \\ $144 * 100$ / \\ BOX \\ 4044141518 / \\ PERMZ \\ $80 * 100$ / \\ BOX \\ 4144164418 / \\ PERMZ \\ 928*100 / \\ BOX \\ 1299918 / \\ PERMZ \\ $232 * 100 /$ \\ BOX \\ 131101018 / \\ PERMZ \\ $248 * 100 /$ \\ BOX \\ 133111118 / \\ PERMZ
}


$264 * 100 /$

BOX

134121318 /

PERMZ

$544 * 100$ /

BOX

135141518 /

PERMZ

560*100/

BOX

136164418 /

PERMZ

$8352 * 100$ /

BOX

144144916 /

PERMZ

$15488 * 10$ /

ENDBOX

-- Specifies Porosity 25\%

BOX

14414418 /

PORO

$15488 * 0.25$ /

BOX

144144916 /

PORO

$15488 * 0.25$ /

ENDBOX

-- Specifies the depth of the top cells: $8000 \mathrm{ft}$ TOPS

$1936 * 8000.0$ /

-- Specifies what is to be written in the GRID output file RPTGRID

11111000 / 
-- Allows for creating a GRID output file GRIDFILE

$21 /$

-- Allows for creating an INIT output file INIT

PROPS

-- Specifies water saturation tables: Water saturation, Water relative permeability, Oil relative permeability

-- and Oil-Water capillary pressure

SWOF

-- Sw krw $\quad$ kro $\quad$ Pcow

$\begin{array}{llll}0.2 & 0 & 1 & 0 \\ 0.25 & 0.004346481 & 0.751314732 & 0 \\ 0.3 & 0.013763162 & 0.545761134 & 0 \\ 0.35 & 0.027010896 & 0.379858861 & 0 \\ 0.4 & 0.043581146 & 0.249999989 & 0 \\ 0.45 & 0.063161081 & 0.152424743 & 0 \\ 0.5 & 0.08553019 & 0.083187501 & 0 \\ 0.55 & 0.110520981 & 0.038106184 & 0 \\ 0.6 & 0.138000001 & 0.012679833 & 0 \\ 0.65 & 0.167857295 & 0.00193272 & 0 \\ 0.7 & 0.2 & 0 & 0 /\end{array}$

-- Specifies PVT properties of water: $\mathrm{Bw}=1.063 ; \mathrm{Cw}=3.03 \mathrm{E}-06$; watervisc $=.8$. All values at 3480 psia and $280 \mathrm{DegF}$

PVTW

34641 3.03E-06 .7 $0.0 /$

-- Specifies PVT properties of the oil: pressure, Bo and oilvisc PVDO

\begin{tabular}{rlr}
-- Pressure & Bo & \multicolumn{2}{c}{ Oil visc } \\
3480 & 1.01 & 2 \\
3600 & 1.00 & $2 /$
\end{tabular}


-- Specifies surface densities: Oil API: 34.2; Water spec. gravity: 1.07; GRAVITY

$34.21 .07 /$

-- Specifies rock compressibility: 5.0E-06 psi -1@3480 psia

ROCK

$3480.05 .0 \mathrm{E}-06 /$

SPECHEAT

0.00 .480 .940 .5

$300.00 .520 .950 .5 /$

SPECRock

0.025

$30025 /$

RTEMP

$210 /$

REGIONS

-- Specifies the number of saturation regions (only one for this case)

SATNUM

30976*1/

SOLUTION

RESTART

'OKEKE_WF_HL_BHP' 69 /

SUMMARY

-- Specifies that a SUMMARY file with neat tables is to be written in text format RUNSUM

-- Specifies that the SUMMARY file is to be created as a separate file in addition from the text file with neat tables

SEPARATE

-- Specifies that reports are to be written only at the timesteps sepcified in the DATA file. Avoids reports to

-- be created at chopped timesteps (to avoid excessive data and clutter). RPTONLY 
-- Specifies that a group of parameters specific to ECLIPSE are going to be written in the SUMMARY files.

ALL

EXCEL

separate

ALL

FOE

SCHEDULE

-- Specifies what is to written to the SCHEDULE file RPTSCHED FIELD 16:55 18 APR 86

$\begin{array}{lllllllllllllllll}1 & 0 & 1 & 0 & 0 & 0 & 2 & 0 & 0 & 0 & 0 & 2 & 0 & 0 & 0 & 0 & 0\end{array}$

$\begin{array}{lllllllllllllllll}0 & 0 & 0 & 0 & 0 & 0 & 0 & 0 & 0 & 0 & 0 & 0 & 0 & 0 & 0 & 0 & 0\end{array}$

$\begin{array}{lllllllllllllllll}0 & 0 & 0 & 0 & 0 & 0 & 0 & 0 & 0 & 0 & 0 & 0 & 0 & 0 & 0 & 0 & /\end{array}$

-- Define well specifications:

WELSPECS

'P' 'G' 4418030 'OIL' /

'I' 'G' 1448030 'WAT' /

/

-- Specifies completion data

COMPDAT

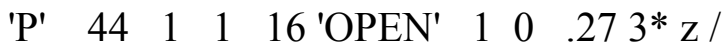

'I' 14441616 'OPEN' $1100.273^{*} \mathrm{z} /$

/

-- Specifies well controls for the producer

-- Name of the well: P

-- Status of the well: open to production

-- Well control mode: reservoir voidage rate

-- The final record specifies target for the control parameter: 530 reservoir barrels

WCONPROD

'P' 'OPEN' 'LRAT' 3* 500 /

I

-- Specifies well controls for the injector 
-- Name of the well: I

-- Status of the well: open to injection

-- Well control mode: reservoir injection rate

-- The final record specifies target for the control parameter: 1200 reservoir barrels

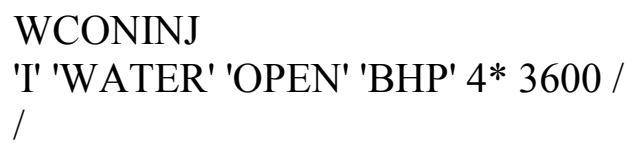

-- Specifies the number and length of the timesteps required: 200 timesteps of 20 days each

\section{TSTEP}

0.10 .30 .613521

312831303130313130313031

312831303130313130313031

312831303130313130313031

312931303130313130313031

312831303130313130313031

312831303130313130313031

312831303130313130313031

312931303130313130313031 /

END 


\section{Polymer Flood Data File}

-- Area of the pattern is 40 acres. Quarter of 5-spot represents 10 acres.

-- Two wells, one injector and one producer, on opposite sides of the 10 ac-pattern

-- Grid dimensions are $660 \mathrm{ft}$ by $660 \mathrm{ft}$ by $60 \mathrm{ft}$

-- Grid represents a 110x110x16 Cartesian model of a quarter of a 40 acre 5-spot

RUNSPEC

TEMP

-- Specifies the dimensions of the grid: $44 \times 44 \times 15$

DIMENS

$444416 /$

-- Specifies phases present: oil, water

OIL

WATER

POLYMER

-- Field units to be used

FIELD

-- Specifies dimensions of saturation and PVT tables

TABDIMS

$\begin{array}{llllll}1 & 1 & 30 & 30 & 1 & 30 /\end{array}$

-- Specifies maximum number of well and groups of wells WELLDIMS

$21622 /$

-- Specifies start of simulation

START

1 'JAN' 2000 /

-- Specifies the size of the stack for Newton iterations

NSTACK

95 /

MESSAGES

$2000200200200202100000010000001000000100000101 /$ 


\section{GRID}

-- Specifies the length of the cell in the $\mathrm{X}$ and Y direction: $10 \mathrm{ft}$

\section{DXV}

$242 * 15.619052 /$

DYV

$242 * 15.619052 /$

-- Specifies the length of the cell in the $\mathrm{X}$ and $\mathrm{Y}$ direction: $4 \mathrm{ft}$

DZ

$30976 * 4$ /

-- Specifies permeabilities in X direction: $100 \mathrm{md}$ on low perm layer and 1200 on high perm layer

BOX

$14414418 /$

PERMX

$15488 * 1200 /$

BOX

$144144916 /$

PERMX

$15488 * 100 /$

ENDBOX

-- Specifies permeabilities in Y direction: $100 \mathrm{md}$ on low perm layer and 1200 on high perm layer

BOX

$14414418 /$

PERMY

15488*1200 /

BOX

144144916 /

PERMY

15488*100 /

ENDBOX 
-- Specifies permeabilities in $\mathrm{Z}$ direction: $10 \mathrm{md}$ on low perm layer and 100 on high perm layer

BOX

14414418 /

PERMZ

$15488 * 100$ /

BOX

144144916 /

PERMZ

$15488 * 10$ /

ENDBOX

-- Specifies Porosity 25\%

BOX

14414418 /

PORO

$15488 * 0.25$ /

BOX

144144916 /

PORO

$15488 * 0.25$ /

ENDBOX

-- Specifies the depth of the top cells: $8000 \mathrm{ft}$

TOPS

$1936 * 8000.0 /$

-- Specifies what is to be written in the GRID output file RPTGRID

$11111000 /$

-- Allows for creating a GRID output file GRIDFILE

$21 /$

-- Allows for creating an INIT output file INIT 
PROPS

-- Specifies water saturation tables: Water saturation, Water relative permeability, Oil relative permeability

-- and Oil-Water capillary pressure

SWOF

-- Sw krw $\quad$ kro $\quad$ Pcow

$\begin{array}{llll}0.2 & 0 & 1 & 0 \\ 0.25 & 0.004346481 & 0.751314732 & 0 \\ 0.3 & 0.013763162 & 0.545761134 & 0 \\ 0.35 & 0.027010896 & 0.379858861 & 0 \\ 0.4 & 0.043581146 & 0.249999989 & 0 \\ 0.45 & 0.063161081 & 0.152424743 & 0 \\ 0.5 & 0.08553019 & 0.083187501 & 0 \\ 0.55 & 0.110520981 & 0.038106184 & 0 \\ 0.6 & 0.138000001 & 0.012679833 & 0 \\ 0.65 & 0.167857295 & 0.00193272 & 0 \\ 0.7 & 0.2 & 0 & 0 /\end{array}$

-- Specifies PVT properties of water: $\mathrm{Bw}=1.063 ; \mathrm{Cw}=3.03 \mathrm{E}-06$; watervisc $=.8$. All values at 3480 psia and $280 \mathrm{DegF}$

PVTW

$346413.03 \mathrm{E}-06 \quad .7 \quad 0.0 /$

-- Specifies PVT properties of the oil: pressure, Bo and oilvisc PVDO

$\begin{array}{rll}\text {-- Pressure } & \text { Bo } & \text { Oil visc } \\ 3480 & 1.01 & 2.0 \\ 3600 & 1.00 & 2.0 /\end{array}$

-- Specifies surface densities: Oil API: 34.2; Water spec. gravity: 1.07;

GRAVITY

$34.21 .07 /$

-- Specifies rock compressibility: 5.0E-06 psi -1@3480 psia

ROCK

3480.0 5.0E-06/

-- Specifies polymer viscosity as function of concentration PLYVISC 
0.01 .0

0.3510 .0

$0.7100 .0 /$

-- Specifies the polymer-rock properties and includes inaccessible pore volume, residual resistance factor, rock mass density, adsorption index and maximum adsorption value PLYROCK

$01620.410 .000003 /$

-- Polymer adsorption properties

PLYADS

$0.0 \quad 0.000$

0.250 .000001

0.500 .000002

$0.750 .000003 /$

-- Mixing Parameter for miscibility between polymer and water between 0.0 and maximum of 1.0

TLMIXPAR

$1.0 /$

-- Specifies maximum value of polymer concentration in solution

PLYMAX

$1.00 .0 /$

SPECHEAT

0.00 .480 .940 .5

$300.00 .520 .950 .5 /$

SPECRock

0.025

$30025 /$

RTEMP

$210 /$

REGIONS

-- Specifies the number of saturation regions (only one for this case)

SATNUM

30976*1/

SOLUTION 
-- Specifies initial equilibration conditions. Datum depth $=8060 \mathrm{ft}$; Reference pressure at datum $=3480$ psia

-- WOC depth $=15000 \mathrm{ft}$ (out of the reservoir means no initial contact present)

-- GOC depth $=0 \mathrm{ft}$ (out of the reservoir means no initial contact present)

EQUIL

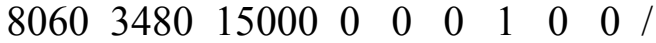

-- Specifies parameters to be written in the SOLUTION section of the RESTART file: pressure, water saturation

-- gas saturation and oil saturation

RPTSOL PRESSURE SWAT SOIL FIP PBLK PLYADS 'FIPPLY=2'/

-- Specifies that RESTART files are to written every timestep

RPTRST

$\mathrm{BASIC}=2$ /

SUMMARY

-- Specifies that a SUMMARY file with neat tables is to be written in text format RUNSUM

FCPR

FCPT

FCPC

FCIR

FCIT

FCIP

FCIC

FCAD

BEPVIS

114 /

214 /

314 /

414 /

$514 /$

614 /

714 /

814 /

914 /

$1014 /$

$1114 /$

$1214 /$

$1314 /$

1414 / 
$1514 /$

$1614 /$

$1714 /$

$1814 /$

/

RPTSMRY

$1 /$

-- Specifies that the SUMMARY file is to be created as a separate file in addition from the text file with neat tables

SEPARATE

-- Specifies that reports are to be written only at the timesteps specified in the DATA file. Avoids reports to

-- be created at chopped timesteps (to avoid excessive data and clutter). RPTONLY

-- Specifies that a group of parameters specific to ECLIPSE are going to be written in the SUMMARY files.

ALL

EXCEL

separate

ALL

FOE

SCHEDULE

-- Specifies what is to written to the SCHEDULE file

RPTSCHED FIELD 16:55 18 APR 86

$\begin{array}{lllllllllllllllll}1 & 0 & 1 & 0 & 0 & 0 & 2 & 0 & 0 & 0 & 0 & 2 & 0 & 0 & 0 & 0 & 0\end{array}$

$\begin{array}{lllllllllllllllll}0 & 0 & 0 & 0 & 0 & 0 & 0 & 0 & 0 & 0 & 0 & 0 & 0 & 0 & 0 & 0 & 0\end{array}$

$\begin{array}{lllllllllllllllll}0 & 0 & 0 & 0 & 0 & 0 & 0 & 0 & 0 & 0 & 0 & 0 & 0 & 0 & 0 & 0 & /\end{array}$

-- Define well specifications:

WELSPECS

'P' 'G' 4418030 'OIL' 2* SHUT /

'I' 'G' 1448030 'WAT' 0.0 STD SHUT NO /

/

-- Specifies completion data COMPDAT 


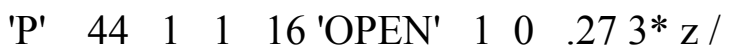

'I' $144 \quad 1 \quad 16$ 'OPEN' $1100.273^{*} \mathrm{z} /$

/

-- Specifies well controls for the producer

-- Name of the well: P

-- Status of the well: open to production

-- Well control mode: reservoir voidage rate

-- The final record specifies target for the control parameter: 530 reservoir barrels

WCONPROD

'P' 'OPEN' 'LRAT' 3* 500 /

/

-- Specifies well controls for the injector

-- Name of the well: I

-- Status of the well: open to injection

-- Well control mode: reservoir injection rate

-- The final record specifies target for the control parameter: 1200 reservoir barrels

WCONINJ

'I' 'WATER' 'OPEN' 'BHP' 4* 3600 /

/

WECON

'P' 2*0.95 2* WELL YES/

/

WTEMP

'I' 70 /

/

TUNING

/

/

$2 * 100 /$

-- Specifies polymer viscosity (1000 ppm)

WPOLYMER

'I' 0.350 .0 /

I

TSTEP

312831303130313130313031

313014 / 


\author{
WPOLYMER \\ 'I' 0.00 .0 / \\ / \\ TSTEP \\ 312831303130313130313031 \\ 312831303130313130313031 \\ 312831303130313130313031 \\ 312931303130313130313031 \\ 312831303130313130313031 \\ 312831303130313130313031 \\ 312831303130313130313031 \\ 312931303130313130313031 / \\ END
}




\section{VITA}

Name: $\quad$ Tobenna Daniel Okeke

Address: $\quad$ Harold Vance Department of Petroleum Engineering

Texas A\&M University

3116 TAMU

College Station, TX 77843

Email: $\quad$ tobenna.okeke@pe.tamu.edu

Education: $\quad$ B.S., Chemical Engineering, Drexel University, 2008

M.S., Petroleum Engineering, Texas A\&M University, 2012 